\author{
Universidade de São Paulo \\ Instituto de Física de SÃo Carlos \\ Departamento de Física e Informática
}

Linder Cândido da Silva

\title{
Simulações por dinâmica molecular aplicadas ao estudo de defeitos em cristais coloidais bidimensionais
}


Linder Cândido da Silva

\section{Simulações por dinâmica molecular aplicadas ao estudo de defeitos em cristais coloidais bidimensionais}

Tese apresentada ao Programa de Pós-Graduação em Física do Instituto de Física de São Carlos da Universidade de São Paulo, para obtenção do título de Doutor em Ciências.

Área de Concentração: Fúsica Aplicada - Opção Física Computacional

Orientador: Prof. Dr. Osvaldo Novais de Oliveira Jr. Co-Orientador: Prof. Dr. Luciano da Fontoura Costa 
AUTORIZO A REPRODUÇÃO E DIVULGAÇÃO TOTAL OU PARCIAL DESTE TRABALHO, POR QUALQUER MEIO CONVENCIONAL OU ELETRÔNICO, PARA FINS DE ESTUDO E PESQUISA, DESDE QUE CITADA A FONTE.

Ficha catalográfica elaborada pelo Serviço de Biblioteca e Informação IFSC/USP

Silva, Linder Cândido da.

Simulações por dinâmica molecular aplicadas ao estudo de defeitos em cristais coloidais bidimensionais / Linder Cândido da Silva; orientador Osvaldo Novais de Oliveira Jr. / co-orientador Luciano da Fontoura Costa.São Carlos, 2008. 109 p.

Tese (Doutorado em Ciências - Área de concentração: Física Aplicada - Opção Física Computacional) - Instituto de Física de São Carlos da Universidade de São Paulo.

1. Cristais coloidais. 2. Defeitos pontuais. 3. Dinâmica molecular.

4. Energia de formação de defeitos. 5. Difusão. I. Título. 
Com amor, dedico à Ariane Bergamin, por sua compreensão, presença e incansável apoio ao longo do período de elaboração deste trabalho. 



\section{Agradecimentos}

Sozinho ninguém vai a lugar algum! Então, vamos aos agradecimentos.

- Agradeço ao meu orientador Prof. Dr. Osvaldo N. de Oliveira Jr. pela oportunidade de estudar sob sua orientação, pela confiança depositada em mim, pela convivência tranqüila e pelas muitas correções de português que ele fez em meu texto. Aprendi muito com ele!

- Agradeço ao meu Co-Orientador Prof. Dr. Luciano da Fontoura Costa, pela oportunidade de trabalhar junto ao grupo de Visão Cibernética e por sua disponibilidade e apoio ao longo do período de realização deste trabalho.

- Agradeço ao professor Prof. Dr. G.-Q. Hai, não só pelas valiosas discussões que enriqueceram enormemente este trabalho, mas principalmente pela amizade e apoio durante toda a minha vida em São Carlos.

- Agradeço ao meu irmão Ladir Cândido da Silva, desta vez não só pelo apoio e amizade, mas também pela colaboração direta, principalmente no que diz respeito à Dinâmica Molecular.

- Agradeço aos amigos do grupo de visão, pela agradável convivência e proveitosas discuções; epecialmente ao Bruno, Silvia, Edson e Ricardo Fabbri.

- Agradeço a todos os colegas e amigos de Barra do Garças pela agradável convivência; especialmente ao Prof. Ivairton, que me quebrou vários galhos.

- Agradeço à minha namorada, Ariane Bergamin, pelo amor, apoio, amizade, companheirismo e paciência ao longo do período de realização deste trabalho.

- Agradeço ao Sr. Osvaldo Bergamin e sua esposa, Maria do Carmo, pelo apoio e por me receberem sempre tão bem em suas casas. 
- Agradeço à minha irmã Lezir e a minha cunhada Silvana pela energia positiva! :) Apesar da distância e pouco contato sei que elas torcem por mim.

- Agradeço aos meus amigos de Novo Brasil, especialmente ao Maiko, Igor e Rubinho; sem eles a vida seria mais chata. :)

- Agradeço especialmente a minha mãe, Eva Maria da Silva, e ao meu pai, Sebastião Cândido da Silva, por tudo o que já fizeram por mim. Ela, sem dúvida, sofreu mais do que eu neste doutorado, pois cada viajem minha para ela era um tormento. Só tendo filho pra saber a preocupação que dá, né mãe? :)

- Agradeço ao pessoal da secretaria, em especial ao Silvio e a Wladerez, e ao pessoal da biblioteca, pelo profissionalismo e atenção.

- Finalmente, quero agradecer a CAPES pelo apoio financeiro durante parte deste doutorado, e a Universidade Federal de Mato Grosso (UFMT) pela minha liberação parcial. 


\section{Resumo}

DASILVA, L. C. Simulações por dinâmica molecular aplicadas ao estudo de defeitos em cristais coloidais bidimensionais. 2008. 109pp. Tese (Doutorado) - Instituto de Física de São Carlos, Universidade de São Paulo, São Carlos, 2008.

Suspensões coloidais de microesferas de poliestireno carregadas proporcionam um sistema experimental excelente para estudar muitos problemas em física da matéria condensada. Sob condições apropriadas as partículas nessas suspensões podem se auto-organizar em um cristal com ordem de longo alcance, o chamado cristal coloidal. Neste trabalho apresentamos resultados de simulações por Dinâmica Molecular relacionados a defeitos pontuais, vacâncias e interstícios, em um cristal coloidal 2D. Calculamos a energia de formação e a interação destes defeitos pontuais, mostrando que um interstício é mais provável de ser criado do que uma vacância e que a interação entre os defeitos (vacância-vacância e interstício-interstício) é atrativa. Em conjunto esses resultados apontaram que os defeitos pontuais podem afetar o mecanismo de fusão do cristal coloidal 2D. Com relação à dinâmica dos defeitos, o foco foi sobre as vacâncias. Calculamos as entalpias de migração deste defeito de uma forma original, baseada na troca de topologias. Concluímos que a vacância não difunde de acordo com um único mecanismo, mas sim um misto de dois comportamentos, são eles: relação de Arrhenius corrigida e relação de potência com a temperatura. Calculamos também as entalpias e entropias relativas de formação das topologias da vacância, o que possibilitou identificar as topologias mais estáveis. Acreditamos que esses resultados serão importantes para trabalhos experimentais envolvendo interfaces e superfícies sólidas.

Palavras-chave: cristais coloidais, defeitos pontuais, dinâmica molecular, energia de formação de defeitos, difusão. 



\section{Abstract}

\section{DASILVA, L. C. Simulações por dinâmica molecular aplicadas ao estudo de de-}

feitos em cristais coloidais bidimensionais. 2008. 109pp. Tese (Doutorado) - Instituto de Física de São Carlos, Universidade de São Paulo, São Carlos, 2008.

Colloidal suspensions of charged polystyrene microspheres provide an excellent experimental system to study many problems in condensed matter physics. Under appropriate conditions the particles in these suspensions organize themselves in a long-range-ordered crystal, the so-called colloidal crystal. In this thesis we report Molecular Dynamics simulations on point defects, vacancies and interstitials, in a 2D colloidal crystal. We have calculated the formation energy and interaction of these point defects, as well as the energy barriers between the various topological configurations that the defects may adopt while in thermal equilibrium. It is shown that the interstitials are more likely to be formed than the vacancies, and the interaction between defects (vacancy-vacancy and interstitialinterstitial) is attractive. Taken together, these results indicate that point defects may affect the melting process of a $2 \mathrm{D}$ colloidal crystal. With regard to the dynamics of the defects, emphasis was placed on the vacancies. The enthalpy for migration of a vacancy was calculated on the basis of exchanges between topologies. We concluded that the vacancy does not diffuse according to a single mechanism, but rather through a mixture of two processes: one is a modified Arrhenius mechanism and the other is represented by a power-law dependence on the temperature. We also calculated the relative enthalpies and entropies associated with the formation of the different topologies of vacancies, which allowed identification of the most stable topologies. We believe these results may have important bearing on experimental works involving interfaces and solid surfaces.

Keywords: colloidal crystals, point defects, molecular dynamics, formation energy of defects, diffusion. 



\section{Lista de Figuras}

Figura 1 - O potencial de pares da teoria DLVO . . . . . . . . . p p. 24

Figura 2 - Esquema de um cristal bidimensional com sua célula unitária . . . p. 27

Figura 3 - Esquema representativo de redes BCC e FCC $\ldots \ldots$. . . . . p. 28

Figura 4 - Ilustração de um cristal com simetria triangular . . . . . . . . p p. 28

Figura 5 - Ilustração de uma vacância e de um interstício . . . . . . . . . . p. 32

Figura 6 - Potencial periódico ao longo da direção $x$ de um cristal $\ldots$. . . . . p. 37

Figura 7 - Condições periódicas de contorno . . . . . . . . . p. p 47

Figura 8 - Digrama de Voronoi para um conjunto de pontos no espaço 2D . . p.57

Figura 9 - Configurações mais observadas para uma vacância . . . . . . . p. 66

Figura 10 - Configurações mais observadas para um interstício . . . . . . p p. 67

Figura 11 - Energia de formação dos defeitos pontuais vs temperatura . . . . p. p. 71

Figura 12 - Energia de ligação vacância-vacância e interstício-interstício p.72

Figura 13 - Trajetória dos defeitos segundo (PERTSINIDIS; LING, 2001a) . . p.77

Figura 14 - Constante de difusão vs temperatura . . . . . . . . . . . p. 78

Figura 15 - Trajetória das principais partículas na transição $V_{3} \rightarrow S V$. . . p. 80

Figura 16 - Trajetória das principais partículas na transição $V_{2 a} \rightarrow S V$. . p. 80

Figura 17 - Deslocamento do centro de uma vacância . . . . . . . . . . . p. 82

Figura 18 - Freqüência de transições topológicas vs $1 / T \ldots \ldots$. . . . . . p. 84 
Figura 19 - Ajuste da equação 4.6 aos dados sobre trocas de topologias . . $\quad$ p. 86

Figura 20 - Ajuste da equação 4.6 aos dados sobre trocas de topologias . . . $\quad$ p. 87

Figura 21 - Ajuste da equação 4.7 aos dados sobre as transições $S V \leftrightarrows V_{2}$. . p.90

Figura 22 - Ajuste da equação 4.14 aos dados sobre trocas de topologias . . . p.93

Figura 23 - Ajuste da equação 4.14 aos dados sobre trocas de topologias . . . p.94

Figura 24 - Entalpia de migração vs temperatura . . . . . . . . . . p p. 95

Figura $25-\left(\Delta H-\Delta H_{0}\right) / \Delta H_{0}$ vs temperatura . . . . . . . . p. 95

Figura 26 - Ajuste de uma reta aos dados sobre a transição $\operatorname{Par} \rightarrow V_{2} \ldots$. p. 97

Figura 27 - Pares isolados de deslocações numa rede hexagonal 2D . . . . . p. 98

Figura 28 - Probabilidade de encontrar o defeito em uma dada topologia . . p.99

Figura 29 - Ajuste de retas aos dados da figura $28 \ldots \ldots$. . . . . . . 100 


\section{Lista de Tabelas}

Tabela 1 - Energia de defeitos para um potencial $V(r)=\epsilon_{0} K_{0}(\kappa r) \ldots$. . . p. 62

Tabela 2 - Energia de formação para uma vacância . . . . . . . . . . p. 69

Tabela 3 - Energia de formação para um interstício . . . . . . . . . . . p. 69

Tabela 4 - Energia de formação das topologias do defeito pontual $\ldots$. . . . p.71

Tabela 5 - Entalpia de migração para uma vacância . . . . . . . . . p. 88

Tabela 6 - Parâmetros obtidos do ajuste da equação 4.14 aos dados . . . . . p. p.93

Tabela 7 - $\Delta H$ e $\Delta S$, relativos, de formação das topologias da vacância . . . p. 101 



\section{Sumário}

1 Introdução: fluidos complexos e cristais coloidais $\quad$ p. 19

1.1 Estabilização de suspensões coloidais . . . . . . . . . . . . . . . p. 21

1.2 Cristais coloidais . . . . . . . . . . . . . . . p. 25

1.3 Cristais coloidais como um sistema modelo . . . . . . . . . . . p. 30

1.4 Defeitos em cristais . . . . . . . . . . . . . . . . . p. . 31

1.5 Visão geral da tese . . . . . . . . . . . . . . . . . . . p. . . . . . . .

2 Dinâmica molecular $\quad$ p. 41

2.1 Princípios básicos . . . . . . . . . . . . . . . . . . . . . p p.41

2.2 Dinâmica molecular e sua relação com a mecânica estatística . . . . . . . . p. 44

2.3 Inicialização . . . . . . . . . . . . . . . . . . . . . . . . . . . p. 45

2.4 Condições periódicas de contorno . . . . . . . . . . . . p. 46

2.5 Integração das equações de movimento . . . . . . . . . . . . p. 50

2.6 Dinâmica molecular no ensemble-NVT . . . . . . . . . . . . . . . . p.53

2.7 Cálculo de quantidades físicas . . . . . . . . . . . . . . . p. 55

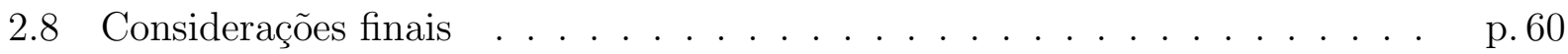

3 Energia de formação e interação defeitos em cristais coloidais $2 \mathrm{D} \quad$ p.61

3.1 Método de Simulação . . . . . . . . . . . . . . . p. p . . . . . . 
3.2 Principais configurações dos defeitos pontuais . . . . . . . . . p. 64

3.3 Resultados . . . . . . . . . . . . . . . . . p. . 68

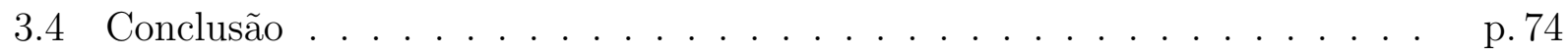

4 Dinâmica de defeitos pontuais em cristais coloidais $2 \mathrm{D} \quad$ p. 75

4.1 Principais trabalhos relacionados . . . . . . . . . . . p. 75

4.2 Resultados e Discussão . . . . . . . . . . . . . . . . . . . p. 78

4.3 Considerações Finais . . . . . . . . . . . . . . . . . . p. 101

5 Conclusões finais e trabalhos futuros $\quad$ p. 103

$\begin{array}{ll}\text { Referências } & \text { p. } 105\end{array}$ 


\section{Capítulo 1}

\section{Introdução: fluidos complexos e cristais coloidais}

Suspensões coloidais são misturas heterogêneas que compartilham a característica comum de serem constituídas por partículas mesoscópicas com diâmetro entre 10-1000 nm dispersas em um solvente composto por partículas microscópicas. Essas misturas são consideradas como um tipo de fluido complexo (em inglês também soft matter), por apresentarem rica variedade de comportamentos físicos proporcionando diferentes propriedades estruturais, mecânicas e químicas (DE GENNES, 1992). Há uma ampla gama de partículas que podem desempenhar o papel do disperso nessas suspensões, o que torna a descrição destes sistemas complicada. Além das partículas coloidais esféricas, que são utilizadas neste trabalho, também surfactantes, polímeros, bactérias, vírus, proteínas e outras macromoléculas podem estar envolvidas. Para complicar ainda mais a descrição teórica, esses sistemas envolvem escalas muito deferentes. Por exemplo, uma partícula coloidal pode ter diâmetro da ordem de um micrômetro, com carga da ordem de milhares de elétrons; mas para a descrição completa do sistema é necessário levar em conta contra-íons com diâmetro que não passa de alguns ângstrons e apenas alguns elétrons de carga.

Uma característica importante das suspensões coloidais é que as partículas estão em 
constante movimento Browniano mediado por oscilações térmicas, pois seu tamanho não é suficientemente grande para que o movimento seja determinado pela gravidade ou por forças de viscosidade, como é o caso de sistemas granulares. Isto possibilita descrever teoricamente esses sistemas de acordo com a mecânica estatística clássica. Além disso, e novamente como consequência do tamanho das partículas, efeitos quânticos em geral podem ser descartados.

O interesse em sistemas coloidais é amplo, tanto na indústria quanto na ciência aplicada e fundamental. Na indústria sua aplicação inclui a fabricação de alimentos, cosméticos, televisores e telas de computadores baseados em cristais líquidos, além de aplicações emergentes como papel eletrônico e novos sensores. Na ciência fundamental esses sistemas são interessantes pois exibem muitas das fases da matéria condensada, servindo como modelo para os mais variados estudos, incluindo transições de fase, ordem estrutural, difusão de partículas, entre outros. Na ciência aplicada pode-se citar o uso de cristais coloidais tridimensionais (uma das fases obtidas a partir de suspensões coloidais) como molde (colloidal templating) para a criação de materiais macroporosos ordenados, os quais podem apresentar grande potencial de aplicação em dispositivos ópticos, principalmente quando usados como cristais fotônicos (HOLLAND et al., 1999; IMHOF; PINE, 1998, 1997).

Este capítulo sumariza os principais resultados com implicação direta para a compreensão das interações entre partículas em suspensões coloidais. Os principais aspectos relacionados a transições de fases e a estabilidade das fases homogêneas são brevemente abordados, enfatizando a fase cristalina. Finalmente, introduziremos alguma teoria básica sobre defeitos pontuais em cristais. Este último tópico, embora seja abordado no contexto de cristais em geral, será de suma importância para a discussão de defeitos em cristais coloidais, que será o foco desta tese. 


\subsection{Estabilização de suspensões coloidais}

Para entender o conceito de estabilização, consideremos uma suspensão coloidal formada por um grande número de partículas, que se movimentam em um solvente. É razoável assumir que essas partículas podem colidir umas com as outras durante o movimento Browniano e, caso a interação seja suficientemente atrativa, pode ocorrer agregação, isto é, elas podem continuar juntas após a colisão. Esse pequeno agregado se moverá mais lentamente do que as partículas individuais, e muito provavelmente colidirá com novas partículas, aumentando o tamanho do agregado a cada nova colisão. Quando o agregado atingir um tamanho crítico, ele se decantará rapidamente da suspensão, formando uma nova fase. Um processo deste tipo ocorre em suspensões que não estão estabilizadas. Ou seja, para obter uma suspensão estável, é essencial evitar o processo de agregação. Na verdade o que se busca é a criação de uma barreira de energia, que impeça a passagem do sistema de um estado metaestável (partículas dispersas no solvente) para o estado de menor energia livre (partículas agregadas). Em geral, existem dois caminhos para produzir este efeito:

\section{1. estabilização eletrostática}

\section{2. estabilização estérica}

Na estabilização eletrostática as partículas coloidais adquirem carga elétrica de mesmo sinal. Como consequência, elas se repelem inibindo a agregação. A principal teoria para descrever esse tipo de estabilização é a teoria DLVO, descrita na próxima subseção.

A estabilização estérica, por outro lado, é conseguida revestindo-se a superfície das partículas com alguma substância (em geral um polímero). Essa substância previne a aproximação das partículas, evitando a agregação. Os princípios que proporcionam este efeito serão descritos em breve, ainda nesta seção. 


\subsubsection{Estabilização eletrostática e a teoria DLVO}

A maioria das partículas coloidais é carregada, como pode ser demonstrado por observação de seu movimento em um campo elétrico. A origem da carga, em muitos casos, deve-se a grupos de superfície, como $-\mathrm{C} 00 \mathrm{H},-0 \mathrm{SO}_{3} \mathrm{H}$ e $\mathrm{NH}_{2}$, os quais podem reagir com um ácido ou com uma base dando origem à carga na superfície do colóide. Embora as partículas coloidais possuam carga elétrica, a suspensão como um todo é neutra, pois existem contra-íons em solução (muitos dos quais vêm dos próprios colóides) que compensam a carga dos colóides. Devido à interação eletrostática, esses contra-íons são atraídos para as vizinhanças dos colóides, mesmo ainda estando sujeitos a oscilações térmicas, que tendem a espalhá-los aleatoriamente pela solução. O resultado deste processo é um balanço de forças que acarreta um acúmulo de contra-íons nas proximidades dos colóides carregados, com a concentração diminuindo à medida que se afasta dos colóides, até que a concentração de bulk seja atingida. A distância na qual a concentração de bulk é atingida depende da concentração de eletrólito, podendo ser somente uma fração de nanômetro, para altas concentrações, ou dezenas de nanômetros, para soluções diluídas (em torno de $\left.10^{-5} \mathrm{M}\right)$. Esta distribuição de cargas é conhecida como a dupla camada elétrica difusa, cuja extensão é uma medida para o alcance do potencial, já que, na prática, essas cargas blindam o potencial de interação entre os colóides. Adicionar sal à suspensão coloidal causa o "encurtamento" da dupla camada elétrica, diminuindo portanto a repulsão entre as partículas, acarretando inclusive a perda de estabilidade da suspensão coloidal.

Além da repulsão eletrostática, as partículas coloidais também estão sujeitas a uma força atrativa universal, isto é, uma força que atua entre quaisquer partículas imersas em um solvente, sejam elas neutras ou não. A existência dessa força entre moléculas foi reconhecida desde os trabalhos clássicos de van der Waals em 1893, mas seus princípios não foram compreendidos até London, em 1930, mostrar como elas podem ser calculadas usando a teoria da mecânica quântica (ISRAELACHVILI, 1992). Segundo esses estudos, moléculas neutras apresentam forças atrativas porque, apesar do momento de dipolo médio ser zero, em qualquer instante a distribuição da nuvem de elétrons varia em relação às 
cargas positivas do núcleo, dando origem a dipolos transientes. Estes dipolos instantâneos geram um campo elétrico que polariza átomos neutros em suas proximidades, induzindo neles um momento de dipolo. A interação resultante entre os dois dipolos gera uma força atrativa instantânea entre os dois átomos, e a média temporal desta força não é nula. Porém, diferentemente do caso atômico e molecular, onde o alcance dessas interações é muito curto (proporcional a $1 / r^{6}$ ), para os colóides o decaimento é proporcional a $1 / r^{2}$, e tipicamente se estende a distâncias da ordem do diâmetro das partículas. Esta diferença no decaimento deve-se ao fato de essas interações serem estimadas assumindo que as forças de dispersão são mais ou menos aditivas, e então somando as contribuições referentes a cada átomo que compõe as partículas coloidais.

Baseado no reconhecimento da existência de duas forças atuantes em qualquer suspensão coloidal (sólido em líquído) estabilizada eletrostaticamente, a repulsão eletrostática e a força atrativa universal, Derjaguin e Landau (1941) e Verwey e Overbeek (1948) independentemente formularam a principal teoria para a estabilidade de suspensões coloidais, conhecida como DLVO, em homenagem aos seus criadores.

Segundo esta teoria, o potencial de interação entre duas partículas coloidais esféricas idênticas, com raio $a$ e carga $-Z e$, sendo $e$ a carga protônica é

$$
V_{D L V O}=\left\{\begin{array}{cc}
\infty & r<2 a \\
V_{E D L}+V_{V W} & r \geq 2 a
\end{array}\right.
$$

onde $V_{E D L}$ é um potencial repulsivo do tipo Yukawa, dado por

$$
V_{E D L}=\frac{\left(Z_{\lambda} e\right)^{2}}{\epsilon} \frac{\exp (-\kappa r)}{r}
$$

com $\kappa$ o inverso do comprimento de blindagem, $\epsilon$ a constante dielétrica do meio, e $Z_{\lambda}=$ $Z^{*} f(\kappa a)$, onde $Z^{*}$ é a carga normalizada (ALEXANDER et al., 1984) e $f(x)$ é um fator que descreve o efeito do tamanho das partículas coloidais. Em geral, $f(x)=\exp (x) /(1+x)$, mas muitos têm definido $f^{*}(x)=\sinh (x) / x$ (SOGAMI, 1983; SOGAMI; ISE, 1984), cujo comportamento funcional é essencialmente o mesmo. Para $x \rightarrow 0$ as duas relações são iguais, mas com o aumento de $x, f^{*}(x) / f(x)$ aumenta para um fator de 2 no limite quando 
$x \rightarrow \infty$. O inverso do comprimento de blindagem é definido em termos da concentração de íons (contra-íons e co-íons) em solução, $n_{3 d}$, sendo

$$
\kappa^{2}=\frac{4 \pi e^{2} n_{3 d}}{\epsilon k_{b} T}
$$

onde $k_{b}$ é a constante de Boltzmann e $T$ é a temperatura do sistema. $V_{V W}$ é o potencial atrativo de van der Waals, dado por

$$
V_{V W}=-\frac{A}{6}\left\{\frac{2 a^{2}}{r^{2}-4 a^{2}}+\frac{2 a^{2}}{r^{2}}+\ln \frac{r^{2}-4 a^{2}}{r^{2}}\right\} \text {, }
$$

com $A>0$ sendo a constante Hamaker (HAMAKER, 1937), que é proporcional ao quadrado da polarizabilidade das partículas.

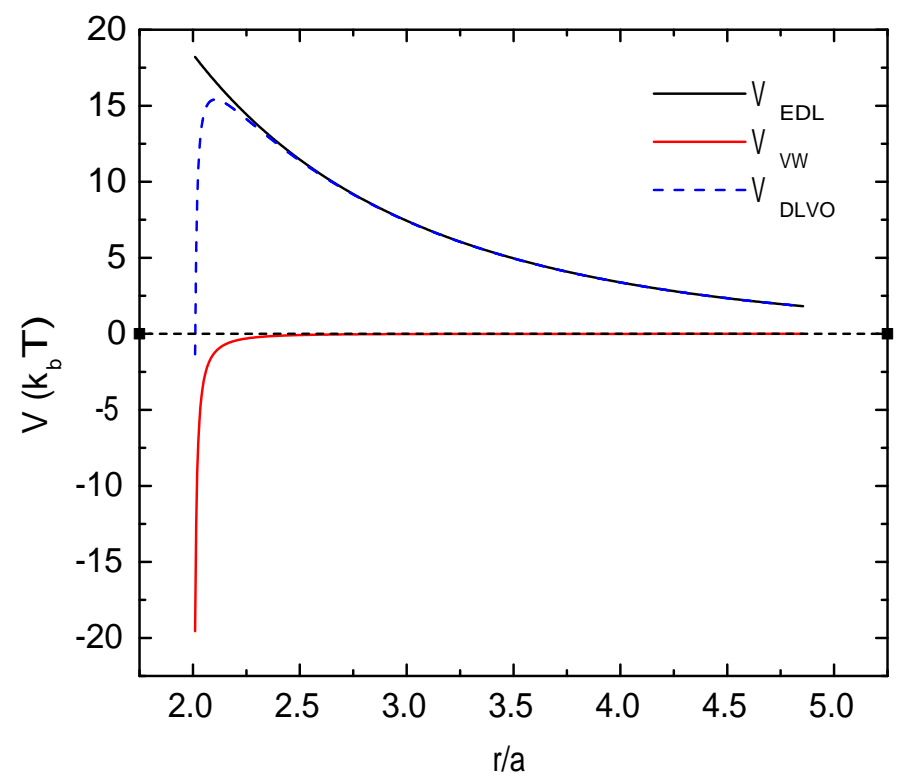

Figura 1. A figura mostra o potencial de pares da teoria DLVO, sua parte repulsiva $V_{E D L}$ e sua parte atrativa $V_{V W}$, como uma função da separação entre os centros das partículas, para um sistema coloidal típico com raio $a=e^{2} / \epsilon k_{b} T$, carga $Z=100$, constante de blindagem $\kappa a=0.5$ e constante de Hamaker $A=10^{-20}$ Joules.

O gráfico da figura 1 mostra o comportamento do potencial de pares da teoria DLVO, juntamente com as contribuições $V_{E D L}$ (repulsiva) e $V_{W V}$ (atrativa). Observe como o alcance da contribuição $V_{W V}$ é muito menor do que o da contribuição $V_{E D L}$ do potencial. Note também que a barreira de energia (algo em torno de $17 k_{b} T$ ) a ser vencida para a formação de agregados é razoavelmente grande. Por isso, dependendo do sistema em questão é muitas vezes seguro desprezar a contribuição atrativa aproximando $A=0$ 
na equação (1.4). Além do mais, experimentalmente o solvente pode ser ajustado para reduzir a constante de Hamaker e, consequentemente, a força atrativa de van der Waals. Embora o potencial $V_{D L V O}$ seja um dos pilares da ciência coloidal, muitas observações experimentais têm mostrado que ele não se aplica quando o sistema envolve eletrólitos assimétricos (BELLONI, 1986) ou íons com valência alta. Isso porque nesses casos as correlações entre os íons (PATEY, 1980; JONSSON, 1996) são muitos fortes, podendo inclusive induzir atração entre partículas coloidais com carga elétrica de mesmo sinal (GROSBERG; NGUYEN; SHKLOVSKII, 2002). Por outro lado, a dedução do potencial $V_{D L V O}$, a partir da linearização da equação de Poisson-Boltzmann, despreza completamente essas correlações, tornando-se inadequada. Apesar desses desvios relativos aos resultados experimentais, essa teoria é adequada na descrição de sistema coloidais onde os contra-íons e co-íons possuem valência \pm 1 .

\subsubsection{Estabilização estérica}

Embora não esteja no foco desta tese, o procedimento alternativo, e talvez mais utilizado para evitar a agregação, é a estabilização estérica. Este procedimento consiste em "revestir" a superfície de uma partícula coloidal liofóbica com uma camada de material liofílico de origem polimérica. Quando essas partículas se aproximam, a interação entre as cadeias de polímero adsorvido causam repulsão que pode ser suficiente para a estabilidade. Sua magnitude pode ser estimada calculando o efeito da separação das partículas sobre a energia livre das moléculas adsorvidas. Quando as partículas são aproximadas, aumenta a energia livre. Este aumento ocorre devido à diminuição da entropia configuracional das moléculas poliméricas que revestem a superficie das partículas. A estabilização estérica é importante em suspensões aquosas, mas é muito mais importante em soluções não aquosas, onde a estabilização eletrostática é raramente possível.

\subsection{Cristais coloidais}

Nesta tese estamos interessados no aparecimento de ordem estrutural de longo alcance em dispersões coloidais carregadas. Em outras palavras, estamos interessados nos chama- 
dos cristais coloidais, isto é, nos arranjos ordenados de partículas coloidais suspensas em um solvente (GAST; RUSSEL, 1998). Nesta seção discutiremos os princípios básicos que levam a sua formação, sua estrutura e alguns aspectos relacionados a sua fusão. Antes, porém, introduziremos conceitos básicos relacionados a cristais em geral.

Em pressão atmosférica, muitos sistemas condensados formam fases sólidas com arranjos cristalinos para temperaturas suficientemente baixas. Um cristal perfeito é um sólido que consiste em um arranjo periódico de cópias idênticas de uma unidade estrutural com alguma distribuição de massa e carga. Um exemplo de cristal bidimensional é mostrado na figura 2. No caso mais simples, a unidade estrutural contém apenas um átomo, mas em geral ela pode conter vários átomos, ou mesmo uma variação contínua na densidade de massa em torno de uma média. A unidade estrutural repetida é chamada de célula unitária, sendo primitiva a célula unitária com o menor volume possível. Pontos equivalentes em células unitárias estão em uma rede periódica, chamada rede de Bravais, que consiste em um arranjo matemático de pontos. Qualquer ponto da rede pode ser especificado por uma combinação linear de vetores de translação independentes. Para um cristal no espaço $d$-dimensional, temos: $\mathbf{r}=l_{1} \mathbf{a}_{1}+l_{2} \mathbf{a}_{2}+\ldots+l_{d} \mathbf{a}_{d}$, onde $\mathbf{l}=\left(l_{1}, \ldots, l_{d}\right)$ é um vetor de inteiros que indexa uma célula unitária particular e $\left(\mathbf{a}_{1}, \mathbf{a}_{2}, \ldots, \mathbf{a}_{d}\right)$ são os vetores de translação do cristal. Para o caso da figura $2, \mathbf{r}=l_{1} \mathbf{a}+l_{2} \mathbf{b}$, com $l_{1}$ e $l_{2}$ sendo números inteiros.

Os cristais coloidais mais estudados são os obtidos com partículas esféricas monodispersas de poliestireno. Quando imersas em água, essas partículas adquirem carga negativa devido à dissociação de grupos sulfato, com densidade típica de um elétron por $\mathrm{nm}^{2}$. Os contra-íons assim gerados formam uma nuvem em volta de cada partícula coloidal, transformando a interação coulômbica de longo alcance em uma interação de alcance mais curto, tal como discutido anteriormente. Neste tipo de dispersão, é possível controlar a força e o alcance da interação entre as partículas, variando a carga dos colóides e a força iônica da solução. Ajustando apropriadamente esses parâmetros, bem como a fração volumar, $\phi$, de partículas coloidais, é possível obter os chamados cristais coloidais. Para entender os princípios básicos, consideremos um sistema em que o comprimento de Debye, 


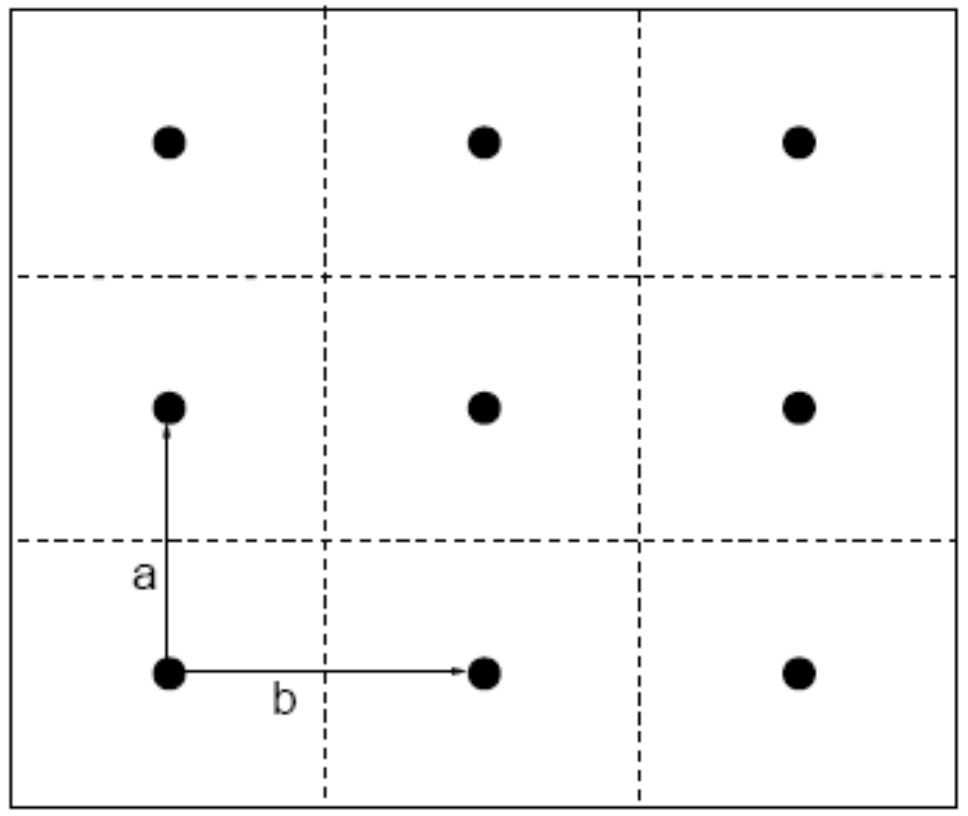

Figura 2. Esquema ilustrando um cristal bidimensional com sua célula unitária que se repete periodicamente no espaço. Os vetores de translação são indicados como a e b.

$\kappa^{-1}$, seja aproximadamente igual ao espaçamento médio entre as partículas. Neste caso, todas as partículas estarão, em maior ou menor grau, interagindo com vários vizinhos. Se a interação eletrostática resultante for suficientemente forte para "congelar" o movimento Browniano das partículas, elas tenderão a se localizar em pontos bem definidos que minimizem a energia livre. O resultado é a indução de ordem cristalina, igual à que encontramos em sólidos cristalinos reais. Para obter um cristal coloidal bidimensional, é necessário ainda isolar uma única camada do cristal. Para isso, normalmente utiliza-se um arranjo com dois substratos de vidro ou sílica, os quais confinam uma camada de partículas coloidais (MURRAY, 1992). A interface entre os substratos e a água possui alta densidade de carga, a qual repele as partículas coloidais, inibindo sua movimentação vertical. Os substratos têm que ser planos na escala do tamanho das partículas coloidais e sua separação precisa ser uniforme. Para partículas com diâmetro entre $0.3-1 \mu \mathrm{m}$, a separação típica do substrato é da ordem de $1-2 \mu \mathrm{m}$.

Existem dois tipos de fases cristalinas 3D para suspensões coloidais carregadas formadas por partículas esféricas (HILTNER; KRIEGER, 1969; WILLIAMS; CRANDALL, 1974; ROBBINS; KREMER; GREST, 1988). Em baixas frações volumares, e com um comprimento 

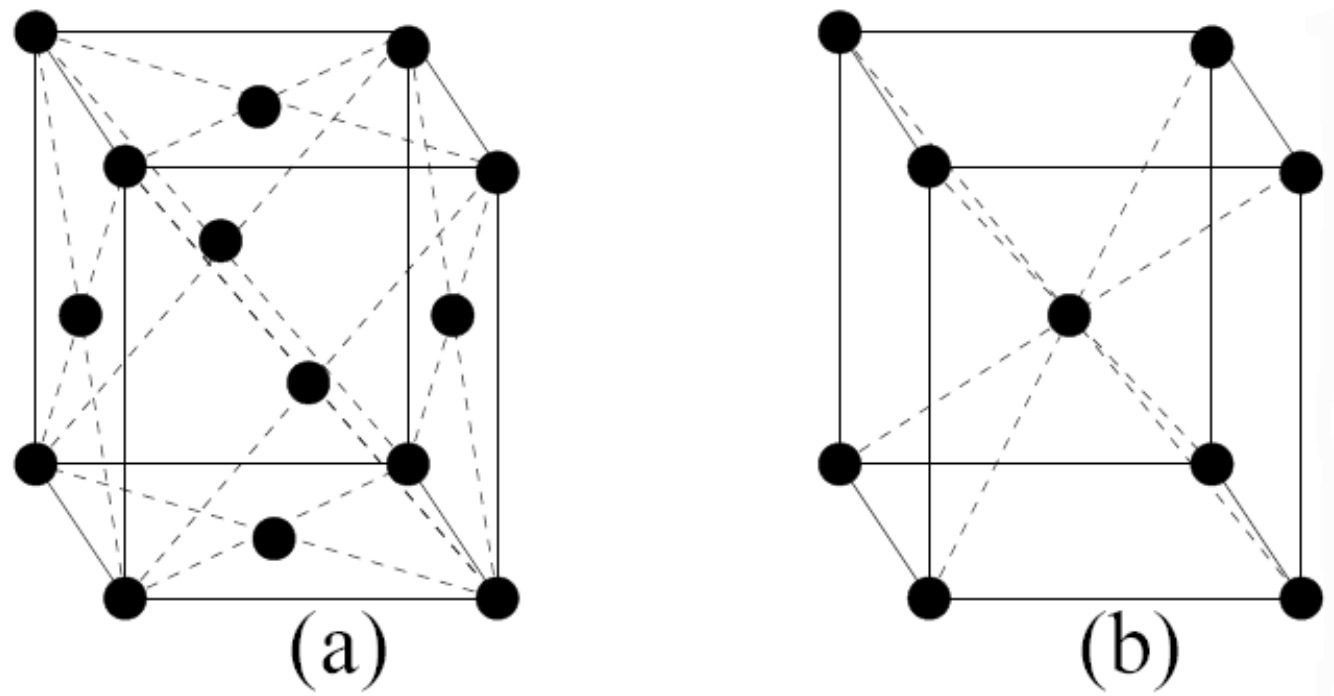

Figura 3. (a) unidade representativa de uma rede cúbica de face centrada FCC; (b) unidade representativa de uma rede cúbica de corpo centrado BCC.

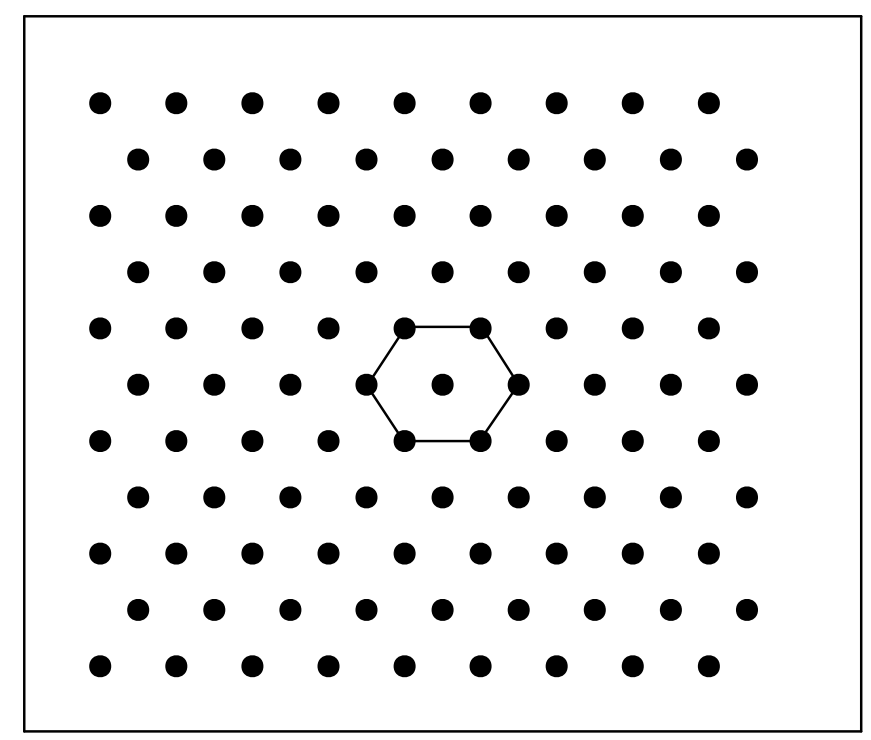

Figura 4. Ilustração de um cristal coloidal bidimensional com simetria triangular. Cada círculo representa um colóide.

de blindagem aproximadamente igual ao espaçamento médio das partículas, uma rede cúbica de corpo centrado (veja figura 3b) é observada. Por outro lado, se o comprimento de blindagem é curto (digamos do tamanho do diâmetro das esferas), a interação ocorre somente quando as partículas estão próximas ao contato. Neste caso forma-se uma rede cúbica de face centrada (veja figura 3a) para suspensões altamente concentradas. A adição de um eletrólito (sal) leva à fusão do cristal, pois altera a força iônica da solução 
e, consequentemente, o alcance da interação (ver subseção 1.1.1). Da mesma forma, se a concentração de partículas for diminuída, o espaçamento médio entre elas será maior que o alcance da interação, possibilitando que a partícula retome o curso de sua movimentação Browniana e, consequentemente, fundindo o cristal. O diagrama de fases de suspensões coloidais carregadas em função de $\phi$ foi investigado experimentalmente por vários pesquisadores (HACHISU; KOBAYASHI; KOSE, 1973; ZHOU; EDWARDS; SULLIVAN, 1989; MURRAY; SPRENGER; WENK, 1990). Para o caso 3D, os resultados mostraram que ela ocorre de forma abrupta, tal como a transição gelo-água, isto é, uma transição de primeira ordem.

Para cristais coloidais bidimensionais, cuja estrutura cristalina mais estável é uma rede com simetria triangular (ver figura 4), a transição de fase se dá de forma diferente. A fim de compreender os princípios desta transição, Murray (MURRAY, 1992) investigou a fusão de um cristal coloidal bidimensional em função da concentração de partículas. Foi observado que, com a diminuição da densidade, as partículas vibravam mais vigorosamente ocorrendo inclusive quebras da ordem local do cristal. Inicialmente, esses defeitos surgem como uma deformação em um eixo do cristal e, para estabilizar essa deformidade, outra deformidade igual surge em uma linha adjacente. Em outras palavras, formam-se deslocações (dislocations), cujo aparecimento inicial é sempre em pares. Esse tipo de defeito desempenha papel fundamental na fusão de cristais bidimensionais em geral, tal como previsto por Michael Kosterlitz e David Thouless (KOSTERLITZ; THOULESS, 1973). Se a concentração continuar a ser diminuída, uma análise estatística do cristal mostra que em média os pares de deslocações se separam. Neste ponto o cristal se torna desordenado; mas diferentemente do caso tridimensional não existe interface bem definida entre o cristal e a fase fluída, isto é, os defeitos surgem de forma contínua no cristal. Além disso, o sistema ainda mantém ordem orientacional, em contraste com um fluido ordinário, que é isotrópico. Este novo estado é chamado de fase hexática, uma fase intermediária entre a fase cristalina e a fase fluída. Se a concentração for diminuída além deste ponto o fluído perde a ordem orientacional e se torna isotrópico. 


\subsection{Cristais coloidais como um sistema modelo}

Dispersões coloidais apresentam ordem estrutural similar a vários sistemas da matéria condensada, incluindo sólidos(HILTNER; KRIEGER, 1969; WILLIAMS; CRANDALL, 1974), líquidos(PUSEY, 1979; ARORA, 1984), gases(BROWN et al., 1975) e até mesmo vidros(PUSEY; VAN MEGEN, 1987). Do ponto de vista da termodinâmica, os cristais coloidais muitas vezes podem ser vistos como uma versão escalada de um sólido atômico, pois a magnitude de muitas variáveis de estado é próxima dos valores obtidos para sólidos reais, desde que elas sejam expressas em unidades "por mol". Por exemplo, uma dispersão coloidal típica com concentração de partículas $\sim 10^{13} \mathrm{~cm}^{-3}$ tem constante elástica $\sim 10 \mathrm{dyn} / \mathrm{cm}^{2}$, ao passo que sólidos atômicos com densidade $\sim 10^{22} \mathrm{~cm}^{-3}$ têm constante elástica $\sim 10^{10} \mathrm{dyn} / \mathrm{cm}^{2}$. A escala perfeita de magnitude dessas constantes com a concentração de partículas leva a crer que a energia de interação entre colóides nessas suspensões é da mesma ordem de magnitude que a interação entre partículas em sólidos atômicos. É importante enfatizar, também, que a força de interação entre partículas em uma suspensão coloidal pode ser facilmente variada, ajustando a força iônica ou a carga dos colóides (veja seção 1.1.1).

Com relação a transições de fase, em sólidos atômicos normalmente são investigadas em função da temperatura ou pressão. Basicamente, o aumento da temperatura, a pressão constante, implica em maior agitação dos átomos, consequentemente aumentando a energia cinética. A fusão do cristal ocorre em torno do ponto onde a energia cinética supera a potencial. No caso de cristais coloidais é complicado estudar experimentalmente a transição de fase em função da temperatura, pois o aumento da temperatura modifica o meio de dispersão, alterando inclusive o alcance das interações. Por outro lado, é possível estudar essas transições a temperatura constante, variando parâmetros como a concentração de partículas ou o comprimento de blindagem, caso a suspensão seja estabilizada eletrostaticamente.

Outra vantagem de utilizar colóides como modelo tem a ver com a escala de tempo com que as partículas se difundem. Como as partículas são relativamente grandes e pesadas, quando comparadas com um átomo ou molécula, sua difusão é mais lenta. A 
escala de tempo relevante para fenômenos associados à difusão dessas partículas é da ordem de milisegundos. Assim, esses sistemas são atraentes para estudar em tempo real fenômenos inacessíveis em sistemas atômicos. Como um complemento, devido ao tamanho das partículas coloidais, é possível observá-las em tempo real utilizando técnicas de microscopia (VAN BLAADEREN; WILTZIUS, 1995; YETHIRAJ; VAN BLAADEREN, 2003), ou até mesmo manipulá-las utilizando pinças ópticas (ASHKIN et al., 1986).

Essa versatilidade das suspensões coloidais levou a comunidade científica a considerálas como modelos experimentais que realmente podem simular a matéria condensada.

\subsection{Defeitos em cristais}

Um cristal perfeito, com todos os átomos do mesmo tipo e nos sítios corretos da rede, sem nenhum tipo de distorção, simplesmente não existe na natureza. Todos os cristais possuem algum tipo de defeito. Existe grande variedade de defeitos, mas neste trabalho estamos interessados nos defeitos pontuais mais importantes, a saber: as vacâncias e os interstícios. Defeitos são importantes por determinar ou contribuir para as propriedades ópticas, mecânicas e de transporte dos mais variados materiais. Em cristais quânticos, como ${ }^{4} \mathrm{He}$ e cristal de Wigner, acredita-se que haja defeitos para qualquer temperatura diferente de zero. Existe também a especulação que mesmo em temperatura zero, defeitos pontuais possam existir, ao passo que em altas concentrações eles possam levar o sistema a uma fase supersólida (KIM; CHAN, 2004; CÂNDIDO; PHILLIPS; CEPERLEY, 2001).

Os defeitos pontuais mais simples são as vacâncias e os interstícios. Uma vacância é caracterizada pela ausência de uma partícula em um sítio da rede, ao passo que um interstício consiste em uma partícula extra fora de qualquer sítio da rede. A figura 5 ilustra esses defeitos em um cristal hexagonal 2D. Embora seja necessária uma quantidade de energia para criar estes defeitos, há aumento de entropia, de modo que a concentração de defeitos no equilíbrio pode ser encontrada minimizando-se a energia livre. Na próxima subseção descreveremos a aplicação da mecânica estatística para determinar uma equação para a concentração de defeitos pontuais em um sólido cristalino, sob condição de 


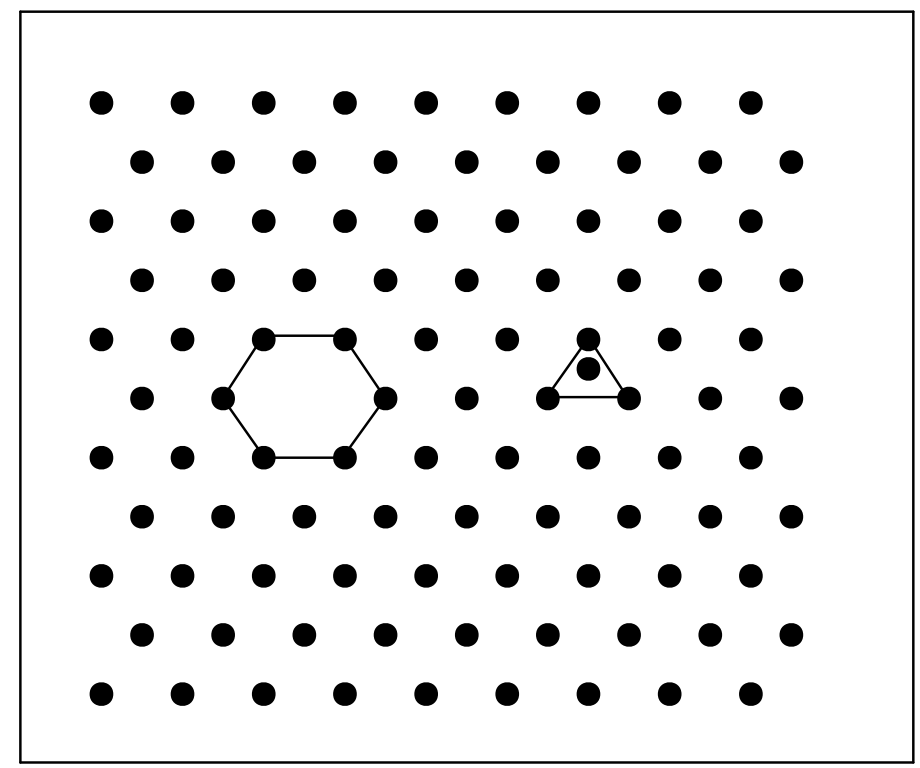

Figura 5. Ilustração de uma vacância (à esquerda) e de um interstício (à direita) em um cristal hexagonal $2 \mathrm{D}$.

equilíbrio termodinâmico. Em seguida, discutiremos a mobilidade destes defeitos, confinando nossa discussão a um resumo das principais conclusões necessárias para propósitos subsequentes. Finalmente, na ultima subseção explicaremos como essas medidas são aplicadas para obter propriedades relacionadas ao transporte atômico, em especial estamos interessados na constante de difusão.

\subsubsection{Concentração de defeitos pontuais em sólidos monoatômicos puros}

Nesta subseção consideraremos a termodinâmica estatística de sólidos monoatômicos puros contendo vacâncias. A discussão é conduzida supondo que a concentração de vacâncias seja muito baixa, de modo que a interação entre elas possa ser desprezada.

Antes de tudo, determinaremos uma expressão para a energia livre de Gibbs, $G(T, P)$, na temperatura $T$ e pressão $P$, do cristal contendo vacâncias. Essa função pode ser escrita como a soma de $G^{0}\left(N_{m}, T, P\right)$, a energia livre de Gibbs de um cristal perfeito com $N_{m}$ sítios de rede, com a mudança na energia livre de Gibbs devido à formação de $N_{v}$ vacâncias 
no cristal perfeito, isto é,

$$
G\left(N, N_{v}, T, P\right)=G^{0}\left(N_{m}, T, P\right)+N_{v} g_{v}^{\infty}-T S_{c o n},
$$

sendo $N_{m}=N+N_{v}, N$ é o número de átomos no cristal com defeitos. A quantidade $g_{v}^{\infty}$ é o trabalho requerido, sob condição de temperatura e pressão constante, para remover um átomo arbitrário do cristal perfeito e levá-lo para o estado de repouso no infinito. Neste processo a rede cristalina relaxa em torno do sítio vacante recém criado, e as vibrações dos átomos são também alteradas. A energia $g_{v}^{\infty}$ é portanto uma quantidade termodinâmica com o caráter de uma energia de Gibbs. A suposição de que não existe interação entre as vacâncias é refletida na proporcionalidade simples com $N_{v}$ no segundo termo à direita na equação (1.5). Essa ausência de interações também significa que todas as configurações distintas, $\Omega$, das $N_{v}$ vacâncias sobre os $N_{m}$ sítios da rede têm a mesma energia, de forma que a entropia configuracional $S_{\text {con }}$ pode ser obtida da equação de Boltzmann considerando $\Omega$ como um fator combinatorial que proporciona o número de caminhos que se pode arranjar $N_{v}$ vacâncias em $N_{m}$ sítios de rede, isto é,

$$
S_{\text {con }}=k_{b} \ln \Omega=k_{b} \ln \left(N_{m} ! / N ! N_{v} !\right)
$$

onde $k_{b}$ é a constante de Boltzmann. A expressão para a energia livre de Gibbs do cristal com vacâncias é portanto

$$
G\left(N, N_{v}, T, P\right)=G^{0}\left(N_{m}, T, P\right)+N_{v} g_{v}^{\infty}-k_{b} T \ln \left(N_{m} ! / N ! N_{v} !\right)
$$

Para muito propósitos é mais conveniente expressar a energia livre em termos do potencial químico das espécies que compõem o material. Neste caso, isto significa expressála em termos do potencial químico dos átomos, $\mu$, e das vacâncias, $\mu_{v}$, os quais podem ser definidos como

$$
\mu=\left(\frac{\partial G}{\partial N}\right)_{T, P, N_{v}}
$$

e

$$
\mu_{v}=\left(\frac{\partial G}{\partial N_{v}}\right)_{T, P, N}
$$


Utilizando a equação 1.7 para $G$ obtemos

$$
\begin{aligned}
\mu & =\left(\frac{\partial G^{0}}{\partial N_{m}}\right)_{T, P}+k_{b} T \ln \left(1-n_{v}\right) \\
& \equiv \mu^{0}+k_{b} T \ln \left(1-n_{v}\right),
\end{aligned}
$$

$\mathrm{e}$

$$
\begin{aligned}
\mu_{v} & =\left(\frac{\partial G^{0}}{\partial N_{m}}\right)_{T, P}+g_{v}^{\infty}+k_{b} T \ln \left(n_{v}\right) \\
& \equiv g_{v}+k_{b} T \ln \left(n_{v}\right),
\end{aligned}
$$

onde $n_{v} \equiv N_{v} /\left(N+N_{v}\right)$ é a fração de sítios vacantes, neste caso igual à fração molar $x_{v}$. A quantidade $g_{v}$ introduzida em 1.13 é o trabalho requerido para criar uma vacância a partir da remoção de um átomo de um sítio arbitráio da rede e incoporá-lo em uma superfície externa. Como os potenciais químicos são quantidades intensivas, ao passo que a energia livre de Gibbs é extensiva, segue que $G$ pode ser expressa como

$$
G=N \mu+N_{v} \mu_{v}
$$

Tendo estabelecido uma expressão para G, podemos seguir adiante e determinar a concentração de defeitos e outras funções termodinâmicas, tudo sob condição de equilíbrio termodinâmico. Deste modo, o número de vacâncias no equilíbrio será tal que mimimize a energia livre de Gibbs em uma dada temperatura e pressão, isto é,

$$
\mu_{v} \equiv\left(\frac{\partial G}{\partial N_{v}}\right)_{T, P, N}=0
$$

Portanto, a concentração de vacâncias no equilíbrio é

$$
n_{v}=\exp \left(-g_{v} / k_{b} T\right)
$$

Outras funções termodinâmicas para o cristal em equilíbrio podem ser obtidas de $G$ por meio de manipulações termodinâmicas bem conhecidas. Por exemplo, a entalpia e a 
entropia do cristal são dadas por

$$
H=\left(\frac{\partial(G / T)}{\partial(1 / T)}\right)_{P, N}=H^{0}+N_{v} h_{v}
$$

e

$$
S=\left(\frac{\partial G}{\partial T}\right)_{P, N}=S^{0}+N_{v} s_{v}-k_{b} N \ln \left(1-n_{v}\right)-k_{b} N_{v} \ln \left(n_{v}\right),
$$

sendo $H^{0}$ e $S^{0}$ a entalpia e entropia do cristal perfeito, os quais estão relacionados a $G$ de forma análoga a $\mu^{0}$. De forma similar, a entalpia, $h_{v}$, e a entropia, $s_{v}$, de formação de uma vacância estão relacionadas à energia de formação da vacância, $g_{v}$, por

$$
h_{v}=\left(\frac{\partial\left(g_{v} / T\right)}{\partial(1 / T)}\right)_{P, N}, \quad s_{v}=\left(\frac{\partial g_{v}}{\partial T}\right)_{P, N}
$$

e

$$
g_{v}=h_{v}-T s_{v}
$$

Finalmente, é importante mencionar que a teoria para sólidos monoatômicos contendo insterstícios é similar em todos os aspectos ao que foi colocado nesta subseção considerando as vacâncias.

\subsubsection{Mobilidade atômica}

Para entender o transporte atômico é necessário considerar, além da concentração de defeitos, também a taxa na qual os defeitos se movem através da rede cristalina. Basicamente, os átomos no núcleo do defeito gastam a maior parte de seu tempo vibrando em torno de suas posições na rede. O movimento dos defeitos é mediado por flutuações térmicas, que ocasionalmente proporcionam energia e momento suficientes para que os átomos "pulem" de uma posição para outra, consequentemente mudando a posição do defeito. Nesta subseção apresentaremos um modelo básico para as taxas de migração em sólidos, o qual pressupõe o reestabelecimento do equilibrio térmico entre os saltos do defeito. Isto é razoável de se adimitir, já que os saltos ocorrem com frequência muito baixa na escala de tempo da vibração da rede.

Se os átomos em torno do defeito mudam de posição somente quando as oscilações 
térmicas superam um determinado valor, isto implica a existência de um ou mais estados intermediários onde a energia potencial da rede é um máximo ao longo do caminho tomado na transição. Este estado intermediário de alta energia é conhecido como o estado de transição. Porém, a energia do estado de transição não é determinada apenas pela posição do átomo que está se movendo; ela obviamente depende das posições relativas dos átomos vizinhos. Em outras palavras, esta energia depende do estado de vibração do cristal e das fases de vibração. Todavia, a amplitude média das vibrações atômicas geralmente é pequena comparada com o deslocamento necessário para levar um átomo de sua posição inicial para a posição de transição. Esta afirmação é suportada pelo critério de Lindemann para a fusão de sólidos cristalinos, que diz que o deslocamento de átomos no ponto de fusão está entre 0.1 - 0.2 do parâmetro de rede.

Faremos agora uma descrição simplificada do processo de deslocamento dos defeitos, considerando o movimento de apenas um átomo em um campo potencial oriundo de sua interação com os outros átomos da rede. Objetivamos com isso enfatizar os princípios básicos envolvidos.

No que segue, discutiremos o movimento de interstícios que se movem saltando de um sítio interstistial para outro. A forma geral dos resultados que obteremos se aplica igualmente para as vacâncias, embora existam algumas pequenas diferenças em sua obtenção, caso este tipo de defeito seja empregado na análise.

A figura 6 ilustra o potencial periódico médio, $V(x)$, no qual um átomo interstistial se move. Por simplicidade consideraremos o movimento apenas na direção $x$. Da física clássica, sabemos que o movimento deste átomo neste potencial é descrito pela função Hamiltoniana

$$
\mathscr{H}\left(x, p_{x}\right)=\left(p_{x}^{2} / 2 m\right)+V(x)
$$

onde $m$ é a massa do átomo e $p_{x}$ é o momento na direção $x$. Da mecânica estatística clássica sabemos que a probabilidade de o átomo estar, em qualquer instante, posicionado 


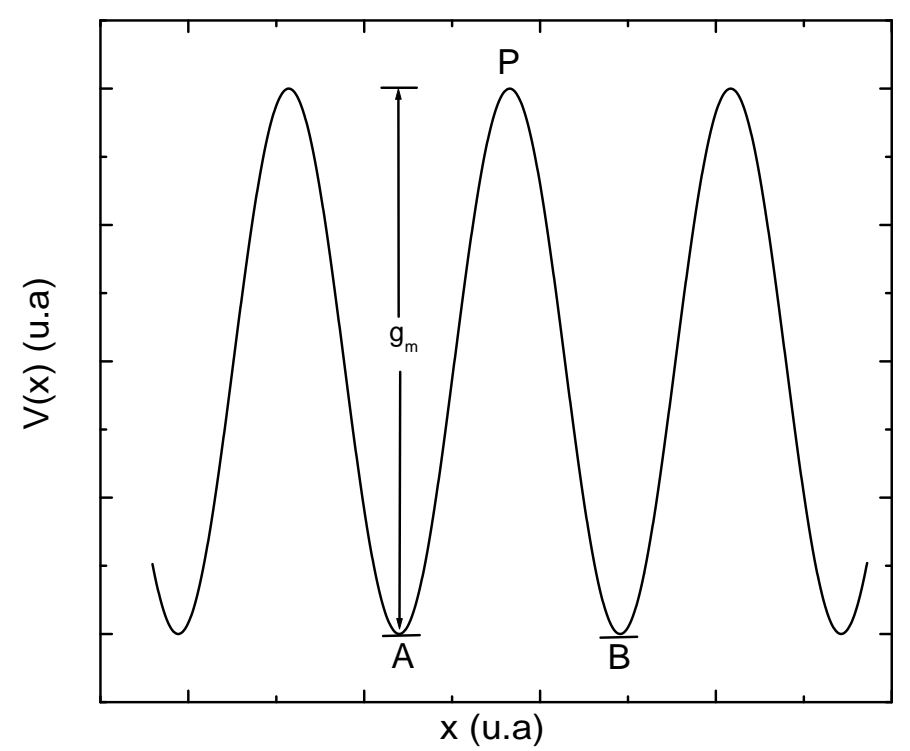

Figura 6. Potencial periódico ao longo da direção $x$ de um cristal. A figura procura ilustrar os pontos de mínimo (A e B) do potencial, onde se alojam os átomos, bem como as barreiras de energia $\left(g_{m}\right)$ entre esses mínimos.

entre $x$ e $x+d x$, e com momento entre $p_{x}$ e $p_{x}+d p_{x}$ é

$$
\frac{\exp \left(-\mathscr{H}\left(x, p_{x}\right) / k_{b} T\right) d x d p_{x}}{\int_{L_{x}} \int_{-\infty}^{\infty} \exp \left(-\mathscr{H}\left(x, p_{x}\right) / k_{b} T\right) d x d p_{x}}
$$

onde a integral espacial é tomada ao longo do comprimento do cristal na direção $x\left(L_{x}\right)$.

Agora observe que todos os átomos dentro de uma distância $d x \equiv v_{x} d t=\left(p_{x} / m\right) d t$ à esquerda do ponto $P$ na figura 6 , tendo velocidade $v_{x}>0$, cruzará o topo da barreira, $P$, no intervalo de tempo $d t$. Consequentemente, o número de átomos interstistiais que cruzarão a barreira no tempo $d t$ é dado por

$$
\frac{d t \int_{0}^{\infty} \exp \left(-\mathscr{H}\left(x_{p}, p_{x}\right) / k_{b} T\right) v_{x} d p_{x}}{\int_{L_{x}} \int_{-\infty}^{\infty} \exp \left(-\mathscr{H}\left(x, p_{x}\right) / k_{b} T\right) d x d p_{x}} .
$$

Substituindo a equação 1.21 em 1.23 obtemos,

$$
\frac{\frac{d t}{m}\left(m k_{b} T\right) \exp \left(-V\left(x_{p}\right) / k_{b} T\right)}{\int_{L_{x}} \exp \left(-V(x) / k_{b} T\right) d x \int_{-\infty}^{\infty} \exp \left(-p_{x}^{2} / 2 m k_{b} T\right) d p_{x}}
$$


o que nos leva a

$$
\frac{d t\left(\frac{k_{b} T}{2 \pi m}\right)^{1 / 2} \exp \left(-V\left(x_{p}\right) / k_{b} T\right)}{\int_{L_{x}} \exp \left(-V(x) / k_{b} T\right) d x} .
$$

Suporemos agora que todos os átomos que cruzam a barreira em $P$ são desativados ao concluírem o cruzamento, isto é, tomaremos como desprezível a chance de um átomo que acabou de cruzar $P$, vindo de $A$ para $B$, retorne ao ponto $A$. Com essa suposição a quantidade 1.25 pode ser vista como o produto de três quantidades: o número de átomos interstistiais sobre o plano $x\left(N s_{x}\right)$, a frequência de pulos $w$, e o intervalo de tempo $d t$. Como o integrando no denominador de 1.25 é periódico, podemos substituí-lo por $L_{x} / s_{x}$ multiplicado pela integral sobre o período $s_{x}$. Portanto,

$$
w=\frac{\left(\frac{k_{b} T}{2 \pi m}\right)^{1 / 2} \exp \left(-V\left(x_{p}\right) / k_{b} T\right)}{\int_{s_{x}} \exp \left(-V(x) / k_{b} T\right) d_{x}} .
$$

Na maioria dos sistemas a altura da barreira de potencial, $V\left(x_{p}\right)-V\left(x_{A}\right)$, é muito maior do que $k_{b} T$. Portanto, a maior contribuição para a integral sobre $x$ vem da região em torno de $A$, onde $V(x)$ é mais baixo. Dentro da integral podemos portanto fazer uma aproximação harmônica em torno da posição $A$ e definir

$$
V(x)=V\left(x_{A}\right)+\frac{1}{2} K x^{2} .
$$

Substituindo esta aproximação em 1.26 obtemos

$$
\begin{aligned}
w & =\frac{1}{2 \pi}\left(\frac{k_{b}}{m}\right)^{1 / 2} \exp \left(-\left(V\left(x_{p}\right)-V\left(x_{A}\right)\right) / k_{b} T\right) \\
& \equiv \nu \exp \left(-e_{m} / k_{b} T\right) .
\end{aligned}
$$

A primeira conclusão extraída destes cálculos é que $w$ segue uma relação de Arrhenius com a temperatura e que $\nu$ é proporcional a $m^{-1 / 2}$. Como enfatizamos no começo desta subseção, o cálculo apresentado omite o movimento dos outros átomos. Porém, isto pode ser levado em conta se considerarmos um comportamento médio, onde $V(x)$ para o átomo saltando é obtido como uma média (obtida da mecânica estatística) do potencial exercido por todos os outros átomos. Para um sistema na temperatura $T$ com uma dada pressão 
externa $P$ isto tem o efeito de mudar $e_{m}$ em 1.29 por uma quantidade com o caráter da energia livre de Gibbs, $g_{m}$. Assim, podemos substituir a equação 1.29 por

$$
w=\nu \exp \left(-g_{m} / k_{b} T\right)
$$

onde $g_{m}=h_{m}-T s_{m}$, sendo $h_{m}$ e $s_{m}$, respectivamente, a entalpia e entropia de migração, este último correspondendo à mudança na vibração da rede associada com o salto do átomo.

Para uma descrição mais precisa e completa deveríamos levar em conta as correlações envolvidas no salto de um átomo e o movimento dos átomos vizinhos. Para entender melhor esses efeitos de muitos corpos veja a formulação de Vineyard (ALLNATT; LIDIARD, 1993).

\subsubsection{Constante de difusão}

É fácil perceber que a constante de difusão de átomos em um sólido cristalino deveria, em princípio, ser proporcional, tanto à concentração de defeitos, quanto à frequência de pulos que estes defeitos desenvolvem. Como essas duas quantidades dependem da temperatura via uma função exponencial de Boltzmann, isto possibilita descrever a difusão como uma relação de Arrhenius

$$
D(T)=D_{0} \exp \left(-Q / k_{b} T\right)
$$

onde $Q$ é conhecida como energia de ativação e $D_{0}$ é um fator pré-exponencial. Porém, existem muitas situações onde o problema é mais complicado. Por exemplo, a frequência de movimento dos defeitos pode ser alterada devido a interações com outros defeitos (do mesmo tipo ou de tipos diferentes). Quando essas interações são atrativas, pode ocorrer a formação de defeitos mais complexos, com tempo de vida longo o suficiente para considerá-los como de tipos distintos. Para obter o coeficiente de difusão nesses casos mais complexos, em geral considera-se a contribuição de cada tipo de defeito, independentemente dos defeitos de outros tipos, e então adicionam-se as contribições individuais de cada tipo, isto é, $D(T)=\sum_{i} D_{i}(T)$. É claro que estamos fazendo apenas uma aproximação 
ao calcularmos propriedades de transporte de acordo com esta suposição de aditividade. Na prática as propriedades de transporte vão depender de como essas sub-populações de defeitos se relacionam, pois determinados tipos de defeitos podem ser convertidos em outros tipos. Por exemplo, quando a população total consiste de vacâncias e um par soluto-vacância, a precisão da suposição de aditividade pode depender da taxa na qual as vacâncias são trocadas entre essas sub-populações.

\subsection{Visão geral da tese}

O objetivo desta tese é estudar defeitos pontuais em cristais coloidais bidimensionais utilizando dinâmica molecular. Neste capítulo, tentamos dar a base necessária para compreensão dos resultados obtidos durante a realização deste trabalho. Em particular, procuramos esclarecer como uma solução coloidal estabilizada eletrostaticamente pode se auto-organizar em uma estrutura cristalina. Além disso, apresentamos também alguma teoria básica sobre os defeitos pontuais em um cristal, especialmente os aspectos relacionados à concentração de equilíbrio e a mobilidade dos defeitos. No próximo capítulo apresentaremos o método numérico utilizado para a obtenção dos resultados, isto é, abordaremos os princípios básicos de uma simulação por dinâmica molecular no ensemble NVT. O capítulo 3 tratará dos cálculos relacionados à energia de formação e interações entre defeitos pontuais em um cristal coloidal bidimensional, enquanto o capítulo 4 abordará a dinâmica desses defeitos. Finalmente, o capítulo 5 apresentará as conclusões da tese e as perspectivas de trabalhos futuros. 


\section{Capítulo 2}

\section{Dinâmica molecular}

Dinâmica Molecular (DM) é uma técnica de simulação computacional utilizada para investigar as propriedades macroscópicas de um sistema em termos das interações microscópicas entre seus elementos. Este tipo de simulação pode oferecer soluções exatas para problemas que, quando abordados analiticamente, ou são intratáveis ou podem ser resolvidos apenas com o uso de aproximações. Deste ponto de vista, esta técnica serve como um teste para teorias, mostrando o quanto elas são eficazes em diferentes contextos. Do ponto de vista experimental, a simulação pode trazer resultados novos, os quais podem direcionar estudos ou mesmo facilitar a interpretação de resultados já obtidos. De fato, com simulação computacional é possível obter resultados sob condições extremas, as quais não podem ser atingidas em laboratório, e.g. experimentos em condições extremas de temperatura e pressão.

Neste capítulo apresentaremos os ingredientes chave para realizar uma simulação por dinâmica molecular no ensamble NVT, incluindo uma breve revisão sobre as teorias clássicas, além dos algoritmos fundamentais para construir o programa.

\subsection{Princípios básicos}

O estado microscópico de um sistema pode ser especificado em termos da posição e do momento de cada partícula que o constitui. Dentro de uma descrição clássica, podemos 
escrever a Hamiltoniana $\mathscr{H}$ de um sistema com $N$ partículas como a soma das funções energia cinética $\mathscr{K}$ e potencial $\mathscr{V}$ do conjunto de coordenadas q e momentos p de cada partícula. Seguindo a notação usada em (ALLEN; TILDESLEY, 1987)

$$
\mathbf{q}=\left(\mathbf{q}_{1}, \mathbf{q}_{2}, \ldots, \mathbf{q}_{N}\right) \quad \text { e } \quad \mathbf{p}=\left(\mathbf{p}_{1}, \mathbf{p}_{2}, \ldots, \mathbf{p}_{N}\right)
$$

temos então,

$$
\mathscr{H}(\mathbf{q}, \mathbf{p})=\mathscr{K}(\mathbf{p})+\mathscr{V}(\mathbf{q})
$$

As coordenadas generalizadas $\mathbf{q}$ são normalmente as coordenadas cartesianas, $\mathbf{r}$, de cada átomo no sistema. Porém, é muitas vezes útil tratar um conjunto de átomos que formam uma molécula como um corpo rígido. Neste caso, q pode envolver além das coordenadas cartesianas dos átomos, variáveis especificando a orientação molecular. Além disso, pode ser necessário tratar agregados compostos de milhões de átomos como uma entidade única e indivisível. É o caso de simulações envolvendo colóides, para as quais as coordenadas generalizadas $\mathbf{q}$ constam apenas das coordenadas cartesianas do centro de massa de cada colóide. Independentemente do caso, $\mathbf{p}$ é sempre o momento associado ao conjunto de partículas.

Tradicionalmente, a energia potencial é calculada dividindo-se a interação total em contribuições devido a 1-corpo, 2-corpos, 3-corpos, e assim por diante. Para sistemas atômicos, onde as coordenadas generalizadas correspondem apenas às coordenadas cartesianas, podemos escrever:

$$
\mathscr{V}(\mathbf{r})=\sum_{i} v_{1}\left(\mathbf{r}_{i}\right)+\sum_{i} \sum_{j>i} v_{2}\left(\mathbf{r}_{i}, \mathbf{r}_{j}\right)+\sum_{i} \sum_{j>i} \sum_{k>j>i} v_{3}\left(\mathbf{r}_{i}, \mathbf{r}_{j}, \mathbf{r}_{k}\right)+\ldots
$$

O primeiro termo à direita representa um campo externo aplicado ao sistema ou o efeito das paredes de um recipiente. O segundo termo é o mais importante: Trata-se do potencial de interação, que depende somente da separação $\mathbf{r}_{i j}=\left|\mathbf{r}_{i}-\mathbf{r}_{j}\right|$ entre os pares de partículas. O terceiro termo é importante em alguns contextos, mas devido ao custo computacional este termo e os de mais alta ordem são, em geral, desconsiderados em uma simulação por dinâmica molecular. Existe uma literatura extensa sobre a forma que estes 
potenciais são determinados experimentalmente, ou modelados teoricamente (MAITLAND; RIGBY; WAKEHAM, 1981; GRAY; GUBBINS, 1984; STONE, 1997).

A forma matemática de $\mathscr{V}$ usada nas simulações (em geral um potencial de interação efetivo entre pares de partículas) depende de propriedades intrínsecas às partículas e, para efeitos práticos na simulação, também da distância típica de interação entre elas. Por exemplo, se o sistema é composto de partículas carregadas, o potencial deverá envolver interações coulômbicas de longo alcance; ao passo que para um sistema composto de partículas neutras, o potencial é de curto alcance e se deve a interações de van der Waals. $\mathrm{Na}$ verdade, interações de van der Waals ocorrem entre todos os átomos e moléculas, ionizadas ou não, mas para efeitos práticos, essa contribuição pode ser desprezada se a distância média entre as partículas excede o alcance da interação. Em outras palavras, não existe uma definição única para o potencial de interação, pois ele depende do sistema estudado. Por outro lado, a energia cinética $\mathscr{K}$ está associada apenas ao movimento das partículas, sendo dada por

$$
\mathscr{K}(\mathbf{p})=\sum_{i=1}^{N} \mathbf{p}_{i}^{2} / 2 m_{i},
$$

onde $m_{i}$ é a massa da partícula $i$. Para realizar uma simulação por dinâmica molecular é necessário resolver numericamente, passo a passo, as equações clássicas de movimento, as quais determinam a evolução temporal do sistema e todas as suas propriedades mecânicas. Para um sistema atômico simples essas equações podem ser escritas como

$$
m_{i} \ddot{\mathbf{q}}_{i}=\mathbf{f}_{i} \quad \text { e } \quad \mathbf{f}_{i}=-\frac{\partial \mathscr{H}}{\partial \mathbf{q}_{i}} .
$$

Existem vários métodos numéricos para resolver estas equações de movimento, os quais variam em complexidade, precisão e em quantidade de recursos necessários para a sua implementação (principalmente no que diz respeito à memória). Porém, independente do método empregado, é sempre necessário calcular a força atuando em cada partícula do sistema. Uma vez que a força é a derivada da Hamiltoniana $\mathscr{H}$ ou, mais precisamente, da energia potencial $\mathscr{V}$, podemos dizer que o ingrediente básico para realizar a simulação computacional é exatamente definir a Hamiltoniana do sistema. Para melhorar o desem- 
penho e evitar problemas envolvendo cálculos com números muito pequenos ou muito grandes (erros de underflow e overflow), em geral normaliza-se a Hamiltoniana de modo a obter um potencial de interação mais simplificado.

\subsection{Dinâmica molecular e sua relação com a mecânica estatística}

Para obter propriedades macroscópicas de um sistema a partir de seu estado microscópico, a mecânica estatística (MCQUARRIE, 1976) lida com médias no ensemble. Um ensemble é uma coleção de pontos no espaço de fase $\Gamma$, os quais são distribuídos de acordo com uma densidade de probabilidade, que é determinada fixando-se alguns parâmetros macroscópicos, por exemplo, temperatura $T$, número de partículas $N$ e pressão $P$. Nesta tese trabalhamos com o ensemble canônico, no qual a temperatura $T$, o número de partículas $N$ e o volume $V$ são mantidos constantes $(N V T)$. Para este ensemble, a média de alguma quantidade $G$, no equilíbrio, é expressa em termos de integrais do espaço de fase envolvendo a energia potencial, $\mathscr{V}$, e cinética, $\mathscr{K}$,

$$
\langle G\rangle=\frac{\int G\left(d \mathbf{p}^{N}, d \mathbf{r}^{N}\right) \exp \left\{-\beta\left[\sum_{i} \mathbf{p}_{i}^{2} / 2 m_{i}+\mathscr{V}\left(\mathbf{r}^{N}\right)\right]\right\} d \mathbf{p}^{N}, d \mathbf{r}^{N}}{\int \exp \left\{-\beta\left[\sum_{j} \mathbf{p}_{j}^{2} / 2 m_{j}+\mathscr{V}\left(\mathbf{r}^{N}\right)\right]\right\} d \mathbf{p}^{N}, d \mathbf{r}^{N}},
$$

onde $\beta=1 / k_{b} T$ e $k_{b}$ é a constante de Boltzmann. Esta média está associada a uma série de medidas sobre um ensemble de sistemas independentes. Por outro lado, a hipótese ergótica (MCQUARRIE, 1976) relaciona as médias no ensemble com médias no tempo para um único sistema em equilíbrio durante o curso de sua evolução natural, mostrando que elas devem produzir os mesmos resultados. Uma simulação por dinâmica molecular evolui no tempo um único sistema e produz médias da forma

$$
\langle G\rangle=\lim _{t \rightarrow \infty} \frac{1}{t} \int_{0}^{t} d t^{\prime} G\left(\mathbf{r}^{N}, \mathbf{p}^{N}, t^{\prime}\right)
$$

Se a amostragem for longa o suficiente para capturar o comportamento típico do sistema, os dois tipos de médias serão idênticos, tal como previsto pela hipótese ergótica. 


\subsection{Inicialização}

Normalmente, uma simulação por dinâmica molecular não é realizada em uma única execução. Em geral, as execuções são interrompidas para fazer uma checagem parcial dos resultados ou por uma interrupção forçada devido, por exemplo, à falta de energia elétrica. Qualquer que seja o caso, o programa deve ser capaz de recomeçar de onde parou utilizando-se de arquivos salvos durante a execução anterior. Para a primeira execução é necessário especificar uma série de condições iniciais para a simulação por DM. Obviamente, cada aplicação possui o seu próprio conjunto de parâmetros de entrada, mas alguns parâmetros são imprescindíveis para qualquer simulação por DM, e é sobre eles que comentaremos aqui.

Primeiramente, é necessário definir o número de partículas $N$ do sistema. É importante encontrar um balanço entre o desejável e o factível, pois o esforço computacional é proporcional a uma função do número de partículas. Assim, dependendo do potencial e método empregado podemos obter algoritmos com complexidade $\ln (N), N, N^{2}$, e assim por diante. Por outro lado, se $N$ for muito pequeno, o sistema pode gerar resultados imprecisos, ou até mesmo ser incapaz de reproduzir os resultados esperados. A recomendação é realizar uma série de testes pequenos variando o número de partículas e observar os resultados gerados. A partir destes testes é possível inferir um número adequado de partículas. Em geral nas simulações por DM o número de partículas varia entre $10^{2}$ e $10^{4}$ para simulações seqüenciais, mas pode chegar a um bilhão de partículas para simulações paralelas (SHIMOJO et al., 2000). Com $N$ escolhido, deve-se especificar um volume $V$ para a caixa de simulação de modo a reproduzir a densidade desejada.

É também necessário especificar uma configuração inicial para as partículas, bem como suas velocidades iniciais. A forma mais simples de distribuir as partículas na caixa de simulação é designando posições randômicas dentro de seus extremos. O problema com esta técnica é que a configuração gerada pode conter sobreposições, o que é absolutamente artificial para alguns potenciais, por exemplo, para um potencial de hard core. Mesmo para potenciais mais suaves, a energia pode ser muito alta dependendo de quanto as 
partículas estão sobrepostas. Isso pode levar a grandes instabilidades numéricas e trazer dificuldades na solução das equações de movimento. Para evitar tais problemas, é comum atribuir às partículas as posições de uma rede periódica, com o parâmetro de rede escolhido de forma a refletir a densidade desejada. O tipo de rede pode ser escolhido baseado em informações prévias sobre a estrutura que se deseja obter no equilíbrio. Por exemplo, para um cristal que no equilíbrio se organiza em uma rede cúbica de face centrada (fcc), é aconselhável inicializar a simulação de uma rede com essa estrutura para que o sistema chegue ao equilíbrio rapidamente. Mas se o objetivo é estudar um líquido, qualquer rede pode servir como ponto de partida, já que durante o curso da simulação a estrutura da rede desaparecerá.

Para as velocidades iniciais das partículas, normalmente são atribuídas direções aleatórias com magnitude vinculada à temperatura e corrigidas de forma que não haja momento resultante

$$
T=\frac{1}{3 N k_{b}} \sum_{i=1}^{N} m_{i} v_{i}^{2} \quad \text { e } \quad \mathbf{P}=\sum_{i=1}^{N} m_{i} \mathbf{v}_{i}=0 .
$$

Na prática não há grandes preocupações quanto à distribuição de velocidades, pois com a ocorrência de colisões em poucos passos de simulação a distribuição de MaxwellBoltzmann é retomada.

\subsection{Condições periódicas de contorno}

Devido a restrições técnicas associadas ao poder computacional que dispomos atualmente, é invariavelmente necessário trabalhar com sistemas cujo número de partículas seja bem menor que o encontrado em sistemas macroscópicos (algo em torno de $10^{23}$ ). Com sistemas pequenos é necessário usar condições periódicas de contorno, a menos que efeitos de superfície sejam o foco de interesse. Como uma ilustração desta necessidade, considere 1000 átomos em um cubo com dimensões 10x10x10. Aproximadamente metade dos átomos ficará sobre as faces do cubo, o que afetará fortemente as propriedades medidas, pois os átomos nas superfícies experimentam forças diferentes dos átomos em bulk. Mesmo para um sistema com 1 milhão de átomos, aproximadamente $6 \%$ residirão nas 


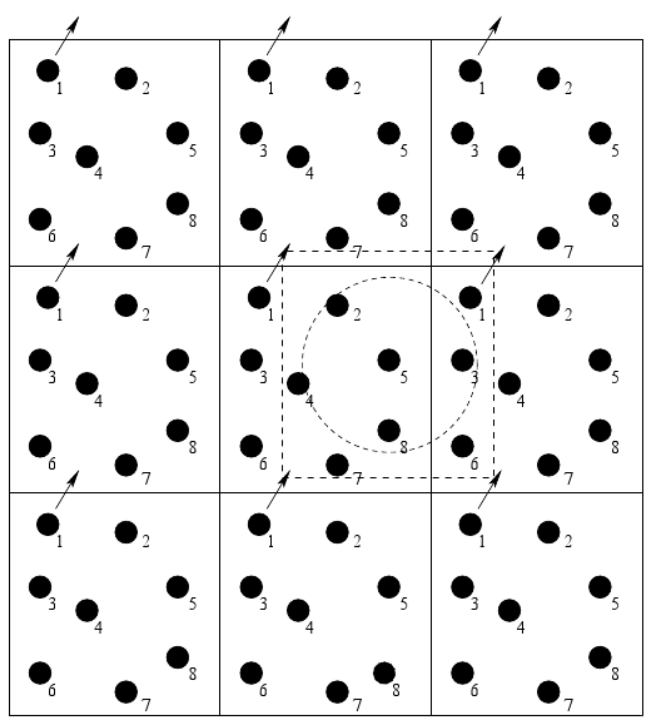

Figura 7. Condições periódicas de contorno para um sistema bidimensional.

superfícies (RAPAPORT, 1995); parcela não desprezível já que em sistemas macroscópicos apenas uma fração muito pequena das partículas reside nas paredes do recipiente.

Aplicar condições periódicas de contorno significa repetir infinitas vezes a caixa de simulação em todas as direções. Dessa forma, as coordenadas das partículas na caixa central são replicadas de acordo com a seguinte equação:

$$
\mathbf{r}_{i}^{\prime}=\mathbf{r}_{i}+\mathbf{m}
$$

sendo $\mathbf{r}_{i}$ as coordenadas das partículas na caixa central, $\mathbf{r}_{i}^{\prime}$ as coordenadas replicadas, $\mathbf{m}=\left(m_{x} L_{x}, m_{y} L_{y}, m_{z} L z\right)$ o vetor de translado, com $m_{i}$ inteiro, e $L_{i}$ os lados da caixa de simulação. As conseqüências desse esquema são as seguintes: quando um átomo deixa uma caixa atravessando uma parede, uma cópia idêntica a ele entra novamente na caixa pela parede oposta. Uma ilustração bidimensional deste efeito é apresentada na figura 7. Quando a partícula 1 deixa a caixa central de simulação, simultaneamente uma cópia idêntica a ela entra pela face oposta, mantendo assim a densidade constante em todas as réplicas da caixa central.

Na prática não é necessário observar as partículas de todas as réplicas, basta atualizar a posição das partículas na caixa central de simulação. Para uma caixa de simulação 
cúbica, podemos utilizar o seguinte algoritmo para atualizar as coordenadas das partículas:

$$
\begin{array}{ll}
\mathbf{s e}\left(r_{x}>L / 2\right) & r_{x}=r_{x}-L \\
\mathbf{s e}\left(r_{x}<-L / 2\right) & r_{x}=r_{x}+L
\end{array}
$$

onde $r_{x}$ é componente $x$ da coordenada de uma partícula e $L$ o comprimento dos lados da caixa de simulação, que deve estar centrada na origem do sistema de coordenadas. Comandos similares devem ser aplicados às componentes $y$ e $z$ das coordenadas das partículas.

Com o sistema sujeito a condições periódicas de contorno, um dos principais aspectos que deve ser considerado é a forma como são calculadas a energia potencial de uma configuração e as forças atuando sobre as partículas. Pressupondo um potencial de interação por pares, uma partícula interage com todas as outras partículas na caixa central de simulação, isto é, existem $N-1$ termos a serem somados. Teoricamente, devem também ser incluídas as interações com as partículas nas réplicas da caixa central, ou seja, um número infinito de termos que na prática é impossível de ser tratado. Devido a essa impossibilidade prática, são aplicadas aproximações. No caso de uma função potencial de curto alcance, uma aproximação comumente empregada é chamada de convenção de mínima imagem. Ela consiste em considerar a partícula de interesse como estando no centro de uma caixa com o mesmo tamanho e forma da caixa central. A partícula de interesse interagirá com todas as partículas dentro desta caixa imaginária. A figura 7 ilustra esta técnica considerando a partícula 5 como a partícula de interesse, a qual interage com as partículas 2, 4, 7 e 8 na caixa central e com as partículas 1, 3, 6 na caixa vizinha da direita.

Quando utilizamos a convenção de mínima imagem, o cálculo da energia potencial devido ao potencial de pares envolve $\frac{1}{2} N(N-1)$ termos. Se o número de partículas for muito grande, digamos 3000, o cálculo pode ainda ser bastante pesado. Isso pode ser contornado se aplicarmos um raio de corte $r_{c u t}$ para o alcance do potencial, tomando como zero a interação com todas as partículas cuja distância à partícula de interesse seja maior do que $r_{c u t}$. Isso é razoável de se implementar, já que as principais contribuições para a energia potencial advêm de partículas próximas à partícula de interesse. A figura 
7 ilustra esta técnica considerando a partícula 5 como a partícula de interesse, a qual interage com as partículas 2 e 8 na caixa central e com a partícula 3 na caixa vizinha da direita. Para um sistema bidimensional o número de vizinhos explicitamente considerados é reduzido por um fator de $\pi r_{c u t}^{2} / L^{2}$, ao passo que para um sistema tridimensional (3D) o fator de redução é $4 \pi r_{\text {cut }}^{3} / 3 L^{3}$. É obvio que, para ter alguma vantagem, o raio de corte tem que ser menor do que $L / 2$.

Quando o sistema envolve partículas carregadas, o cálculo da energia potencial e força é mais complicado, pois o alcance da interação pode se estender por distâncias muito maiores do que o lado da caixa de simulação. Em geral, define-se uma interação como sendo de longo alcance quando o decaimento espacial é mais lento do que $r^{-d}$ com $r$ a distância e $d$ a dimensionalidade do sistema. Assim, um dos maiores problemas para simulação de sistemas carregados é o tratamento de interações coulômbicas, cujo decaimento espacial é proporcional a $1 / r$. Em princípio, todas as cargas interagem com todas as outras, levando a um esforço computacional da ordem de $\mathcal{O}\left(N^{2}\right)$ já dentro da caixa central de simulação. Com o uso de condições periódicas de contorno, essa soma deveria incluir também a interação com as infinitas réplicas que cercam a caixa central de simulação, o que é impossível de ser tratado na prática. Para resolver esse problema, a famosa soma de Ewald (HEYES, 1981; DE LEEUW; PERRAM; SMITH, 1980) quebra a soma lentamente convergente em duas somas que convergem exponencialmente. Contudo, este método sofre de duas deficiências. Primeiro, uma das somas é feita no espaço recíproco, o que torna necessário o uso de transformadas de Fourier. Segundo, o algoritmo escala com $N^{2}$, sendo $N$ o número de partículas carregadas na caixa central, ou no melhor dos casos $N^{3 / 2}$, caso seja aplicado um raio de corte otimizado com relação ao parâmetro de quebra (PERRAM; PETERSEN, 1988). O problema se torna ainda pior caso as condições periódicas de contorno sejam aplicadas apenas de forma parcial, isto é, se o sistema for confinado em uma ou duas direções. Existem algoritmos mais modernos para tratar esse problema, sendo que um bom ponto de partida para estudá-los é o livro de Daan Frenkel (FRENKEL; SMIT, 2002). 


\subsection{Integração das equações de movimento}

Para realizar uma simulação por dinâmica molecular, é necessário saber a posição e velocidade de cada uma das $N$ partículas do sistema. Isso envolve resolver um sistema de $3 N$ equações diferenciais de segunda ordem, equação (2.10), ou um sistema de $6 N$ equações diferenciais de primeira ordem, equação (2.11).

$$
\begin{gathered}
m_{i} \ddot{\mathbf{r}}_{i}=\mathbf{f}_{i}=-\nabla \mathscr{V} \\
\dot{\mathbf{r}}_{i}=\mathbf{p}_{i} / m_{i} \quad \text { e } \quad \dot{\mathbf{p}}_{i}=\mathbf{f}_{i}=-\nabla \mathscr{V}
\end{gathered}
$$

onde $\mathbf{r}_{i}$ é a posição da partícula $i=(1,2,3, \ldots, N), m_{i}$ é a sua massa, $\mathbf{p}_{i}$ é o seu momento e $\mathbf{f}_{i}$ é a força atuando nela. Trata-se de sistemas muito complicados para os quais não existe solução analítica. Contudo, é possível resolvê-los numericamente utilizando vários algoritmos, que variam em precisão, complexidade e em desempenho (relativo à velocidade e a quantidade de recursos computacionais necessários para a sua implementação). Na sequência, apresentaremos dois dos principais algoritmos para resolver as equações de movimento em uma simulação por DM.

\subsubsection{O método de Verlet}

Um dos métodos mais usados para integrar as equações de movimento de Newton, e também um dos mais simples, é aquele inicialmente adotado por Verlet (VERLET, 1967), que proporciona uma solução direta para equações diferenciais de segunda ordem (2.10). Baseado nas posições atuais das partículas $\mathbf{r}(t)$, na aceleração $\mathbf{a}(t)$ e nas posições calculadas no passo de tempo anterior $\mathbf{r}(t-\delta t)$, este método oferece boa estabilidade, é exatamente reversível no tempo e conserva o volume no espaço de fase, além de requerer poucos recursos computacionais (RAPAPORT, 1995; FRENKEL; SMIT, 2002). De fato, do ponto de vista da conservação da energia, este método oferece melhores resultados que os métodos de mais alta ordem, tais como o que vamos discutir na próxima subseção. Deduzir a equação para evoluir as posições das partículas é um exercício muito simples. 
Primeiro escrevemos duas expansões em série de Taylor em torno de $t$.

$$
\begin{gathered}
\mathbf{r}(t+\delta t)=\mathbf{r}(t)+\delta t \mathbf{v}(t)+(1 / 2) \delta t^{2} \mathbf{a}(t)+(1 / 6) \delta t^{3} \mathbf{b}(t)+\mathcal{O}\left(\delta t^{4}\right) \\
\mathbf{r}(t-\delta t)=\mathbf{r}(t)-\delta t \mathbf{v}(t)+(1 / 2) \delta t^{2} \mathbf{a}(t)-(1 / 6) \delta t^{3} \mathbf{b}(t)+\mathcal{O}\left(\delta t^{4}\right)
\end{gathered}
$$

O próximo passo é adicionar as equações (2.12) e (2.13), para obter a seguinte expressão

$$
\mathbf{r}(t+\delta t)=2 \mathbf{r}(t)-\mathbf{r}(t-\delta t)+\delta t^{2} \mathbf{a}(t)+\mathcal{O}\left(\delta t^{4}\right)
$$

A aceleração de cada partícula no instante $t$ é obtida diretamente da força exercida sobre elas $\mathbf{a}_{i}=\left(1 / m_{i}\right) \mathbf{f}_{i}$. A estimativa das novas posições contém um erro que é da ordem de $\delta t^{4}$, onde $\delta t$ é o passo de tempo da simulação por DM. Como o cálculo das trajetórias não envolve a velocidade das partículas, é preciso calculá-las indiretamente. Subtraindo as equações (2.12) e (2.13) obtemos

$$
\mathbf{v}(t)=\frac{\mathbf{r}(t+\delta t)-\mathbf{r}(t-\delta t)}{2 \delta t}
$$

As velocidades são imprescindíveis para o cálculo da energia cinética, que por sua vez é importante para a verificação da conservação da energia total, $E=\mathscr{K}+\mathscr{V}$, e para obtermos o valor da temperatura instantânea. O erro na estimativa da velocidade é da ordem de $\mathcal{O}\left(\delta t^{2}\right)$, mas é possível obter expressões mais precisas para a velocidade com base em passos de tempo anteriores. Porém, isso raramente é necessário. De fato, um erro desta ordem, $\mathcal{O}\left(\delta t^{2}\right)$, pode ser perfeitamente aceitável, desde que o tamanho do passo de tempo seja suficientemente pequeno.

\subsubsection{O método de Gear: predictor-corrector}

Em geral, o método de Verlet é suficiente para a maioria das simulações por dinâmica molecular. Em alguns casos, porém, é desejável utilizar métodos de mais alta ordem, para possibilitar aumentar o tamanho do passo de tempo sem perder a precisão, ou para aumentar a precisão para um dado tamanho de passo de tempo. Contudo, os métodos de mais alta ordem demandam mais recursos computacionais em sua implementação e, em 
geral, não são reversíveis no tempo e nem preservam volume no espaço de fase (RAPAPORT, 1995; FRENKEL; SMIT, 2002).

O método de Gear está entre os métodos de alta ordem mais utilizados. Em linhas gerais o método é composto de três passos: primeiro é feita uma expansão em série de Taylor para prever (predictor) as posições, velocidades e acelerações das partículas, bem como as derivadas de mais alta ordem. Em seguida as forças sobre as partículas e suas acelerações são calculadas. Tendo a aceleração prevista e a aceleração calculada, é possível estimar o erro nas previsões e então corrigi-las (corrector). Matematicamente, o passo de previsão é dado por

$$
\begin{aligned}
\mathbf{r}^{p}(t+\delta t) & =\mathbf{r}(t)+\delta t \mathbf{v}(t)+(1 / 2) \delta t^{2} \mathbf{a}(t)+(1 / 6) \delta t^{3} \mathbf{b}(t)+\ldots \\
\mathbf{v}^{p}(t+\delta t) & =\mathbf{v}(t)+\delta t \mathbf{a}(t)+(1 / 2) \delta t^{2} \mathbf{b}(t)+\ldots \\
\mathbf{a}^{p}(t+\delta t) & =\mathbf{a}(t)+\delta t \mathbf{b}(t)+\ldots \\
\mathbf{b}^{p}(t+\delta t) & =\mathbf{b}(t)+\ldots
\end{aligned}
$$

onde $\mathbf{b}(t)$ é a terceira derivada da posição com relação ao tempo e o sobrescrito $p$ indica que esses são os valores previstos. Como essas expansões não são as equações de movimento, é obvio que a trajetória gerada por elas é incorreta. Assim, é necessário corrigi-las. Para isso, o próximo passo envolve calcular a força atuando nas partículas para as posições previstas, e então a aceleração $\mathbf{a}^{c}$, tal como indicado pela equação (2.10). Para estimar o erro, basta comparar o valor calculado para a aceleração com o valor previsto pela expansão em série de Taylor:

$$
\triangle \mathbf{a}(t+\delta t)=\mathbf{a}^{c}(t+\delta t)-\mathbf{a}^{p}(t+\delta t)
$$

Com a estimativa do erro, corrigem-se os valores previstos. 


$$
\begin{aligned}
\mathbf{r}^{c}(t+\delta t) & =\mathbf{r}^{p}(t+\delta t)+c_{0} \triangle \mathbf{a}(t+\delta t) \\
\mathbf{v}^{c}(t+\delta t) & =\mathbf{v}^{p}(t+\delta t)+c_{1} \triangle \mathbf{a}(t+\delta t) \\
\mathbf{a}^{c}(t+\delta t) & =\mathbf{a}^{p}(t+\delta t)+c_{2} \triangle \mathbf{a}(t+\delta t) \\
\mathbf{b}^{c}(t+\delta t) & =\mathbf{b}^{p}(t+\delta t)+c_{3} \triangle \mathbf{a}(t+\delta t) .
\end{aligned}
$$

Os valores dos coeficientes $c_{0}, c_{1}, c_{2}$ e $c_{3}$ dependem da ordem da equação diferencial e visam a dar mais estabilidade ao cálculo das trajetórias. Maiores detalhes sobre esses coeficientes podem ser encontrados, por exemplo, no livro de M. P. Allen e D. J. Tildesley (ALLEN; TILDESLEY, 1987).

\subsection{Dinâmica molecular no ensemble-NVT}

As médias obtidas com uma simulação por dinâmica molecular "convencional" equivalem às médias obtidas no ensemble microcanônico $(N V E)$. Por outro lado, experimentos reais muitas vezes são realizados sob condição de temperatura e/ou pressão constante. Felizmente, existem muitos métodos que modificam uma simulação por DM de modo a obter diferentes ensembles. Nesta seção apresentaremos dois métodos comumente utilizados para realizar uma simulação por DM no ensemble canônico $(N V T)$, isto é, com número de partículas, volume e temperatura constantes.

\subsubsection{Termostato de Berendsen}

Em princípio é possível fixar a temperatura em uma simulação por DM alterando a velocidade das partículas em cada passo de tempo pelo fator $\left(T_{\text {req }} / T_{\text {inst }}\right)^{1 / 2}$, onde $T_{\text {req }}$ é a temperatura requerida e $T_{\text {inst }}$ é a temperatura instantânea. Isto significa mudar a energia cinética das partículas, cujo valor está relacionado com a temperatura pela equação (2.8). Apesar de sua implementação ser muito simples, este método não está entre os mais indicados, principalmente quando se deseja alta precisão sobre as flutuações da energia total. 
Embora a técnica desenvolvida por Berendsen (BERENDSEN et al., 1984) para fixar a temperatura também seja baseada em reescalar a velocidade das partículas, o cálculo do fator de reescala parece ser mais "refinado" e, em geral, proporciona melhores resultados. Nesta técnica o fator de escala para as velocidades é dado por:

$$
\chi=\left(1+\frac{\delta t}{\tau}\left(\frac{T_{\text {req }}}{T_{\text {inst }}}-1\right)\right)^{1 / 2},
$$

onde $\delta t$ é o passo de tempo, $T_{r e q}$ é a temperatura requerida, $T_{i n s t}$ é a temperatura instantânea e $\tau$ é um parâmetro ajustável que controla o acoplamento do termostato ao sistema (quanto menor o valor de $\tau$ maior o acoplamento).

Não existe um "receita" para descobrir o melhor valor para o parâmetro $\tau$, pois este valor varia de sistema para sistema. Em geral o melhor caminho é realizar alguns testes preliminares com sistemas pequenos, a fim de ajustar um valor que leve a uma convergência rápida para a temperatura desejada, ao mesmo tempo em que minimize as flutuações. A vantagem da utilização deste método é a simplicidade em sua implementação, já que as equações de movimento não são alteradas. De fato, sua aplicação inclui apenas definir um intervalo de tempo a partir do qual a velocidade das partículas será escalada pelo fator $\chi$.

\subsubsection{Método baseado em restrição}

Outro caminho para forçar uma simulação a temperatura constante é introduzir uma restrição nas equações de movimento, de forma a gerar uma dinâmica com temperatura constante. Para isso, podemos projetar um sistema de equações com um tipo de "coeficiente de atrito" que varia de forma a restringir a temperatura a um valor constante (EVANS, 1983)

$$
\begin{aligned}
\dot{\mathbf{r}} & =\mathbf{p} / m \\
\dot{\mathbf{p}} & =\mathbf{f}-\xi(\mathbf{r}, \mathbf{p}) \mathbf{p},
\end{aligned}
$$

onde a quantidade $\xi(\mathbf{r}, \mathbf{p}) \mathbf{p}$ é o referido "coeficiente de atrito", que também pode ser visto como uma "freqüência" (pelo menos do ponto de vista da dimensão), que varia de forma 
a restringir a temperatura a um valor constante.

Manter o sistema em uma temperatura constante é equivalente a impor que $\dot{\mathscr{K}}=0$, pois a temperatura é proporcional à energia cinética por partícula. Portanto, matematicamente

$$
\dot{\mathscr{K}} \propto \frac{d}{d t}\left(\sum_{i} p_{i}^{2}\right) \propto \sum_{i} \dot{\mathbf{p}}_{i} \cdot \mathbf{p}_{\mathbf{i}}=0
$$

Considerando $\xi$ um multiplicador de Lagrange (um termo de restrição utilizado para minimizar uma função), e aplicando a restrição (2.28) na equação (2.27), obtemos o seguinte resultado

$$
\xi=\frac{\sum_{i} \mathbf{p}_{i} \cdot \mathbf{f}_{i}}{\sum_{i}\left|\mathbf{p}_{i}\right|^{2}}
$$

Para resolver as equações de movimento (2.26) e (2.27) pode-se usar, por exemplo, o método de Gear ou Verlet.

\subsection{Cálculo de quantidades físicas}

Como discutido na seção 2.2, uma propriedade macroscópica qualquer $\mathcal{A}$ pode ser calculada como a média temporal de valores instantâneos da quantidade $\mathcal{A}$ durante um longo curso de simulação.

$$
\mathcal{A}=\langle\mathcal{A}(\Gamma)\rangle_{t}=\frac{1}{\tau} \lim _{\tau \rightarrow \infty} \int_{0}^{\tau} \mathcal{A}(\Gamma(t)) d t
$$

onde $\Gamma$ é um ponto no espaço de fase, isto é, o estado microscópico instantâneo do sistema, dado pelas posições e momentos das partículas. Nesta seção mostraremos como se calcula as propriedades físicas de interesse nesta tese. Mais detalhes sobre as deduções matemáticas são encontrados em livros sobre dinâmica molecular e simulação computacional (FRENKEL; SMIT, 2002; RAPAPORT, 1995; ALLEN; TILDESLEY, 1987).

\subsubsection{Propriedades termodinâmicas}

As quantidades termodinâmicas em que estamos interessados são a energia interna $E$ e a temperatura $T$. A energia interna é obtida diretamente das médias associadas à 
energia cinética e potencial do sistema

$$
E=\langle\mathscr{K}(\mathbf{p})\rangle_{t_{o b s}}+\langle\mathscr{V}(\mathbf{r})\rangle_{t_{o b s}}
$$

A energia cinética é obtida a partir da média temporal da energia cinética instantânea de todas as partículas (veja equação (2.4)),

$$
\langle\mathscr{K}\rangle_{t_{o b s}}=\frac{1}{\tau_{o b s}} \sum_{\tau=1}^{\tau_{o b s}} \mathscr{K}(\mathbf{p}),
$$

onde $t_{o b s}$ indica o tempo de observação e $\tau_{o b s}$ o número de passos de tempo, isto é, o número de passos de tempo cujo tamanho é $\delta t=t_{o b s} / \tau_{o b s}$. Já a energia potencial é obtida a partir da média temporal da soma da interação entre todos os pares, trios, quádruplos, etc, de partículas e, obviamente, depende do potencial em uso (veja equação (2.3)),

$$
\langle\mathscr{V}\rangle_{t_{o b s}}=\frac{1}{\tau_{o b s}} \sum_{\tau=1}^{\tau_{o b s}} \mathscr{V}(\mathbf{r}) .
$$

A temperatura pode ser aproximada a partir da energia cinética do sistema, usando o teorema de equipartição de energia,

$$
T=\frac{2\langle\mathscr{K}(\mathbf{p})\rangle_{t_{o b s}}}{N d k_{b}}
$$

onde $d$ é a dimensão do sistema. Segundo esse teorema, cada partícula contribui, por grau de liberdade, com $k_{b} T / 2$ para a energia cinética do sistema.

\subsubsection{Organização local - Diagrama de Voronoi}

As propriedades estruturais mais estudadas para um sistema de muitos corpos incluem a função de distribuição radial, RDF (Radial Distribution Function), e o fator de estrutura. Essas medidas fornecem informações sobre a organização média em torno de uma dada partícula. Por outro lado, muitas vezes são necessárias informações detalhadas sobre a organização estrutural do sistema em dado instante. Por exemplo, para estudar defeitos pontuais em um cristal, foco desta tese, é necessário identificá-los, isto é, saber onde eles estão, qual sua topologia, etc. Como a função de distribuição radial e o fator de 
estrutura proporcionam apenas informações médias acerca da organização em torno de uma partícula, elas não são suficientes para esses propósitos.

Para obter informações detalhadas sobre a organização local em um sistema com várias partículas o mais indicado é construir um diagrama de Voronoi (STOYAN; KENDALL; MECKE, 1995). Neste diagrama cada partícula é cercada por um poliedro construído de acordo com algumas regras. O resultado final da aplicação dessas regras é o particionamento do espaço em um conjunto de poliedros, de forma que o conjunto de pontos mais próximo de uma determinada partícula esteja dentro do seu poliedro. A figura 8 mostra o diagrama de Voronoi para um conjunto de pontos no espaço 2D. Uma vez definido o diagrama de Voronoi, é possível identificar de forma única os vizinhos de cada partícula, definindo que duas partículas são vizinhas se seus poliedros compartilham uma face comum. O próprio poliedro também é interessante, pois as interações entre as partículas podem modificar sua forma geométrica.

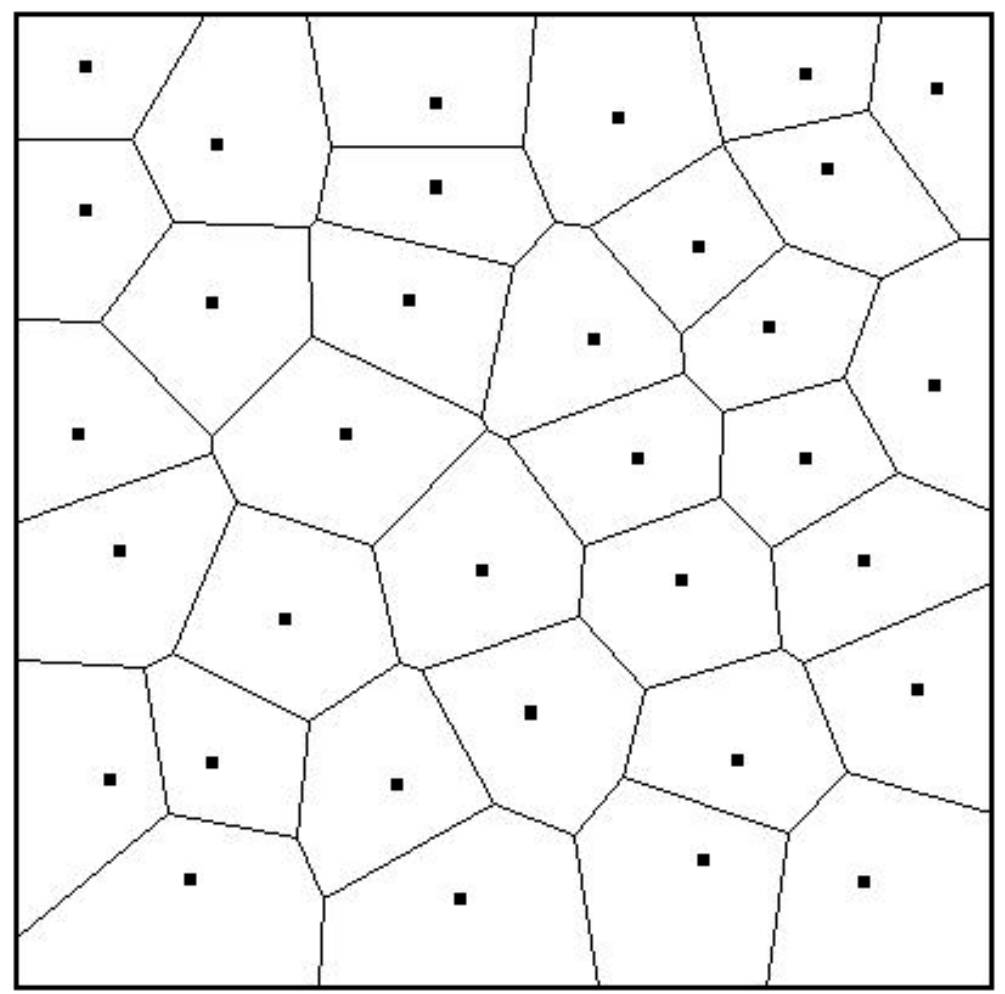

Figura 8. Digrama de Voronoi para um conjunto de pontos no espaço 2D.

Existem várias formas de implementar o diagrama de Voronoi. Neste trabalho usamos um algoritmo do tipo divisão-e-conquista, cuja complexidade é da ordem $\mathcal{O}(n \log n)$. A 
idéia básica, como todo algoritmo deste tipo, é subdividir o problema em subproblemas menores, e ir compondo as subsoluções até alcançar a solução para o problema original. Neste caso, em particular, cada subproblema envolve encontrar a reta que está equidistante a dois pontos. Para compor as subsoluções é preciso encontrar os pontos de intersecção entre as retas determinadas.

\subsubsection{Propriedades dinâmicas}

Na simulação de um sistema por DM, as trajetórias completas das partículas ficam disponíveis para análise, em qualquer tempo. Assim, é possível medir propriedades dependentes do tempo tão facilmente quanto medir propriedades estruturais ou termodinâmicas. Mostraremos agora como calcular algumas dessas propriedades, incluindo a função de autocorrelação de velocidade, que possibilita, entre outras coisas, obter o coeficiente de difusão. Embora nossos resultados não incluam o cálculo da constante de difusão por simulação, discutiremos resultados já publicados sobre essas medidas, de modo que o conteúdo a seguir parece útil dentro do contexto da presente tese.

\subsubsection{Função de autocorrelação de velocidade $Z(t)$}

Em uma simulação por DM é possível medir o coeficiente de correlação entre duas quantidades, pois as flutuações podem ser facilmente obtidas. Quando se mede o coeficiente de correlação em tempos diferentes, obtém-se uma função de correlação temporal, isto é, uma função que mede a dependência linear entre duas quantidades, em função do tempo. Como será visto a seguir, essas funções são de grande interesse em simulação.

Funções de correlação temporal que envolvem as mesmas variáveis são chamadas de função de autocorrelação. Uma importante função é a de autocorrelação de velocidades, $Z(t)$, que fornece a cada instante de tempo $t$ uma média do produto $\mathbf{v}(0) \cdot \mathbf{v}(t)$,

$$
Z(t)=\langle\mathbf{v}(0) \cdot \mathbf{v}(t)\rangle
$$

Essa função mede o grau de dependência linear da velocidade num tempo $t$ relativo 
à velocidade no tempo zero. Informalmente, pode-se dizer que se está medindo como a direção e sentido da velocidade variam, em média, com relação à velocidade no tempo 0 . A versão normalizada desta função é dada por

$$
C(t)=\frac{\langle\mathbf{v}(0) \cdot \mathbf{v}(t)\rangle}{\langle\mathbf{v}(0) \cdot \mathbf{v}(0)\rangle}
$$

Há várias razões para o interesse nesta função. Primeiramente, esta função fornece informações sobre a dinâmica das partículas, pelo menos no que diz respeito ao comportamento médio. Além disso, a integral desta função no tempo está diretamente relacionada ao coeficiente de difusão. Finalmente, sua transformada de Fourier fornece o espectro vibracional.

\subsubsection{Coeficiente de difusão}

Em um sistema contínuo o coeficiente de difusão é definido pela lei de Fick que relaciona o fluxo de massa com o gradiente de densidade:

$$
J=-D \nabla \rho
$$

onde $J$ é o fluxo de difusão e $\rho$ é a densidade ou concentração local, de forma que a evolução temporal de $\rho$ é descrita pela equação

$$
\frac{\partial \rho}{\partial t}=-\nabla J=D \nabla^{2} \rho
$$

Partindo desta expressão, Einstein deduziu a seguinte equação para o coeficiente de difusão (MCQUARRIE, 1976)

$$
D=\left\langle|\mathbf{r}(t)-\mathbf{r}(0)|^{2}\right\rangle
$$

Esta equação é válida para um grande tempo $t$, quando comparado com o intervalo de colisões. Em uma simulação por DM, essa equação precisa ser usada com cuidado pois em um sistema finito existem limitações para os deslocamentos permitidos. No caso da aplicação de condições periódicas de contorno, é necessário recuperar os deslocamentos atômicos reais, eliminando o efeito das bordas (RAPAPORT, 1995). 
Uma alternativa para o cálculo do coeficiente de difusão é baseada na função de autocorrelação de velocidades (MCQUARRIE, 1976)

$$
D=\frac{1}{3} \int_{0}^{\infty}\langle\mathbf{v}(0) \cdot \mathbf{v}(t)\rangle d t
$$

Pode-se mostrar que as duas expressões para $D$ são equivalentes. Caso seja desejável utilizar a forma normalizada da função de autocorrelação de velocidades, usamos o fato que $\langle\mathbf{v}(0) . \mathbf{v}(0)\rangle=3 k_{b} T / m$ e obtemos

$$
D=\frac{k_{b} T}{m} \int_{0}^{\infty} \frac{\langle\mathbf{v}(0) \cdot \mathbf{v}(t)\rangle}{\langle\mathbf{v}(0) \cdot \mathbf{v}(0)\rangle} d t
$$

\subsection{Considerações finais}

Neste capítulo apresentamos os princípios básicos para realizar uma simulação por dinâmica molecular no ensemble NVT. O intuito foi cobrir os aspectos de simulação necessários para compreender os próximos capítulos, onde aplicaremos as técnicas discutidas aqui para calcular várias propriedades dos defeitos pontuais em um cristal coloidal 2D. Portanto, este capítulo servirá como fonte para consultas, quando algum conceito sobre simulação for abordado de forma mais superficial no texto a seguir. 


\section{Capítulo 3}

\section{Energia de formação e interação de defeitos pontuais em cristais} coloidais bidimensionais

Defeitos pontuais são de interesse considerável, pois eles podem influenciar ou até mesmo definir várias propriedades dos materiais. Em temperaturas finitas, acredita-se que todos os sólidos tenham uma quantidade mínima de defeitos termicamente excitados, incluindo os cristais quânticos como o ${ }^{4} \mathrm{He}$ e os cristais de Wigner. Para esses últimos, caso a concentração de defeitos seja alta o suficiente, efeitos coletivos interessantes podem surgir, levando o sistema a uma fase supersólida (KIM; CHAN, 2004; KHAIRALLAH; CEPERLEY, 2005; CÂNDIDO; PHILLIPS; CEPERLEY, 2001). Como discutido anteriormente, os defeitos topológicos como as deslocações são importantes na transição da fase cristalina para a fase fluida em um cristal bidimensional, levando o sistema a um processo de fusão em duas etapas, com a formação de uma fase intermediária chamada hexática (KOSTERLITZ; THOULESS, 1973).

Muitos autores estudaram a energia de defeitos pontuais em vários sistemas 2D. Fisher e colaboradores (FISHER; HALPERIN; MORF, 1979) consideraram defeitos em um cristal de Wigner bidimensional, com potencial de interação $V(r)=-\epsilon_{0} / r$. Usando cálculos 
Tabela 1- Energia de defeitos pontuais para um potencial $V(r)=\epsilon_{0} K_{0}(\kappa r)$ em unidades da energia de ligação do cristal, $\epsilon_{0}$. Dados obtidos da referência (JAIN; NELSON, 2000). Entradas como "SV" indicam instabilidade da topologia em questão.

\begin{tabular}{cccccc}
\hline \hline$\kappa a$ & $\mathrm{SV}$ & $V_{2 a}$ & $V_{3}$ & $V_{2 b}$ & $V_{6}$ \\
\hline 0 & $V_{2 a}$ & 0.107018876 & 0.108206944 & 0.10932035 & $V_{3}$ \\
1 & 0.096728537 & 0.096661116 & 0.097578530 & 0.099169907 & $V_{3}$ \\
3 & 0.046095915 & $\mathrm{SV}$ & 0.046131759 & 0.047174046 & $V_{3}$ \\
5 & 0.0133112 & $\mathrm{SV}$ & 0.0133146 & 0.0136217 & $V_{3}$ \\
7 & $V_{6}$ & $V_{6}$ & $V_{6}$ & $V_{6}$ & 0.002171295 \\
\hline \hline
\end{tabular}

numéricos estimaram a energia de formação das seguintes configurações de defeitos pontuais: sixfold symmetric vacancy $\left(V_{6}\right)$, divacancy (D) e centered e edge interstitial (CI e EI, respectivamente). Descobriram que a energia de formação desses defeitos era apenas uma fração da energia de ligação do cristal, $\epsilon_{0}$. Porém, um estudo mais detalhado (COCKAYNE; ELSER, 1991) mostrou que nem todas as configurações previstas no estudo anterior eram estáveis, isto é, não eram mínimos de energia. Em particular, demonstrou-se que um EI relaxa para um CI.

Uma investigação numérica mais completa (JAIN; NELSON, 2000) considerou dois potenciais de interação: $V(r)=\epsilon_{0} K_{0}(r / \lambda)$ no intervalo $a / \lambda=0-7$ ( $a$ é o espaçamento de rede) e $V(r)=1 / r^{p} \operatorname{com} p$ variando de 1-12. Foi observado que a configuração $V_{2 a}$ é estável para potenciais de longo alcance $(\kappa a=0-2$ e $p=1-4)$, ao passo que a configuração $V_{6}$ se torna estável para potenciais de curto alcance $(\kappa a>5.8$ e $p>5)$. Na tabela 1 estão reproduzidos os resultados publicados neste estudo para a energia dos defeitos. Como está claro, a diferença de energia entre diferentes configurações topológicas é uma pequena fração da energia do defeito, da ordem de $10^{-2} \epsilon_{0}$ para potenciais de mais longo alcance e $10^{-4} \epsilon_{0}$ para potenciais com alcance mais curto.

Há alguns anos, observou-se que vacâncias podem ser criadas artificialmente em um cristal coloidal bidimensional utilizando-se pinças ópticas (PERTSINIDIS; LING, 2001b). Esse feito motivou ainda mais o estudo de defeitos, pois foi demonstrado que a dinâmica das vacâncias criadas poderia ser observada em tempo real. Por outro lado, a energia de defeitos pontuais para um sistema cristalino com potencial de Coulomb blindado, o qual se aplica diretamente a um cristal coloidal, ainda não havia sido estudado. Neste 
capítulo apresentaremos nossos resultados sobre a energia de formação e interação de defeitos pontuais em cristais coloidais bidimensionais.

\subsection{Método de Simulação}

Simulamos um cristal coloidal bidimensional usando dinâmica molecular (DM). As partículas coloidais do sistema são modeladas como esferas idênticas de raio $a$, suspensas em um solvente descrito apenas por sua permissividade dielétrica $(\epsilon=80)$, e confinadas entre duas superfícies sólidas e paralelas. Na verdade essas superfícies fazem parte do aparato experimental usado para inibir a movimentação dos colóides ao longo de um eixo, de modo que na simulação não é necessário incluí-las explicitamente, basta fazer a simulação em 2D. Quando imersos neste solvente, os colóides adquirem grande carga $Z$ devido à dissociação de grupos iônicos de sua superfície. Os contraíons assim gerados garantem a neutralidade de carga do sistema e formam uma "nuvem" em volta de cada colóide, a qual blinda o alcance das interações Coulômbicas. Os colóides são livres para se movimentar em 2D e interagem por meio de um potencial do tipo Yukawa. Na prática o que estamos fazendo é desprezar a parte atrativa do potencial DLVO (veja o capítulo 1), já que a distância típica de interação para nosso sistema excede o alcance dessa contribuição. A Hamiltoniana para este sistema é

$$
H=\sum_{i=1}^{N} \frac{\mathbf{P}_{i}^{2}}{2 m}+\sum_{i<j}^{N} \frac{\left(Z_{\lambda} e\right)^{2}}{\epsilon} \frac{\exp \left(-\mathbf{r}_{i j} / \lambda\right)}{\mathbf{r}_{i j}}+N U_{B}
$$

onde o primeiro termo à direita é a energia cinética e o segundo é a interação coulômbica blindada colóide-colóide, que corresponde exatamente à parte repulsiva do potencial da teoria DLVO (veja capítulo 1 ). O terceiro termo, $U_{B}=-2 \pi \lambda\left(Z_{\lambda} e\right)^{2} /\left(a_{0}^{2} \epsilon\right)$, corresponde à interação entre os colóides e os contraíons, aqui tratados apenas como um fundo contínuo de cargas positivas (PEETERS; WU, 1987). Nesta equação, $b=(2 / \sqrt{3})^{1 / 2} a_{0}$ é o parâmetro de rede e $a_{0}$ é a separação média entre os colóides; esta definição vem de uma rede triangular com vetores de translação $(b, 0)$ e $(b / 2, b \sqrt{3} / 2)$ com $a_{0}=1 / \sqrt{\rho}$, onde $\rho$ é a densidade de colóides. A energia, comprimento, temperatura e tempo estão em unidades de 
$E_{0}=\left(Z_{\lambda} e\right)^{2} / \epsilon b$, onde $b=1.1 \mu \mathrm{m}$ (parâmetro de rede típico para sistemas experimentais), $T_{0}=E_{0} / k_{b}\left(k_{b}\right.$ a constante de Boltzmann $)$, e $t_{0}=\left(E_{0} / m b^{2}\right)^{-1 / 2}$, respectivamente.

Para um cristal perfeito, as posições iniciais para os colóides são os sítios de uma rede triangular acomodada em uma caixa retangular com condições periódicas de contorno para evitar problemas tais como os efeitos de superfície, ou o desaparecimento do defeito ao migrar para uma borda. Para simular um sistema com defeitos, inicializamos um sistema perfeito e em seguida adicionamos ou removemos um colóide de uma posição próxima ao centro da amostra: uma única sixfold cordinated vacancy num sítio central da rede ou um threefold centered interstitial em uma das células unitárias triangulares. Não existe nenhum tipo de imposição para restringir o centro de cada colóide à sua própria célula de Wigner, isto é, as partículas podem relaxar para outras posições depois da criação do defeito. Isto significa que o defeito está livre para se movimentar e pode mudar sua simetria/topologia durante sua evolução em equilíbrio termodinâmico.

Usamos colóides com raio $a \sim 0.18 \mu \mathrm{m}$, comprimento de blindagem $\lambda \sim 0.39 \mu \mathrm{m}$ e carga $\sim 1650$ e, correspondentes a dados experimentais típicos (PERTSINIDIS; LING, 2001b). Para dar uma idéia das energias e temperaturas envolvidas nos cálculos, para um cristal com densidade $\rho=0.954 \mu \mathrm{m}^{-2}$, as unidades são $E_{0}=7.13 \times 10^{-18} \mathrm{~J}$ e $T_{0}=5.165 \times 10^{5} \mathrm{~K}$.

As simulações foram realizadas no ensemble canônico (NVT) mantendo a temperatura do sistema constante usando o termostato de Berendsen com parâmetro de acoplamento $\tau$ variando de 0.01 a 0.1 (BERENDSEN et al., 1984). A evolução das equações de movimento foram feitas com o algoritmo predictor-corrector de quarta ordem. Pressupomos que o equilíbrio termodinâmico foi atingido nos primeiros 50.000 passos de tempo. A partir daí, as quantidades físicas foram obtidas pela média de 700 blocos de 10.000 passos de tempo.

\subsection{Principais configurações dos defeitos pontuais}

Quando um defeito pontual é criado, as partículas em sua vizinhança relaxam de suas posições na rede criando uma deformação local. Essa deformação é caracterizada pela presença de partículas mal coordenadas, isto é, partículas cujo número de vizinhos é 
diferente de 6 , as quais formam determinadas estruturas topológicas no núcleo do defeito. Tanto a vacância quanto o interstício podem assumir várias configurações topológicas em equilíbrio termodinâmico. De fato, em temperaturas suficientemente altas o defeito tende a mudar de topologia constantemente. Para caracterizar a configuração do defeito, usamos um diagrama de Voronoi. É possível descobrir o número de vizinhos $n v$ de cada colóide contando o número de lados em cada polígono do diagrama de Voronoi. Em uma rede triangular ideal, todas as partículas possuem $n v=6$. Por outro lado, o sistema com defeito possui uma partícula a mais ou a menos, sendo o núcleo do defeito cercado por algumas partículas com número de vizinhos $n v \neq 6$. Diferentes configurações topológicas são identificadas inspecionando o diagrama de Voronoi gerado a cada passo de tempo. Todas as configurações identificadas em nosso sistema conservam a vizinhança média igual a seis. Além disso, são as mesmas configurações observadas em (LIBÁL; REICHHARDT; REICHHARDT, 2007), onde defeitos pontuais em cristais coloidais 2D foram estudados usando dinâmica Browniana. A figura 9 ilustra as topologias comumente encontradas em nossas simulações para um defeito do tipo vacância, adotando a mesma nomenclatura usada na literatura (PERTSINIDIS; LING, 2001b; JAIN; NELSON, 2000). A figura 9(a) mostra uma configuração $V_{2 a}$, a qual consiste em dois pares aproximadamente paralelos de partículas com vizinhança $n v=5$ e $n v=7$. A topologia $V_{2 b}$ (não ilustrada na figura) é uma reflexão em relação ao eixo de simetria das partículas com vizinhança sete da configuração $V_{2 a}$. A figura 9(b) ilustra uma topologia SV para a vacância, que contém três partículas com $n v \neq 6$, formando uma linha quase reta com duas partículas com vizinhança cinco em lados opostos de uma partícula com vizinhança oito. A próxima configuração, mostrada na figura 9(c), é uma topologia com simetria mais alta chamada $V_{3}$. Ela consiste em três pares de partículas com vizinhança cinco e sete, formando um triângulo em torno da vacância. Essas três topologias foram observadas experimentalmente (PERTSINIDIS; LING, 2001b, 2001a). A última topologia importante observada em nossos estudos é ilustrada na figura $9(\mathrm{~d})$. Trata-se de uma topologia simétrica chamada $V_{4}^{\prime}$ (LIBÁL; REICHHARDT; REICHHARDT, 2007), formada por quatro pares de partículas com vizinhança cinco e sete, em torno de uma partícula com vizinhança seis. Como será discutido em breve, 


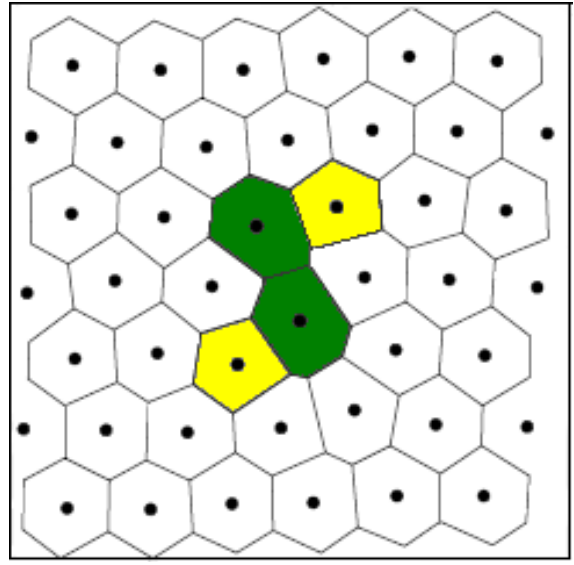

(a)

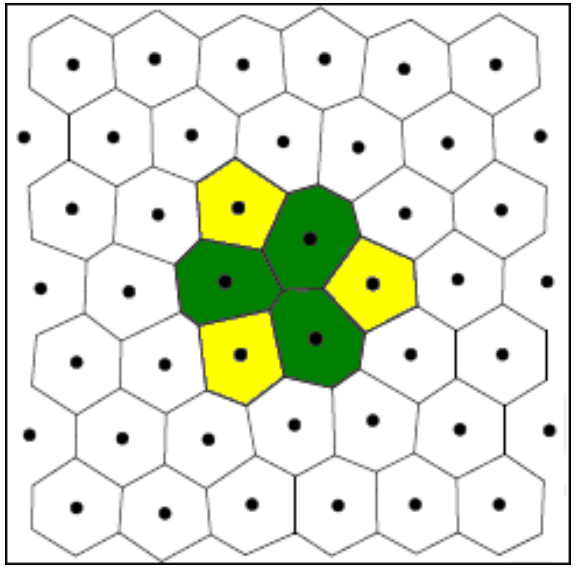

(c)

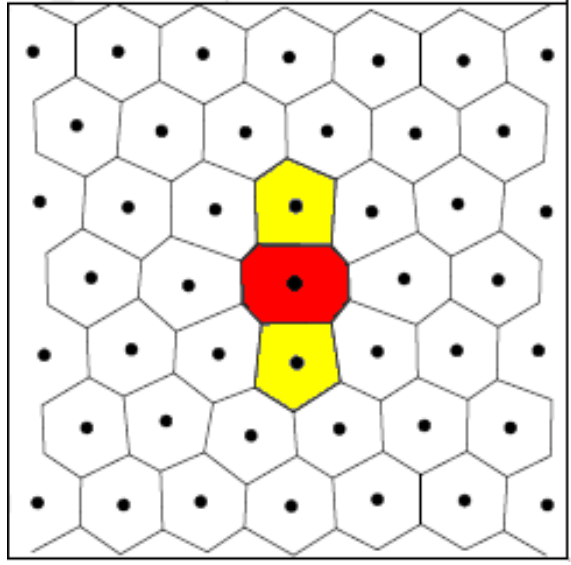

(b)

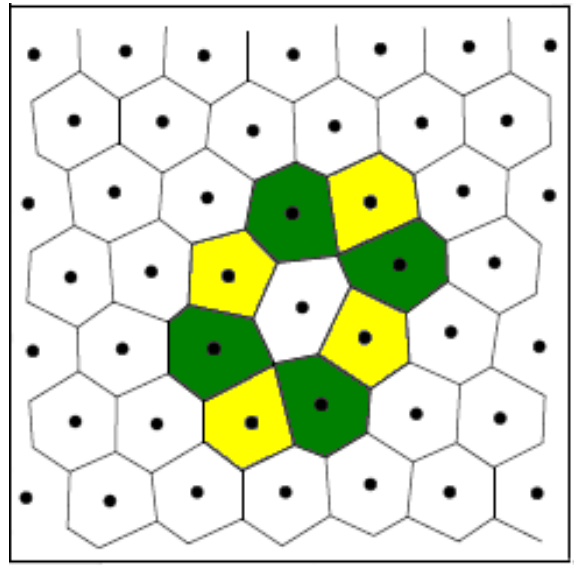

(d)

Figura 9. Diagrama de Voronoi para as configurações mais observadas para um defeito do tipo vacância. As posições dos colóides são indicadas por pontos em preto. As células do diagrama de Voronoi estão coloridas de acordo com o número de vizinhos do colóide considerado: branco $n v=6$; amarelo $n v=5$; verde $n v=7$ e vermelho $n v=8$. Em (a) temos uma topologia $V_{2 a}$ (twofold crushed vacancy), em (b) temos uma topologia SV (split vacancy), em (c) temos uma topologia $V_{3}$ (threefold symmetric vacancy) e em (d) temos uma topologia $V_{4}^{\prime}$ (fourfold symmetric vacancy).

essa topologia apresenta alta energia de formação e aparece com freqüência considerável apenas em altas temperaturas, possivelmente o motivo por não ter sido observada experimentalmente. Apesar disso, essa topologia parece ter alguma importância na difusão da vacância, como será visto no próximo capítulo.

A figura 10 mostra as configurações mais importantes para um defeito do tipo interstício. Similar às vacâncias, tratam-se de quatro configurações topológicas. A figura 10(a) ilustra uma topologia $I_{2}$. Esta configuração pode se quebrar em uma topologia formada por dois pares de partículas com vizinhança cinco e sete, chamada de $I_{2 d}$, ilustrada na figura 10(b). Como será detalhado futuramente, isso pode acontecer também com as 


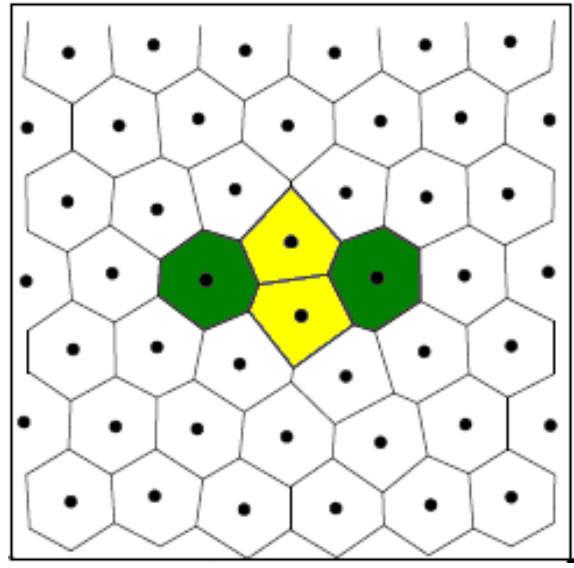

(a)

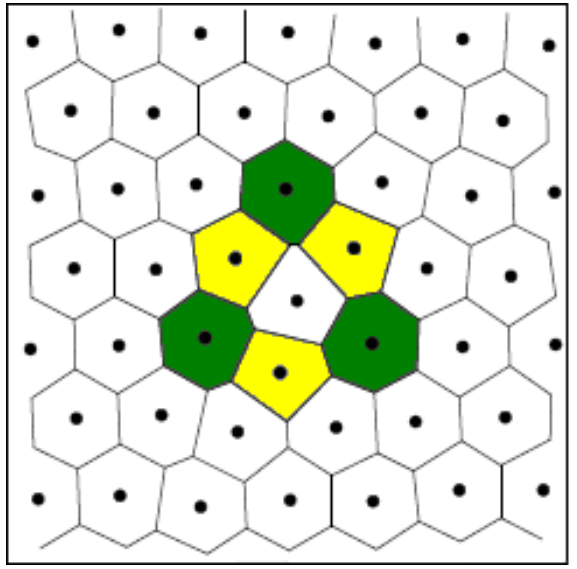

(c)

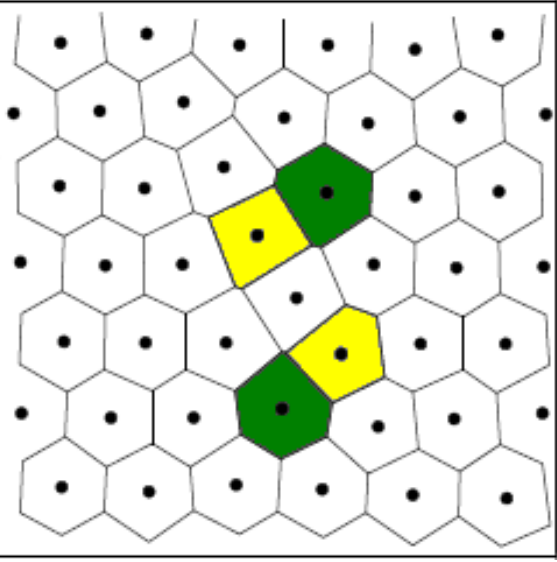

(b)

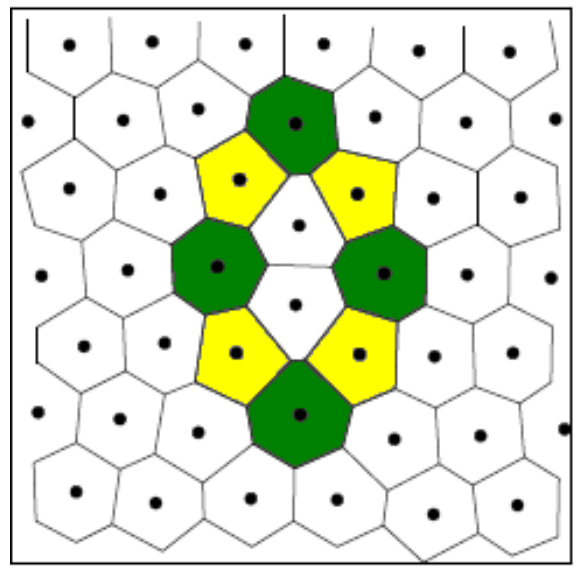

(d)

Figura 10. Diagrama de Voronoi para as configurações mais observadas para um defeito do tipo interstício. As posições dos colóides são indicadas por pontos em preto. As células do diagrama de Voronoi estão coloridas de acordo com o número de vizinhos do colóide considerado: branco $n v=6$; amarelo $n v=5$ e verde $n v=7$. Em (a) temos uma topologia $I_{2}$ (twofold symetric interstitial), em (b) temos uma topologia $I_{2 d}$ (disjoint symetric interstitial), em (c) temos uma topologia $I_{3}$ (threefold symmetric interstitial) e em (d) temos uma topologia $I_{4}^{\prime}$ (fourfold symmetric interstitial).

topologias $V_{2 a}$ e $V_{2 b}$ para a vacância, fato que foi analisado em detalhes experimentalmente (PERTSINIDIS; LING, 2001b, 2001a). A figura 10(c) ilustra uma topologia simétrica, $I_{3}$, formada por um arranjo triangular com três pares de partículas com vizinhança cinco e sete, centrados no interstício. Esta configuração é muito similar à configuração $V_{3}$ para a vacância. Finalmente, a figura 10(d) mostra uma topologia $I_{4}^{\prime}$, formada por quatro pares de partículas com vizinhança cinco e sete. Embora os interstícios em cristais coloidais 2D ainda não tenham sido estudados experimentalmente, podemos dizer que a topologia $I_{4}^{\prime}$ dificilmente poderia ser observada em laboratório, porque assim como a topologia $V_{4}^{\prime}$ para a vacância, essa topologia só aparece significativamente em altas temperaturas. 


\subsection{Resultados}

Para calcular a energia necessária para criar um único defeito, realizamos duas simulações independentes na mesma densidade e temperatura: uma simulação para o cristal perfeito e uma simulação para o cristal com defeito. Para o último, depois de introduzir o defeito, reescalamos a dimensão da caixa de simulação por um fator $f=\sqrt{N_{d} / N_{p}}$ para retomar a densidade original do sistema, com $N_{d}$ e $N_{p}$ sendo o número de colóides para o sistema com defeito e para o sistema perfeito, respectivamente. Isto é feito para evitar a necessidade de corrigir a energia devido à inclusão ou remoção de um colóide, que obviamente altera a densidade. A diferença entre a energia do sistema com defeito e a energia do sistema perfeito é a energia necessária para criar o defeito. Formalmente, podemos definir o número de defeitos $N_{\text {def }}$ como o número de colóides menos o número de sítios na rede. Portanto, a energia de formação de $N_{\text {def }}$ defeitos em um cristal com $N_{m}$ sítios de rede é

$$
\nabla E_{d e f}=\left[\tilde{E}\left(N_{m}+N_{d e f}\right)-\tilde{E}\left(N_{m}\right)\right]\left(N_{m}+N_{d e f}\right)
$$

onde $\tilde{E}(N)$ é a energia por colóide para um sistema contendo $N$ colóides. Para uma vacância ou um interstício, $N_{d e f}=N_{v a c}=-1$ e $N_{d e f}=N_{\text {int }}=+1$, respectivamente.

As condições periódicas de contorno de nosso sistema impedem que o defeito desapareça ao migrar para uma borda. Porém, como a interação entre defeitos topológicos é normalmente de longo alcance (ALLNATT; LIDIARD, 1993), efeitos oriundos do tamanho finito são sempre uma preocupação. Isto é particularmente importante se múltiplos defeitos estiverem envolvidos. Em nosso caso, temos um único defeito, que experimenta uma interação simétrica com suas imagens. Isto tende a minimizar o impacto das réplicas periódicas. Em todo caso, para checar efeitos de tamanho finito realizamos cálculos da energia de formação dos defeitos pontuais (vacância e interstício) para vários tamanhos de sistema ( $N=29,30,31,129,130,131,269,270,271,479,480$, e 481 colóides). Sistemas maiores não seriam práticos computacionalmente, porque é necessária uma alta precisão nos cálculos para obter as diferenças de energia. Para eliminar a dependência da energia de formação com o tamanho do sistema, extrapolamos os resultados da simulação para o 
Tabela 2- Energia de formação em unidades reduzidas obtidas de simulações por DM para uma vacância. $N_{m}$ denota o número de sítios da rede e $\rho$ a densidade considerada em $(\mu \mathrm{m})^{-2}$. As quantidades entre parênteses são o erro estimado na última casa decimal. Também é apresentado a energia para um sistema infinito $\left(\Delta E_{V a c}^{\infty}\right)$, além dos parâmetros $\mathrm{c}(\rho)$ e $\chi^{2}$. A temperatura do sistema e o comprimento de blindagem são $T=3.74 \times 10^{-4} T_{0}$ e $\kappa^{-1}=0.39 \mu$, respectivamente.

\begin{tabular}{ccccc}
\hline \hline & & Vacância & & \\
$N_{m}=30$ & $0.0261(5)$ & $0.0543(4)$ & & \\
$N_{m}=120$ & $0.029(1)$ & $0.0550(4)$ & $0.1029(4)$ & $0.1933(4)$ \\
$N_{m}=270$ & $0.029(2)$ & $0.055(1)$ & $0.1032(4)$ & $0.1958(7)$ \\
$N_{m}=480$ & $0.029(3)$ & $0.055(1)$ & $0.1032(9)$ & $0.1958(6)$ \\
$\Delta E_{V a c}^{\infty}$ & $0.029(1)$ & $0.0551(4)$ & $0.1033(4)$ & $0.1969(7)$ \\
$\mathrm{c}(\rho)$ & $-0.10(3)$ & $-0.02(2)$ & $-0.05(8)$ & $-0.4(1)$ \\
$\chi^{2}$ & 0.086 & 0.032 & 0.023 & 0.6 \\
\hline \hline
\end{tabular}

limite termodinâmico usando a seguinte fórmula:

$$
\nabla E_{d e f}^{N}=\nabla E_{d e f}^{\infty}(\rho)+\frac{c(\rho)}{N}
$$

onde os parâmetros dependentes da densidade, $\nabla E_{d e f}^{\infty}(\rho)$ e $c(\rho)$, são determinados por uma regressão linear usando método dos mínimos quadrados, baseado nos dados obtidos por dinâmica molecular em diferentes $N$. A energia de formação para os defeitos pontuais obtidas por DM, bem como o valor extrapolado para o limite termodinâmico e o $\chi^{2}$ (que mede quão bom é o ajuste da curva aos dados) como função de $\rho$, com a temperatura e o comprimento de blindagem fixados, são mostrados na tabela 2 para a vacância, e na tabela 3 para o interstício.

Tabela 3- Energia de formação em unidades reduzidas obtidas de simulações por DM para um interstício. $N_{m}$ denota o número de sítios da rede e $\rho$ a densidade considerada em $(\mu \mathrm{m})^{-2}$. As quantidades entre parênteses são o erro estimado na última casa decimal. Também é apresentada a energia para um sistema infinito $\left(\Delta E_{V a c}^{\infty}\right)$, além dos parâmetros $\mathrm{c}(\rho)$ e $\chi^{2}$. A temperatura do sistema e o comprimento de blindagem são $T=3.74 \times 10^{-4} T_{0}$ e $\kappa^{-1}=0.39 \mu$, respectivamente.

\begin{tabular}{ccccc}
\hline \hline \multicolumn{5}{c}{ Interstício } \\
& $\rho=0.402$ & $\rho=0.589$ & $\rho=0.954$ & $\rho=1.804$ \\
\hline$N_{m}=30$ & $0.0238(5)$ & $0.0430(4)$ & & \\
$N_{m}=120$ & $0.024(1)$ & $0.0435(6)$ & $0.0781(5)$ & $0.1425(3)$ \\
$N_{m}=270$ & $0.024(2)$ & $0.043(3)$ & $0.0783(6)$ & $0.1426(4)$ \\
$N_{m}=480$ & $0.024(2)$ & $0.043(6)$ & $0.0785(5)$ & $0.1428(5)$ \\
$\Delta E_{I n t}^{\infty}$ & $0.024(1)$ & $0.0436(7)$ & $0.0785(6)$ & $0.1428(5)$ \\
$c(\rho)$ & $-0.00(3)$ & $-0.01(3)$ & $-0.0(1)$ & $-0.03(8)$ \\
$\chi^{2}$ & 0.00056 & 0.046 & 0.018 & 0.049 \\
\hline \hline
\end{tabular}

O $\chi^{2}$ da curva ajustada é particularmente bom, indicando que a dependência com 
o tamanho é bem descrita pela equação 3.3. A energia de formação para o interstício é consistentemente menor do que a energia necessária para criar uma vacância, variando de $12 \%$ - 28\%. Portanto, um defeito do tipo interstício é mais estável e mais provável de ser criado. Porém, os valores extrapolados da energia de formação se mostram muito altos. Por exemplo, na densidade $\rho=0.954$ temos $\Delta E_{V a c}^{\infty}=0.1033 E_{0}$ e $\Delta E_{I n t}^{\infty}=0.0785 E_{0}$. Nesta densidade a unidade de energia é $E_{0}=7.13 \times 10^{-18} \mathrm{~J}$. Portanto, a energia de formação para a vacância e para o interstício são, em Joule, respectivamente, $7.36 \times 10^{-19} \mathrm{~J}$ e $5.6 \times 10^{-19} \mathrm{~J}$. Na temperatura considerada, $T=3.74 \times 10^{-4} T_{0}(\sim 194 \mathrm{~K})$, a energia média do sistema é $k_{b} T=2.67 \times 10^{-21} \mathrm{~J}$. Isto implica que a energia de formação para a vacância e para o interstício são aproximadamente $276 k_{b} T$ e $210 k_{b} T$. Em outras palavras, não é possível criar defeitos pontuais termicamente dentro de um grande intervalo de temperaturas, devido a alta energia requerida para a sua criação.

A energia de formação desses defeitos é praticamente independente da temperatura, para o intervalo $3 \times 10^{-5} T_{0}<T<5 \times 10^{-2} T_{0}$ abaixo do ponto de fusão, como mostrado na figura 11. Para todo o intervalo de temperaturas estudado, a energia de formação do interstício é sempre menor do que a da vacância. Próximo ao ponto de fusão $\left(T>5 \times 10^{-2} T_{0}\right)$ a energia de formação desses defeitos se torna muito ruidosa devido às grandes flutuações na energia total e vai a zero dentro do erro estatístico. Isto sugere que defeitos pontuais podem ser criados termicamente próximo ao ponto de fusão, e podem desempenhar um papel importante no mecanismo de fusão de cristais coloidais bidimensionais.

Até o momento, discutimos um tipo de energia de formação média, pois cada defeito pode assumir diferentes configurações topológicas, as quais correspondem a diferentes mínimos de energia. Detalhando um pouco mais, em temperaturas finitas, este sistema de muitos corpos vibra em torno de mínimos locais de energia devido a oscilações térmicas. Enquanto o sistema reside em torno de um determinado mínimo local, as distorções na rede são elásticas e o arranjo topológico das partículas não muda. Isto permite calcular a energia do sistema para cada topologia. Para realizar tais cálculos, identificamos a topologia a cada passo de tempo, após o sistema ter alcançado o equilíbrio termodinâmico, tal como descrito na seção 3.2. Uma vez identificada a topologia do defeito, a energia 


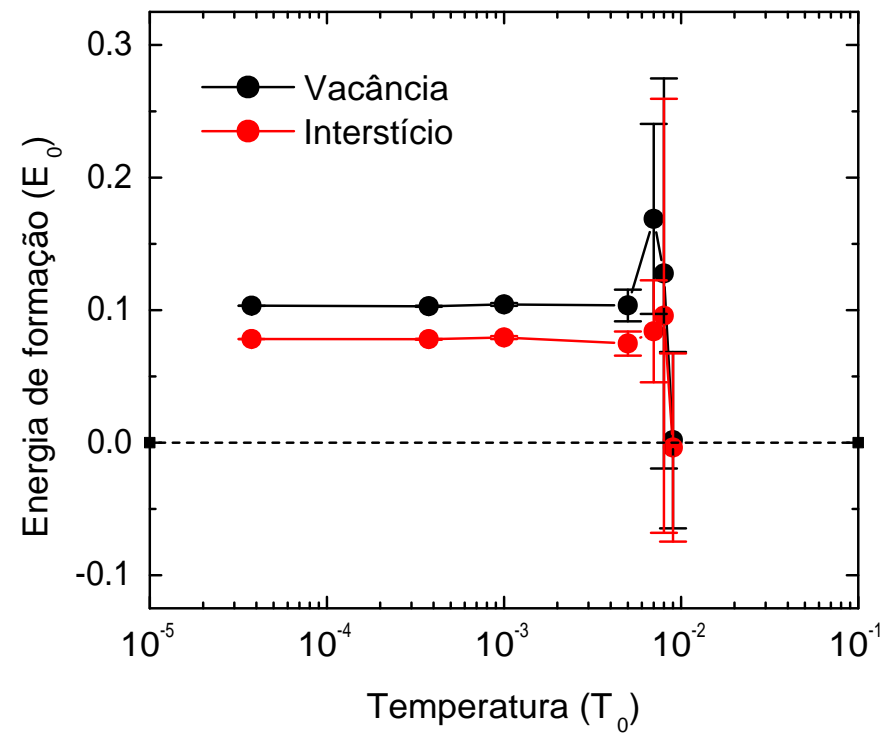

Figura 11. Energia de formação de uma vacância e de um interstício em função da temperatura para um cristal coloidal 2D com $\rho=0.954 \mu \mathrm{m}^{-2}$. calculado para sistemas com 120 sítios de rede.

Tabela 4- A tabela mostra a energia de formação, $\Delta E$, das diferentes configurações topológicas que um defeito pontual pode assumir para o cristal coloidal $2 \mathrm{D} \operatorname{com} \rho=0.954(\mu \mathrm{m})^{-2}$. Os dados foram obtidos durante $\sim 7.0 \times 10^{6}$ passos de tempo depois que o sistema alcançou o equilíbrio. Quantidades entre parênteses são o erro estimado na última casa decimal. A temperatura e o comprimento de blindagem do sistema são $T=1.0 \times 10^{-3} T_{0}$ e $\kappa^{-1}=0.39 \mu \mathrm{m}$, respectivamente.

\begin{tabular}{ccccc}
\hline \hline \multicolumn{5}{c}{ Vacância } \\
& $V_{2}$ & $V_{3}$ & $S V$ & $V_{4}^{\prime}$ \\
\hline$\Delta E$ & $0.1044(6)$ & $0.1046(6)$ & $0.1040(6)$ & $0.1086(6)$ \\
& \multicolumn{5}{c}{ Interstício } \\
& $I_{2}$ & $I_{2 d}$ & $I_{3}$ & $I_{4}^{\prime}$ \\
\hline$\Delta E$ & $0.0798(6)$ & $0.0799(6)$ & $0.0790(6)$ & $0.0829(6)$ \\
\hline \hline
\end{tabular}

correspondente é armazenada.

A tabela 4 resume os resultados para a vacância e interstício, respectivamente. Como esperado, as energias de formação das várias topologias são muito próximas uma da outra, o que dificulta a separação dos mínimos de energia, pois isso requer uma precisão numérica muito alta. Com base nos valores obtidos, não podemos afirmar, por exemplo, que a topologia SV da vacância é a mais estável, pois o valor obtido está dentro da barra de erro das topologias $V_{2}$ e $V_{3}$. O mesmo se aplica às topologias $I_{2}$ e $I_{2 d}$ do interstício. Apesar desta falta de precisão, os valores são um bom indicativo sobre quais topologias são mais estáveis. No próximo capítulo calcularemos a taxa de tempo que o defeito 
dispende em cada topologia, o que nos dará mais indícios sobre quais são as topologias mais estáveis, pois o tempo que um defeito despende em uma dada topologia depende do mínimo local em questão e das barreiras entre diferentes mínimos locais. Calculamos a energia de formação para as diferentes configurações topológicas fixando a temperatura bem abaixo do ponto de fusão. Perto da fusão é difícil calcular estas energias devido às fortes flutuações térmicas, que fazem com que as diferenças de energia fiquem dentro do erro estatístico. Além da energia de formação, estudamos a interação entre pares de

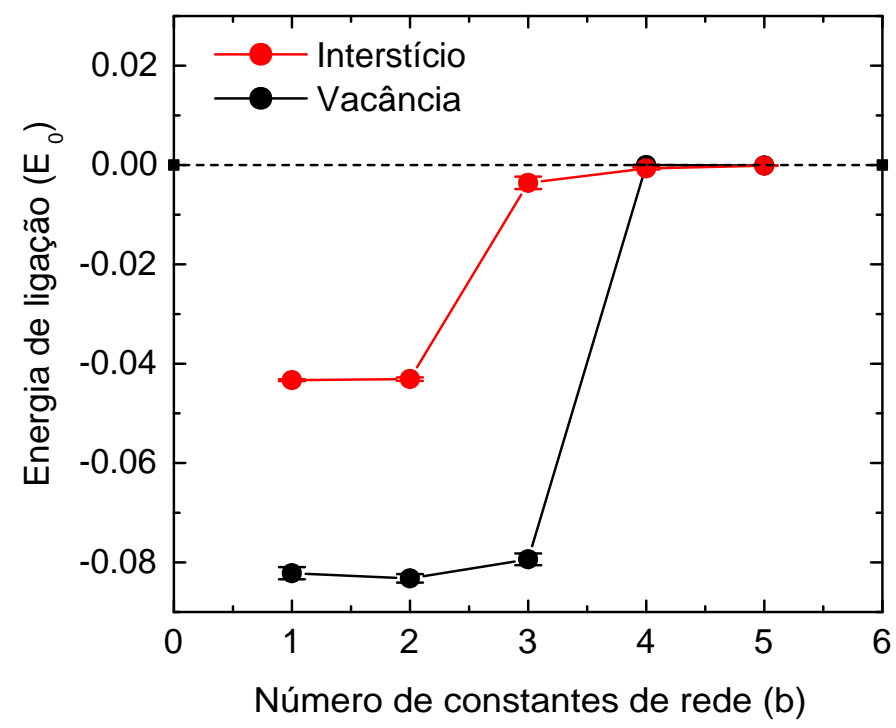

Figura 12. Energia de ligação de um par de defeitos vacância-vacância e interstício-interstício como função da distância entre os defeitos para um cristal coloidal 2D com $\rho=0.954 \mu \mathrm{m}^{-2}, T=10^{-10} T_{0}$. Calculado para sistemas com 120 sítios de rede.

defeitos pontuais como função da distância entre eles. A diferença entre as energias para criar dois defeitos separados por um dado número de constantes de rede e a energia para criar dois defeitos isolados é a energia de ligação entre os defeitos, definida como segue,

$$
E_{\text {lig }}=\nabla E_{\text {def }}\left(N_{\text {def }= \pm 2}\right)-2 \nabla E_{\text {def }}\left(N_{\text {def }}= \pm 1\right)
$$

onde o primeiro termo à direita corresponde à energia para criar dois defeitos separados por algumas constantes de rede, ao passo que o último termo é a energia para criar dois defeitos isolados. A figura 12 mostra a energia de ligação vs a separação entre os defeitos. Para conseguir precisão na posição dos defeitos, baixamos a temperatura para 
$\sim 10^{-10} T_{0}$. Isso foi suficiente para manter os defeitos em posições fixas. Ambos os pares de vacância-vacância e interstício-interstício são fortemente atrativos para distância curtas, com a atração indo a zero para distâncias maiores do que três constantes de rede. Para distâncias curtas, a energia de ligação para os defeitos é $\sim-0.08$ e $\sim-0.04$ para a vacância e para o interstício, respectivamente. Sendo, portanto, maior do que o valor esperado da temperatura próximo a fusão em $\rho=0.954 \mu \mathrm{m}^{-2}$, que é $\sim-0.01$ de acordo com a figura 11. Uma vez que qualquer atração deve ser suficiente para permitir recombinação, os resultados sugerem que a energia do estado fundamental do cristal coloidal 2D, próximo à fusão, pode ser dominado por pares ligados de defeitos. Além disso, como os interstícios têm a menor energia de formação, esperamos que este estado envolva principalmente pares de interstícios. Embora os mecanismos envolvidos na formação dos pares ligados de defeitos ainda não sejam completamente compreendidos, notamos uma similaridade entre nossos resultados e os já publicados para defeitos em cristais quânticos, tal como cristais de Wigner 2D (CÂNDIDO; PHILLIPS; CEPERLEY, 2001), onde os pares de defeitos não são suficientemente fortes para levar a uma fase supersólida. Para experimentais observando a evolução de sistemas coloidais 2D usando microscopia, acreditamos que nossos resultados oferecem o desafio de observar a formação dos pares de defeitos próximos à fusão do cristal.

Antes de concluir, comentaremos sobre a entropia, a qual está embutida nos cálculos da energia de formação dos defeitos. Bem abaixo do ponto de fusão tal contribuição pode ser desprezada, uma vez que nesse regime ela é muito menos importante do que a energia. Perto da temperatura de fusão, é provável que a entropia afete os valores calculados para a energia de formação, mas o quadro qualitativo geral deveria ser preservado. De fato, essa expectativa parece ser satisfeita, pois nossos cálculos explicam muitas das observações experimentais. 


\subsection{Conclusão}

Calculamos quantitativamente a energia de formação de defeitos pontuais (vacância e interstício) em cristais coloidais 2D. Mostramos que a energia para criar um único interstício é $12 \%$ - 28\% menor do que a energia necessária para criar uma vacância. A energia de formação desses defeitos vai a zero perto do ponto de fusão, sugerindo que defeitos pontuais podem ser criados termicamente nesse regime e podem desempenhar um papel importante no mecanismo de fusão do cristal coloidal 2D. Finalmente, descobrimos que a interação entre os defeitos é fortemente atrativa e, conseqüentemente, a maioria dos defeitos deve existir como pares ligados possivelmente formando defeitos mais complexos. Acreditamos que nossos resultados possam ter influências importantes sobre trabalhos experimentais envolvendo interfaces e superfícies sólidas. 


\section{Capítulo 4}

\section{Dinâmica de defeitos pontuais em}

\section{cristais coloidais bidimensionais}

O processo de migração de átomos através de sólidos contribui para muitos fenômenos de interesse em física e química do estado sólido, metalurgia e ciência dos materiais. A mobilidade atômica em sólidos cristalinos é, em geral, mediada pela presença de defeitos, os quais "perturbam" a estrutura ideal do material. Deste modo, muitas das propriedades dos materiais cristalinos dependem fortemente do tipo e concentração de defeitos, além da forma com que essa distribuição evolui, pois isto pode acarretar mudanças nas propriedades dos materiais. Por exemplo, a reologia dos cristais líquidos nemáticos é dominada pela formação e movimento de defeitos (PISMEn; RUBINSTEIN, 1992). Portanto, compreender como os defeitos se movem é de suma importância para esclarecer aspectos relacionados às propriedades dos sistemas ordenados. Neste capítulo estudaremos a dinâmica de vacâncias em cristais coloidais bidimensionais.

\subsection{Principais trabalhos relacionados}

Em um esforço para compreender a dinâmica de defeitos pontuais individuais, Pertsinidis e Ling conduziram experimentos nos quais os defeitos pontuais (mono-vacâncias e di-vacâncias) foram artificialmente criados em cristais coloidais bidimensionais, manipu- 
lando os colóides com pinças ópticas (PERTSINIDIS; LING, 2001a). Basicamente o aparato experimental usado para criar o defeito inclui um feixe de laser de argônio, com o qual um ou mais colóides são capturados e arrastados para fora de seus sítios na rede, gerando assim vacâncias. Usando um algoritmo de triangulação mapearam individualmente, no espaço e tempo reais, a posição desses defeitos por um longo período de tempo para obter medidas confiáveis de sua constante de difusão. A posição do defeito foi definida como a média das posições das partículas com vizinhança cinco, as quais fazem parte do núcleo do defeito. Para medir a mobilidade do defeito calcularam o deslocamento médio quadrático como função do intervalo de tempo entre as medidas $\delta t$, isto é, $\left\langle\triangle x^{2}(\delta t)\right\rangle$. Os resultados obtidos para mono- e di-vacâncias foram, respectivamente, $D_{\text {mono }} / a^{2}=3.27 \pm 0.03 \mathrm{~Hz}$ e $D_{d i} / a^{2}=3.71 \pm 0.03 \mathrm{~Hz}$, sendo $a \approx 1.1 \mu \mathrm{m}$ a constante de rede do cristal coloidal $2 \mathrm{D}$. Em um estudo anterior (PERTSINIDIS; LING, 2001b), os mesmos autores já haviam observado que as possíveis configurações estáveis para as mono- e di-vacâncias não são apenas defeitos pontuais "bem identificados", mas que existem configurações onde os defeitos pontuais aparecem como pares de deslocações (dislocations). No estudo sobre a difusão foi apontado que essa quebra do defeito pontual em um par de deslocações contribui significativamente para a difusão das di-vacâncias, mas que essa quebra não era tão relevante para o caso de uma mono-vacância. Com relação aos detalhes do processo de difusão, descobriu-se que a trajetória dos defeitos não é feita em uma caminhada aleatória (random walk) pura sobre a rede triangular, isto é, o defeito não se move com probabilidade igual para os seis sítios vizinhos, e existe alguma correlação entre os movimentos subseqüentes. Em particular, o movimento do defeito ficaria restrito a direções específicas durante um longo período de tempo, e essas direções estariam relacionadas à baixa simetria das configurações estáveis do defeito relativo à rede triangular perfeita. A figura 13 ilustra a trajetória dos defeitos obtida nesse estudo.

Um estudo mais detalhado sobre a dinâmica de defeitos pontuais em cristais coloidais bidimensionais foi conduzido por Líbal e colaboradores (LIBÁL; REICHHARDT; REICHHARDT, 2007), usando dinâmica Browniana. Diferentemente do trabalho experimental, onde foram estudadas apenas as vacâncias, as simulações foram conduzidas considerando 


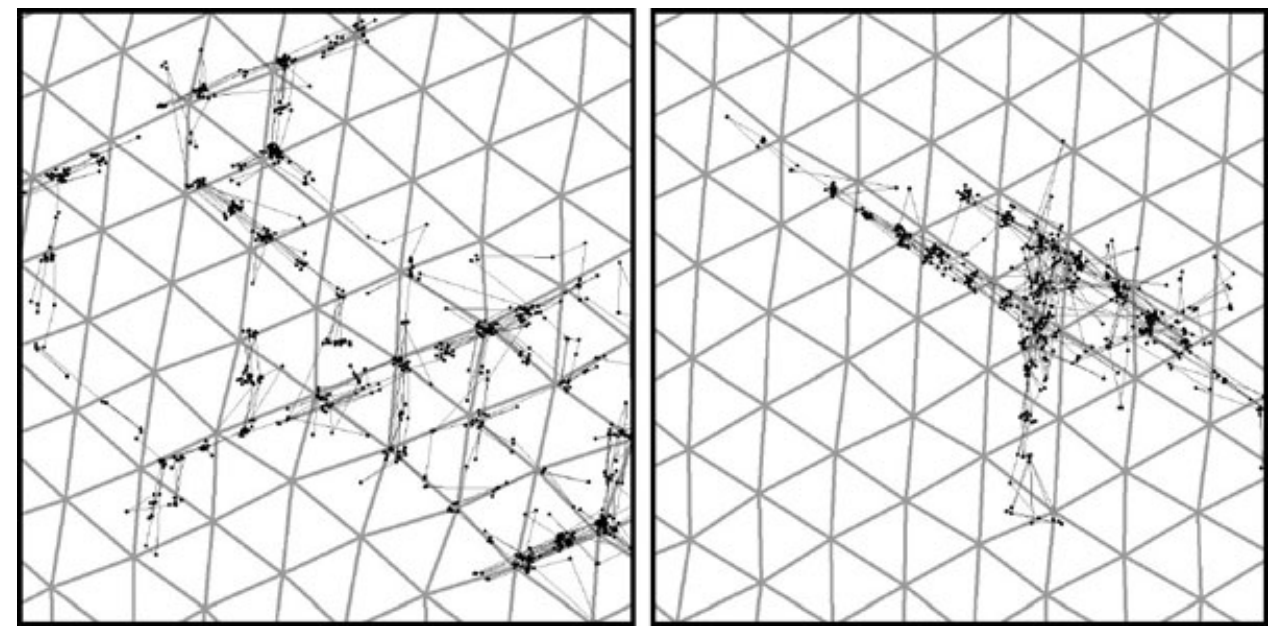

Figura 13. Trajetória dos defeitos segundo (PERTSINIDIS; LING, 2001a): à esquerda, mono-vacância; à direita, di-vacância. As linhas em cinza correspondem à posição da rede, sobreposta sobre a posições dos defeitos, durante alguns segundos de difusão. As medidas são feitas a cada $\frac{1}{60} \mathrm{~s}$, o que dá uma resolução de $\sim 0.1 a$.

também os interstícios. Para estudar o movimento dos dois tipos de defeitos foi definida a posição do defeito, $\mathbf{r}_{d}$, como sendo o centro dos $N$ colóides com $n v \neq 6$ no sistema. Estas partículas mal coordenadas foram identificadas utilizando um diagrama de Voronoi, tal como discutido em capítulos anteriores. Assim como no estudo experimental, observouse que os defeitos possuem direções preferenciais para a difusão. Além disso, os autores explicaram o processo em detalhes, especialmente apontando que as configurações topológicas $V_{2}, S V, I_{2}$ e $I_{2 d}$, denominadas gliding configurations, são as responsáveis pelo movimento unidimensional ao longo de uma direção, ao passo que as configurações $V_{3}$, $V_{4}^{\prime}, I_{3}$ e $I_{4}^{\prime}$ podem redirecionar o movimento do defeito. No caso da vacância, o defeito gasta a maior parte do seu tempo nas topologias $V_{2}, S V$, as quais possuem direções paralelas bem definidas para a difusão em 1D. Esse processo seria então marcado pelo aparecimento das topologias $V_{3}$ e $V_{4}^{\prime}$, que não possuem direção preferencial para a difusão e podem reorientar a direção do movimento do defeito. Assim, para curtos períodos de tempo, o defeito vacância faria uma caminhada aleatória em 1D, ao passo que para longos períodos de tempo a difusão seria isotrópica. De forma similar, as topologias $I_{2}$ e $I_{2 d}$ são as responsáveis pela difusão em 1D dos interstícios, enquanto as topologias $I_{3}$ e $I_{4}^{\prime}$ permitiriam as reorientações. Porém, no caso do interstício o defeito gasta muito mais tempo na topologia $I_{3}$. Conseqüentemente, isso promoveria ao interstício um caráter de difusão muito mais bidimensional do que a vacância. Além desses esclarecimentos sobre os 
detalhes acerca da mobilidade dos defeitos, foi calculado também o coeficiente de difusão para a vacância e para o interstício em várias temperaturas. Demonstrou-se que um defeito interstício é mais móvel do que uma vacância para todo o intervalo de temperaturas estudado, tal como pode ser observado na figura 14 .

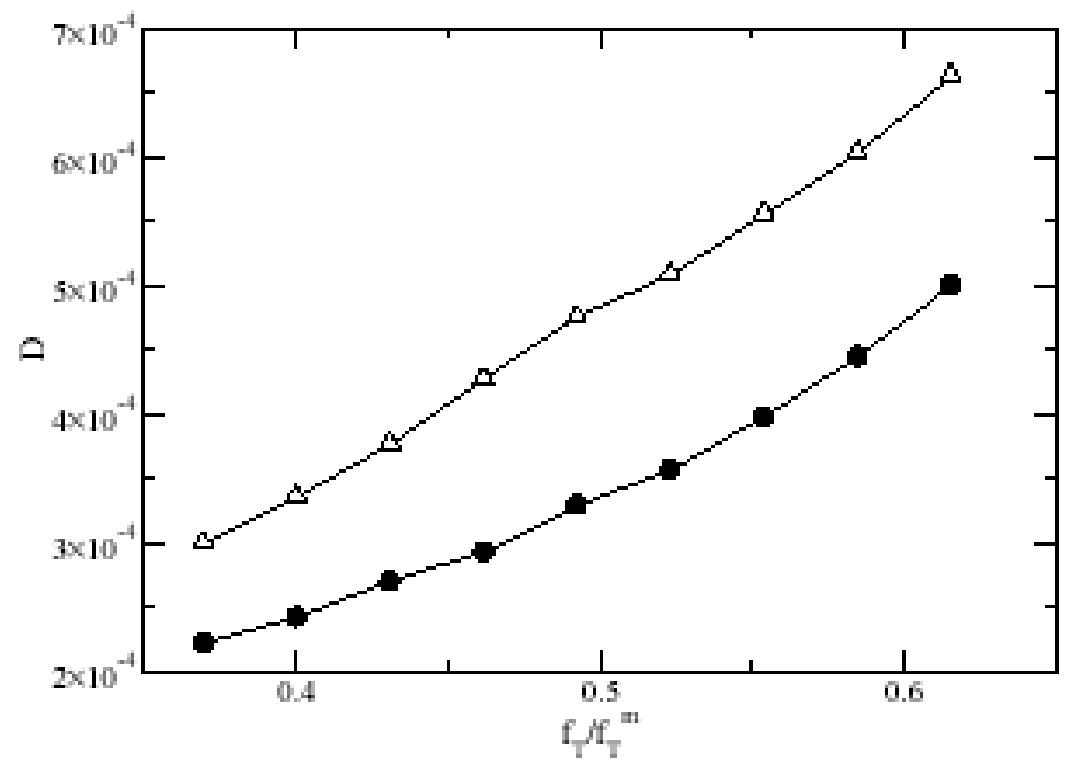

Figura 14. Constante de difusão D como função da temperatura. Triângulos abertos: interstício. Círculos preenchidos: vacância. Dados obtidos da referência (LIBÁL; REICHHARDT; REICHHARDT, 2007).

Embora os resultados apresentados por esses trabalhos tenham melhorado nossa compreensão sobre a dinâmica dos defeitos pontuais em cristais coloidais 2D, muito ainda precisa ser esclarecido. Particularmente, ainda não se sabe se a difusão é sempre mediada pela troca de topologias, ou se existem topologias que difundem por si só num processo de "deslizamento", ou mudando dela para ela mesma ao pular de sítio para sítio. Neste capítulo calcularemos as barreiras de energia entre as diferentes configurações topológicas dos defeitos pontuais, o que nos habilitará a compreender os mecanismos microscópicos que definem a dinâmica dos defeitos pontuais individuais.

\subsection{Resultados e Discussão}

Como discutido no primeiro capítulo desta tese, a mobilidade de defeitos pontuais em sólidos pode ser entendida como um movimento no qual flutuações térmicas randômicas proporcionam energia e momento suficiente para fazer com que o defeito "pule" de uma 
posição para outra. Na maior parte do tempo, os átomos em torno do defeito ficam vibrando em torno de suas posições na rede, de modo que, na escala de tempo do período de vibração da rede, esses pulos são ocasionais. Nos modelos mais simples considera-se que o movimento do defeito é determinado pelo movimento de um único átomo. Porém, isto é uma simplificação e, na verdade, mais de um átomo pode estar envolvido neste movimento. Como sabemos, na criação de um defeito os átomos em sua vizinhança podem relaxar de suas posições originais na rede para posições mais estáveis. Uma vez estabilizado, se uma das partículas envolvidas no defeito deslocar para uma nova posição, partículas vizinhas podem se tornar instáveis, possivelmente relaxando para outras posições. Em outras palavras, existem correlações na movimentação das partículas que fazem parte do núcleo do defeito. Na subseção seguinte apresentaremos o método que utilizamos para caracterizar o "pulo" do defeito. Este ponto é fundamental, pois o método para calcular as barreiras de energia depende diretamente de estimativas acerca da freqüência de pulos do defeito.

\subsubsection{Caracterização do "pulo" do defeito}

O primeiro passo para compreender a dinâmica dos defeitos pontuais no cristal coloidal 2D é exatamente caracterizar o "pulo" do defeito. A suposição preliminar que adotamos foi a de que o "pulo" ocorre exatamente no momento em que a topologia do defeito muda. Como veremos a seguir, nossos resultados sustentam essa hipótese.

Tal como no capítulo anterior, a cada passo de tempo geramos um diagrama de Voronoi da configuração, a partir do qual obtivemos o número de vizinhos de cada partícula. O núcleo do defeito é caracterizado pela presença de partículas mal coordenadas, isto é, partículas cujo número de vizinhos é diferente de seis. Com o objetivo de verificar nossa hipótese, mapeamos a trajetória das partículas mal coordenadas, bem como dos primeiros vizinhos destas partículas, durante várias trocas de topologias. As figuras 15 e 16 são exemplos de resultados para trocas de topologias de uma vacância.

Na figura 15 temos uma mudança de uma topologia $V_{3}$ (partículas quando em vermelho 


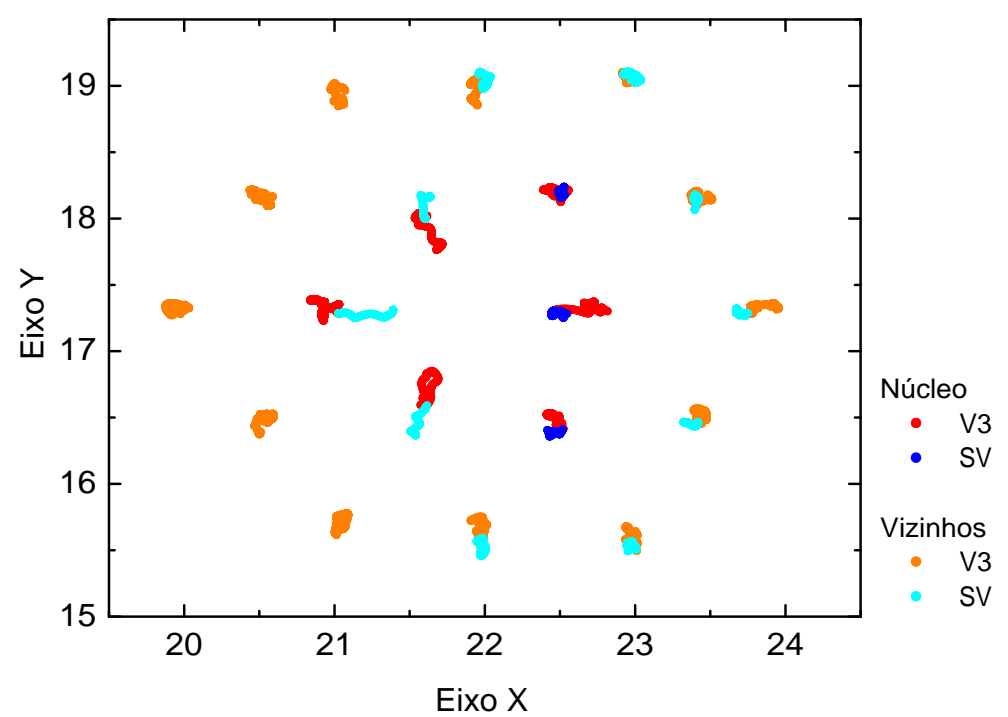

Figura 15. Trajetória das principais partículas envolvidas no defeito vacância, durante uma transição $V_{3} \rightarrow S V$ com a temperatura fixada em $T=300 \mathrm{~K}$.

e laranja) para uma topologia $S V$ (partículas quando em azul escuro e azul claro). Observe que a troca de topologia é exatamente o evento que marca o processo de relaxação das partículas para novas posições. Isto é, é um evento que, ao ocorrer, marca o início de um processo irreversível que em última análise caracteriza o "pulo" do defeito.

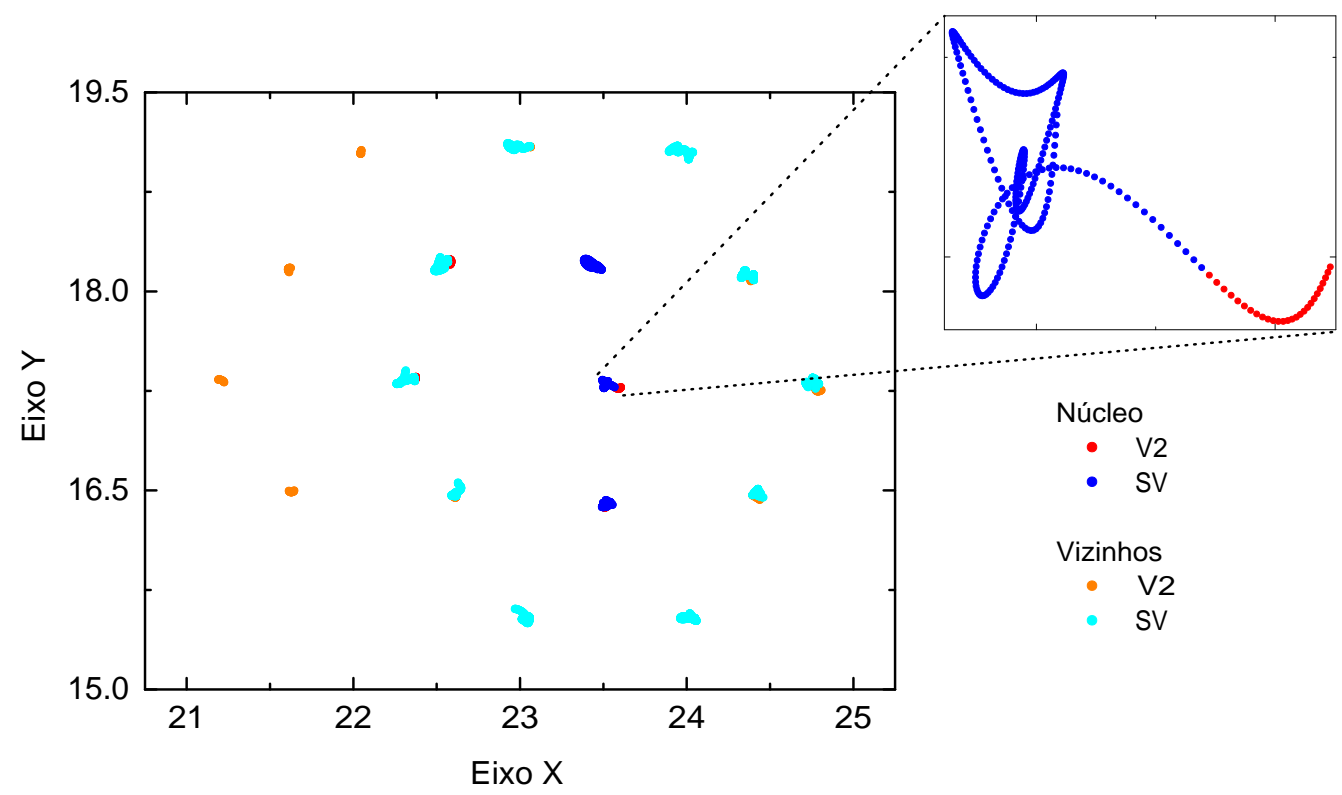

Figura 16. Trajetória das principais partículas envolvidas no defeito vacância, durante uma transição $V_{2 a} \rightarrow S V$ com a temperatura fixada em $T=300 \mathrm{~K}$. 
Na figura 16 temos um caso mais sutil, que envolve a troca de uma topologia $V_{2}$ (partículas quando em vermelho e laranja) para uma topologia $S V$ (partículas quando em azul escuro e azul claro). Apesar de a mudança na posição das partículas não ser tão nítida como no caso anterior, ela existe. Se observarmos com mais detalhes a trajetória das partículas centrais (na figura destacada com uma ampliação), veremos que com a mudança de topologia a partícula deixa de vibrar em torno de sua posição, e efetivamente relaxa para outra posição. Individualmente cada partícula desloca-se pouco em relação a sua posição de equilíbrio, mas o centro da vacância sofre um deslocamento considerável. Quando a vacância se encontra numa topologia $V_{2}$ o núcleo do defeito está entre as partículas com vizinhança igual a sete. Por outro lado, quando a vacância se encontra numa topologia $S V$ o núcleo do defeito é exatamente a partícula com vizinhança oito, a qual está deslocada aproximadamente meio parâmetro de rede do centro do defeito quando na topologia anterior. O fato de individualmente as partículas mudarem pouco de posição indica uma barreira de energia baixa entre essas duas topologias.

Tendo esclarecido que a mudança de topologia realmente caracteriza o processo de deslocamento do defeito, vamos agora estimar quanto o defeito desloca em cada transição topológica. Para isto definimos a posição do defeito como sendo o centro do conjunto de partículas mal coordenadas:

$$
\mathbf{r}_{d e f}(t)=\frac{1}{N_{n v} \neq 6} \sum_{i=1}^{N} \mathbf{r}_{i}(t)\left(1-\delta\left(n v_{i}-6\right)\right) .
$$

O deslocamento do defeito é então calculado como a diferença entre a posição do defeito antes e depois da troca de topologia. Isto é, supondo que a troca tenha sido identificada no tempo $t$, o deslocamento do defeito será $\Delta r_{d e f}=\left|\mathbf{r}_{d e f}(t)-\mathbf{r}_{d e f}(t-1)\right|$.

A figura 17 mostra os histogramas do deslocamento do centro do defeito na ocorrência das principais trocas topológicas. Com exceção das trocas envolvendo $V_{2 a}$ e $V_{2 b}$ todas as outras deslocam o centro do defeito aproximadamente meio parâmetro de rede. Na troca $V_{2 a} \leftrightarrows V_{2 b}$ o centro do defeito praticamente não se move pois, em geral, ocorre apenas uma reflexão das partículas com vizinhança cinco em relação ao eixo perpendicular à 


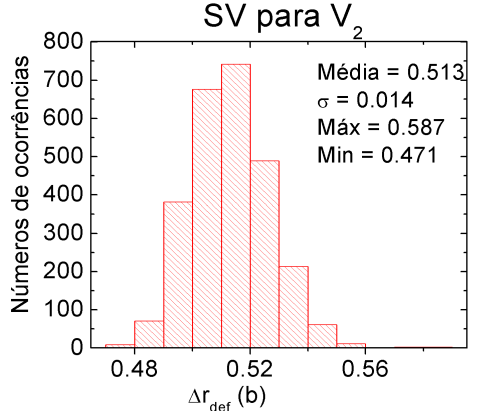

(a)

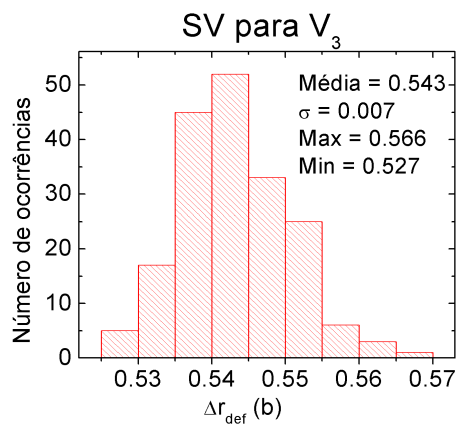

(c)

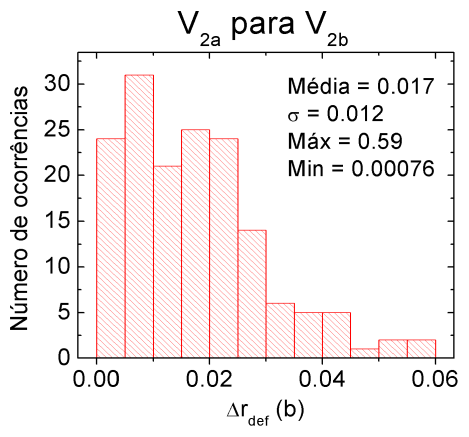

(e)

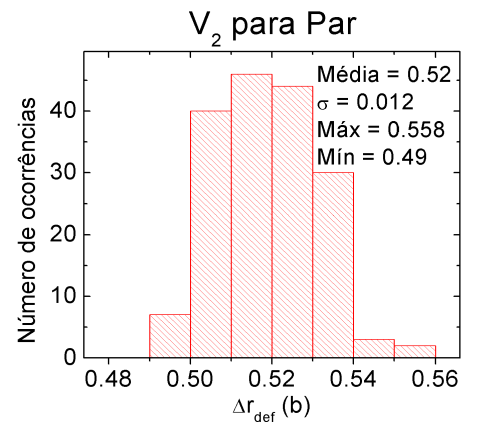

(g)

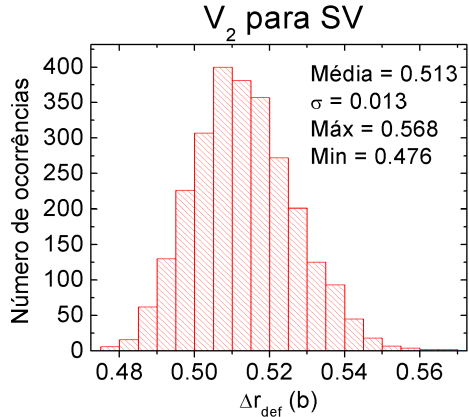

(b)

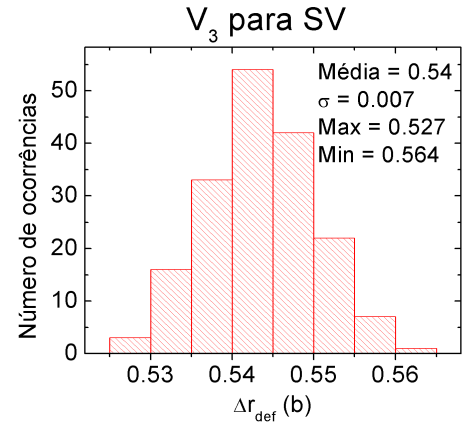

(d)

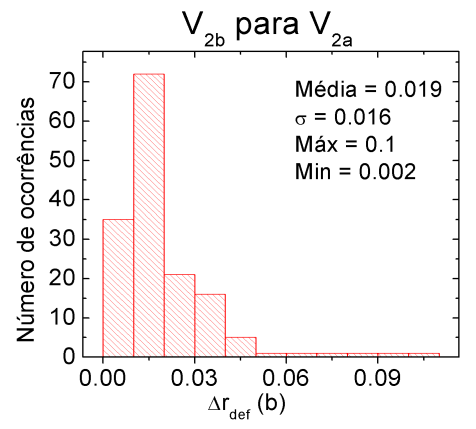

(f)

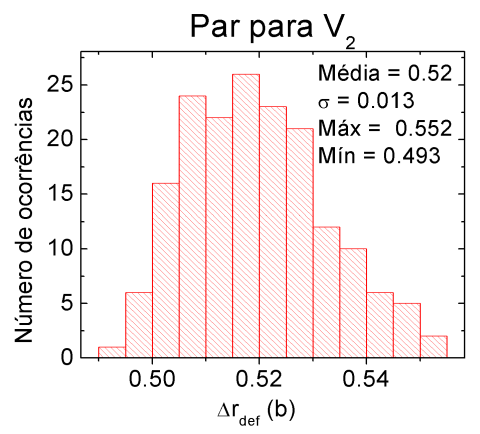

(h)

Figura 17. Deslocamento do centro de uma vacância durante as principais transições topológicas. 
reta que liga as partículas com vizinhança sete, conseqüentemente mantendo o centro do defeito praticamente inalterado. As transições $S V \rightleftarrows V_{3}$ apresentam os menores desvios com relação à média, $\sigma=0.007$, o que está ligado a um mecanismo de transição melhor definido.

\subsubsection{Barreiras de energia}

Os "pulos" do defeito pontual através do cristal procedem por meio de ativação térmica sobre alguma barreira de energia separando duas configurações vizinhas. A constante de difusão destes defeitos, $D(T)$, pode ser expressa como (veja seção 1.4)

$$
D(T)=g f a^{2} P(T) C(T),
$$

onde $g$ é um fator geométrico determinando a distância de pulo, $f$ é um fator de correlação, $a$ é o parâmetro de rede, $P(T)$ é a freqüência de pulo do defeito, $C(T)$ é concentração de defeitos e $T$ é a temperatura do sistema. Tal como discutido no primeiro capítulo, a freqüência de pulo do defeito é dada por

$$
P(T)=p_{0} \exp \left(s_{m} / k_{b}\right) \exp \left(-h_{m} / k_{b} T\right)
$$

onde $s_{m}$ e $h_{m}$ são, respectivamente, a entropia e a entalpia de migração, que juntas definem a energia de ativação para o processo de migração, $g_{m}=h_{m}-T s_{m}$, e $p_{0}$ é a freqüência característica de vibração do defeito, ou o número de tentativas de pulo na unidade de tempo. Da mesma forma, a concentração de defeitos em equilíbrio termodinâmico na temperatura $T$ é dada por (veja seção 1.4)

$$
C(T)=\exp \left(s_{f} / k_{b}\right) \exp \left(-h_{f} / k_{b} T\right)
$$

onde $s_{f}$ e $h_{f}$ são, respectivamente, a entropia e entalpia de formação do defeito. Como a concentração e a freqüência de pulos do defeito são definidas por uma função exponencial, podemos expressar a constante de difusão como uma relação de Arrhenius, isto é,

$$
D(T)=D_{0} \exp \left(-h / k_{b} T\right),
$$


onde $D_{0}=g f p_{0} a^{2} \exp \left(s / k_{b}\right) \operatorname{com} s=s_{f}+s_{m}$ a entropia de ativação do processo de difusão, e $h=h_{f}+h_{m}$ a entalpia de ativação do processo de difusão. Na maioria dos materiais a difusão é caracterizada por uma relação como esta, com coeficiente $D_{0}$ e energia de ativação constantes e independentes da temperatura, de modo que um gráfico de $\ln (D(T)$ ) vs $1 / T$ resulta em uma reta, cuja inclinação dá entalpia de ativação do processo de difusão. De forma análoga, é possível obter as entalpias de migração computando a freqüência de pulos do defeito para várias temperaturas e ajustando uma reta ao gráfico de $\ln (P(T)$ ) vs $1 / T$. O coeficiente angular desta reta seria a entalpia de migração do defeito.

No caso do cristal coloidal, constatamos na seção anterior que o pulo do defeito pode ser caracterizado pela troca de topologias. Assim, identificando a topologia corrente a cada passo de tempo e registrando a ocorrência de transição, podemos estimar a freqüência de pulos com base nas trocas topológicas. Se a simulação for executada por um longo período de tempo, é possível obter a convergência das freqüências de pulos para uma dada temperatura. Se obtivermos estas freqüências em várias temperaturas podemos obter as entalpias de migração do defeito.

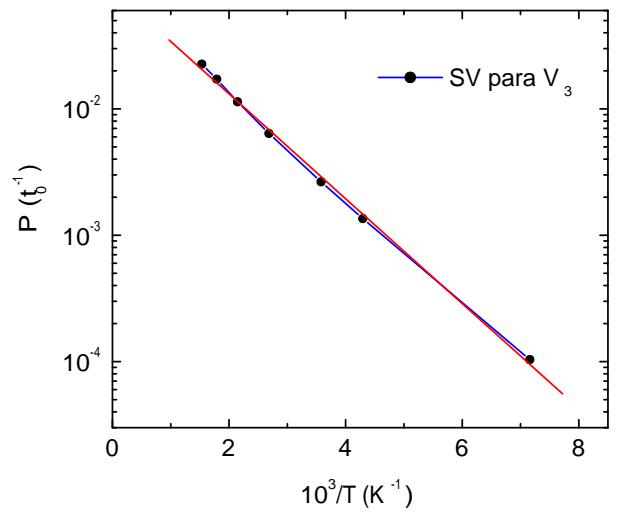

(a)

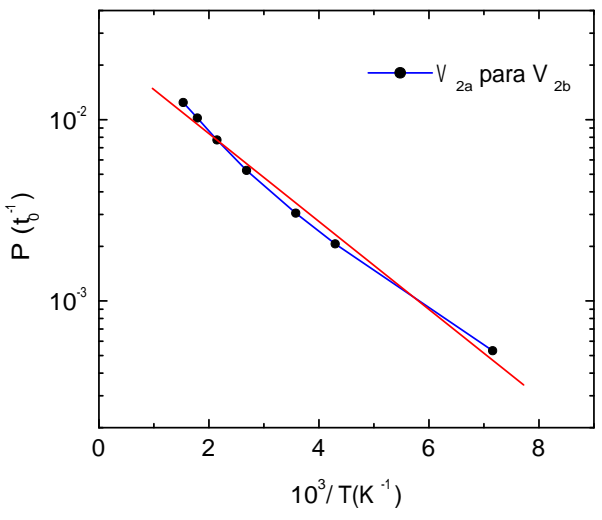

(b)

Figura 18. Freqüência de transições topológicas contra o inverso da temperatura. (a) $S V \rightarrow V_{3}$, (b) $V_{2 a} \rightarrow V_{2 b}$. A reta em vermelho foi ajustada aos dados usando o método dos mínimos quadrados. Em azul temos apenas a ligação entre os pontos do gráfico. Como está claro, o comportamento difusivo não segue estritamente uma relação de Arrhenius.

A figura 18 ilustra comportamentos típicos obtidos para o gráfico da freqüência de pulos contra o inverso da temperatura para duas transições topológicas, a saber: $S V \rightarrow V_{3}$ 
e $V_{2 a} \rightarrow V_{2 b}$. Em vermelho apresentamos o ajuste de uma reta aos dados de acordo com o método dos mínimos quadrados. A transição $S V \rightarrow V_{3}$ (figura 18(a)) segue quase uma relação de Arrhenius, porém já é possível perceber certa curvatura no gráfico. No caso da transição $V_{2 a} \rightarrow V_{2 b}$ (figura 18(b)) a curvatura é ainda mais acentuada. Em outras palavras, o ajuste não é bom, pois o comportamento difusivo não segue estritamente uma relação de Arrhenius.

Desvios da relação de Arrhenius não são uma novidade. Eles podem surgir devido a fatores que vão desde aspectos fundamentais envolvendo os mecanismos de migração atômica até efeitos associados a impurezas e características microestruturais. Como exemplos de materiais que apresentam desvios consideráveis desta relação podemos citar casos de metais tidos como "normais", incluindo sódio (MUNDY, 1971), potássio (MUNDY; MiLLER; PORTE, 1971), prata (ROTHMAN; PETERSON; ROBINSON, 1970), bem como em metais "anômalos" como o $\beta$-titânio (MURDOCK; LUNDY; STANSBURY, 1964) e $\beta$-zircônio (FEDERER; LUNDY, 1963). Freqüentemente, estes desvios têm sido atribuídos a efeitos seqüenciais ou simultâneos de dois ou mais defeitos diferentes contribuindo para o processo difusional (ROTHMAN; PETERSON; ROBINSON, 1970; KIDSON, 1963), sendo a difusão expressa como uma soma de termos exponenciais, cada um com sua energia de ativação e termo pré-exponencial independentes da temperatura. Porém, é claro que essa hipótese não se aplica ao nosso caso, pois estamos trabalhando com a difusão de um único defeito no cristal coloidal 2D. Em outras abordagens considera-se um único tipo de defeito, cuja difusão é determinada por uma entalpia e entropia de ativação dependentes da temperatura. Na sequência analisaremos os dados que obtivemos por DM de duas formas diferentes, sendo que ambas estão de acordo com a segunda abordagem, isto é, partem do princípio de que a curvatura no gráfico de $\ln (D(T))$ contra 1/T advém de uma dependência da temperatura da energia livre de migração e/ou formação de um único tipo de defeito no cristal. 


\subsubsection{Abordagem fenomenológica}

Uma das abordagens mais utilizadas para descrever a curvatura no gráfico $\ln (P(T))$ contra $1 / T$ trata o problema construindo uma expressão fenomenológica para a energia livre de migração dos átomos (SANCHEZ; DE FONTAINE, 1975), a qual passa a incorporar um termo não harmônico de terceira ordem. Neste método, a freqüência de pulos do defeito passa a ser expressa como

$$
P(T)=p_{0} \exp \left(-h_{m} / k_{b} T\right) \exp \left(\alpha T_{m}^{2} / k_{b} T^{2}\right) .
$$

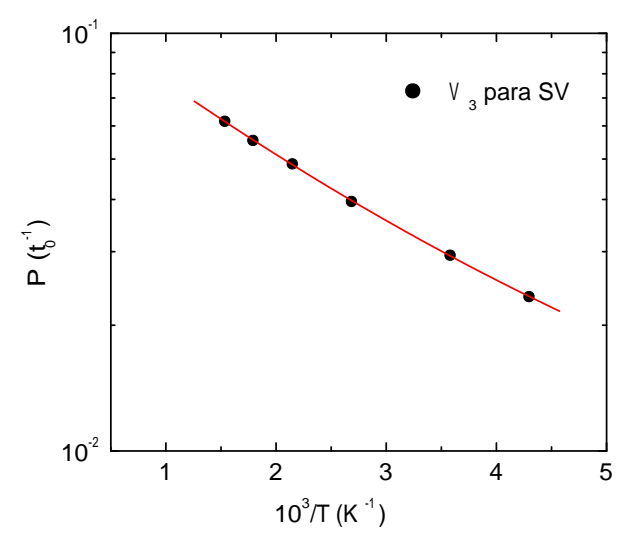

(a)

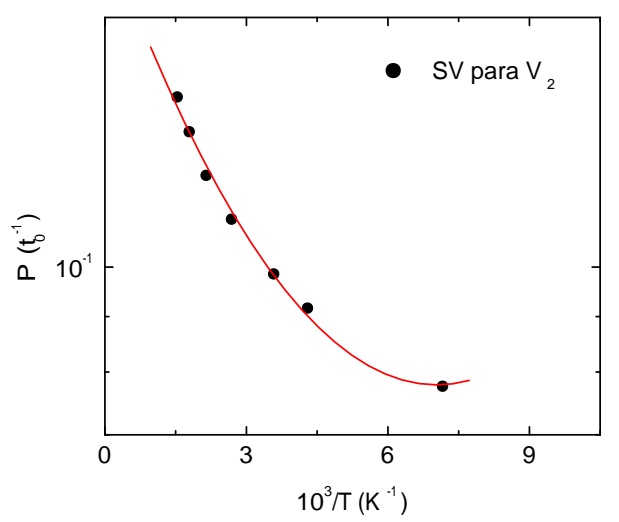

(c)

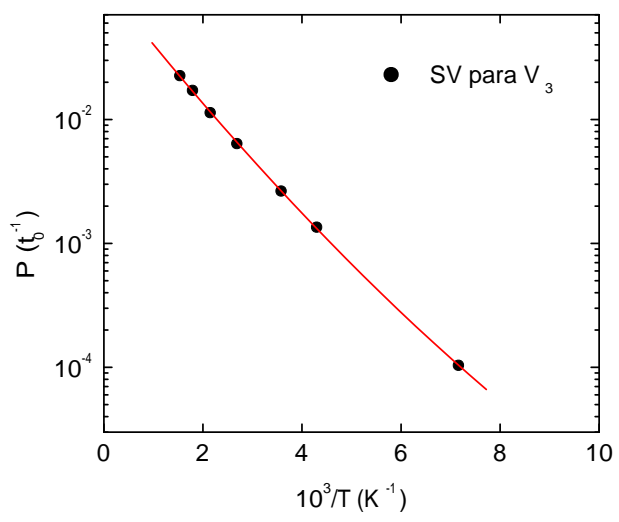

(b)

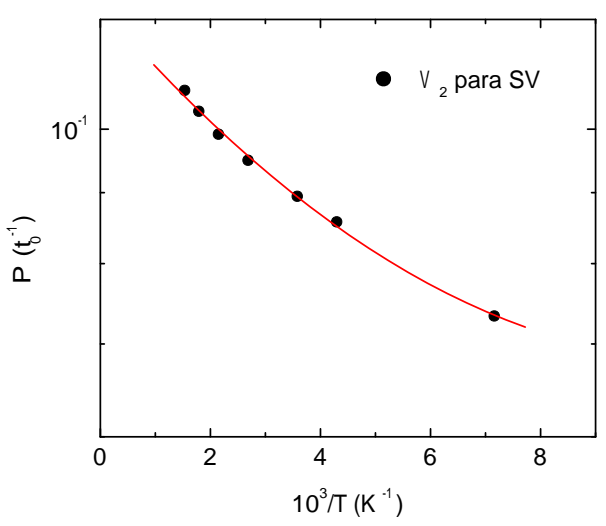

(d)

Figura 19. Os gráficos mostram que uma regressão polinomial de segunda ordem, baseada na equação 4.6 (em vermelho), descreve muito bem as transições entre várias topologias para a vacância. Os pontos em preto são os dados obtidos por DM. 


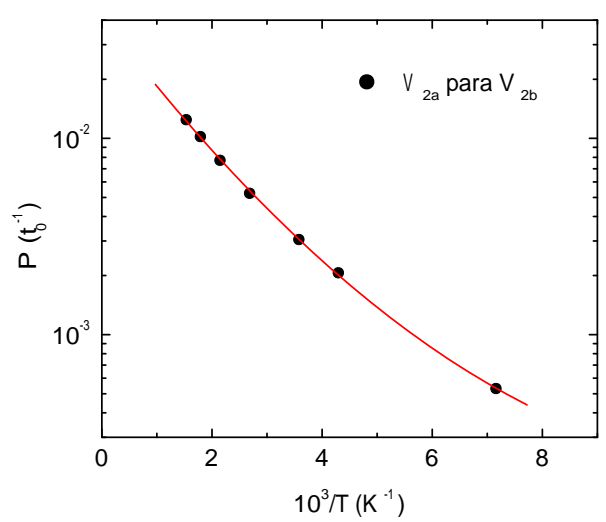

(a)

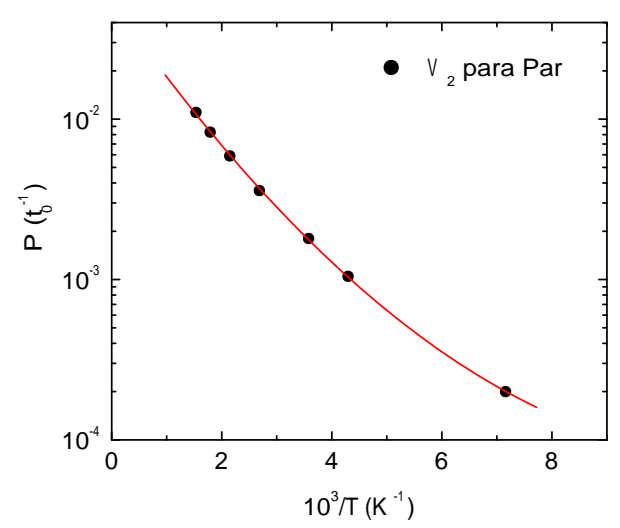

(c)

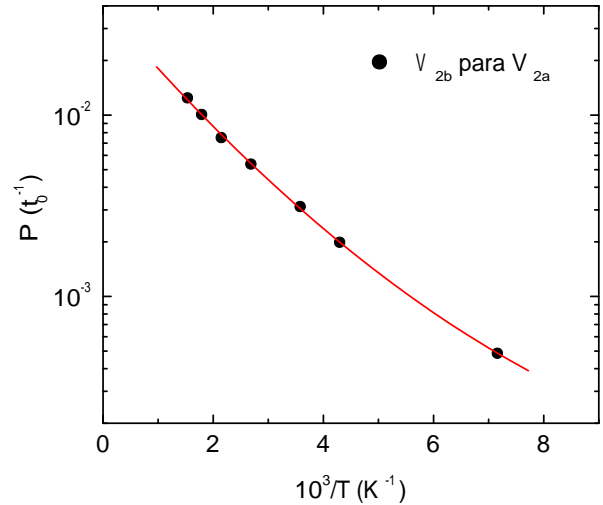

(b)

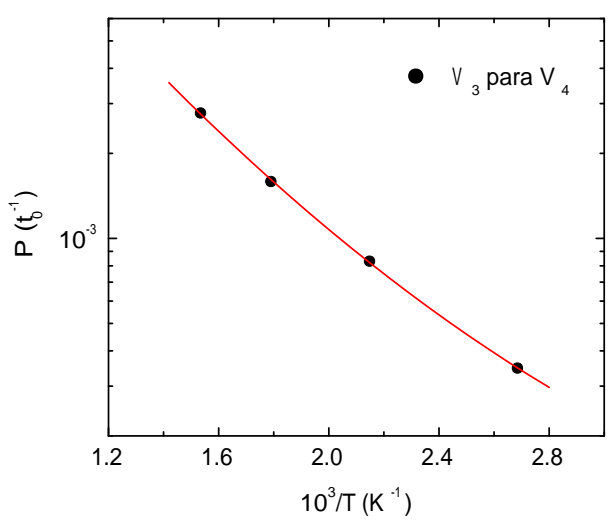

(d)

Figura 20. Os gráficos mostram que uma regressão polinomial de segunda ordem, baseada na equação 4.6 (em vermelho), descreve muito bem as transições entre várias topologias para a vacância. Os pontos em preto são os dados obtidos por DM.

O parâmetro adimensional $\alpha$ corresponde diretamente à curvatura do gráfico e a temperatura $T_{m}$ é introduzida apenas para normalizar o segundo exponencial. Essa abordagem inclui a possibilidade de mudanças na energia livre de migração da vacância com a temperatura devido a alguma razão física, sendo que a difusão como um todo é conduzida por um único mecanismo. Acreditamos que para nosso sistema, as razões físicas que podem resultar na dependência da energia livre de migração com a temperatura incluem principalmente grandes efeitos não harmônicos nas vizinhanças da vacância (GILDER; LAZARUS, 1975; VAROTSOS; AlEXOPOUlOS, 1986). Para outros casos (SANCHEZ; DE FONTAINE, 1975; DE FONTAINE; BUCK, 1973), esta dependência parece ser oriunda de in- 
Tabela 5- Entalpia de migração para as mudanças topológicas executadas por uma vacância no cristal coloidal 2D. Valores obtidos segundo uma regressão polinomial de grau 2 de acordo com a equação 4.6, $\operatorname{com} T_{m}=1000 \mathrm{~K}$.

\begin{tabular}{c|ccc}
\hline \hline & $\ln \left(p_{0}\right)$ & $h_{m}(\mathrm{~K})$ & $\alpha$ \\
\hline$S V \rightarrow V_{2}$ & $-1.58 \pm 0.04$ & $275 \pm 21$ & $0.040 \pm 0.005$ \\
$V_{2} \rightarrow S V$ & $-2.10 \pm 0.02$ & $105 \pm 9$ & $0.010 \pm 0.002$ \\
$S V \rightarrow V_{3}$ & $-2.07 \pm 0.04$ & $1165 \pm 24$ & $0.050 \pm 0.005$ \\
$V_{3} \rightarrow S V$ & $-2.13 \pm 0.02$ & $456 \pm 17$ & $0.037 \pm 0.007$ \\
$V_{2 a} \rightarrow V_{2 b}$ & $-3.17 \pm 0.04$ & $850 \pm 25$ & $0.069 \pm 0.006$ \\
$V_{2 b} \rightarrow V_{2 a}$ & $-3.22 \pm 0.05$ & $819 \pm 29$ & $0.058 \pm 0.003$ \\
$V_{2} \rightarrow$ Par & $-2.92 \pm 0.05$ & $1127 \pm 27$ & $0.099 \pm 0.006$ \\
$V_{3} \rightarrow V_{4}^{\prime}$ & $-1.8 \pm 0.3$ & $3174 \pm 313$ & $0.7 \pm 0.1$ \\
\hline \hline
\end{tabular}

stabilidades decorrentes de uma tendência, em baixas temperaturas, a uma transformação na estrutura do sólido.

Para interpretar os dados obtidos por DM sobre a mobilidade do defeito, utilizaremos a equação 4.6 com $\alpha$ sendo um parâmetro fenomenológico cuja magnitude corresponde diretamente à curvatura do gráfico de $\ln (P(T))$ contra $1 / T$.

Os gráficos 19 e 20 mostram que a equação 4.6 descreve bem o comportamento para muitas das transições topológicas do defeito vacância no cristal coloidal 2D. A curva em vermelho foi obtida usando uma regressão polinomial de segunda ordem baseada na equação 4.6, sendo as freqüências de pulo calculadas por DM tal como descrito anteriormente.

A tabela 5 resume os resultados para entalpia de migração envolvida nas transições topológicas da vacância no cristal coloidal 2D, bem como os demais parâmetros para ajuste das curvas aos dados. Os valores estão em perfeito acordo com o que se espera. Por exemplo, tomando o estado $V_{3}$ como referência, notamos que a barreira entre $V_{3}$ e $S V$ é muito menor do que a barreira entre $V_{3}$ e $V_{4}^{\prime}$. Isto deveria ser esperado, já que o estado $V_{4}^{\prime}$ é muito pouco acessível, pois possui alta energia de formação (veja o capítulo anterior). As transições não mencionadas na tabela, como $V_{3} \rightarrow V_{2}$, são muito improváveis de ocorrer, devido a uma barreira de energia muito alta. Na verdade essas transições podem ocorrer em número baixo em altas temperaturas, mas para o intervalo de temperatura que estamos estudando são desprezíveis. 
Com relação às transições $V_{2 a, b} \rightarrow S V$ e $S V \rightarrow V_{2 a, b}$, os dados da tabela indicam entalpia de migração $h_{m}=105 \pm 9 \mathrm{~K}$ e $h_{m}=275 \pm 21 \mathrm{~K}$, respectivamente. Estas energias são muito baixas, já que a temperatura média do intervalo estudado está em torno de 300 K. Como vimos no primeiro capítulo, a relação de Arrhenius para a migração do defeito vem de uma aproximação harmônica para o potencial que confina as partículas, a qual é valida para barreiras de energia altas com relação à temperatura do sistema. Conseqüentemente, uma simples correção de curvatura parece não ser apropriada, pois nesse caso não podemos nem mesmo lançar mão do conceito de barreira de energia, já que os valores obtidos para a entalpia são próximos à temperatura do sistema. Os baixos valores destas barreiras de energia ajudam a explicar porque o defeito tende a ficar em 1D durante curtos intervalos de tempo. Como as barreiras de energia entre estas duas topologias são muito baixas, a troca entre elas é favorecida; além disso, como estas topologias possuem baixa simetria em relação à rede hexagonal, existem direções preferenciais para esta troca. Finalmente, resta-nos uma pergunta: se a relação de Arrhenius corrigida não é apropriada para esta troca de topologia, qual seria a relação apropriada? Em termos numéricos, a freqüência de pulos entre as topologias $S V$ e $V_{2}$ varia pouco com a temperatura, o que promove uma inclinação pequena ao longo da curva. Este fato nos levou a pensar numa possível relação de potência que variasse mais lentamente com a temperatura do que a relação exponencial. Por isso, analisamos os dados sobre essas trocas de topologia segundo a relação

$$
P(T) \propto(1 / T)^{\alpha}
$$

A figura 21 mostra as retas ajustadas aos gráficos de $\log (P(T))$ contra $\log (1 / T)$. Observe que esta relação descreve bem o comportamento dos dados obtidos por DM. Para a transição $V_{2} \rightarrow S V$ obtivemos $\alpha=-0.23 \pm 0.01$ e para a transição $S V \rightarrow V_{2}$ obtivemos $\alpha=-0.41 \pm 0.01$. Assim, a transição $S V \rightarrow V_{2}$ tem uma dependência maior com a temperatura, pois o expoente $\alpha$ para esta transição é quase o dobro do valor obtido para a transição contrária. Estes valores estão relacionados de alguma forma à estrutura e simetria destes defeitos em relação à rede subjacente. 


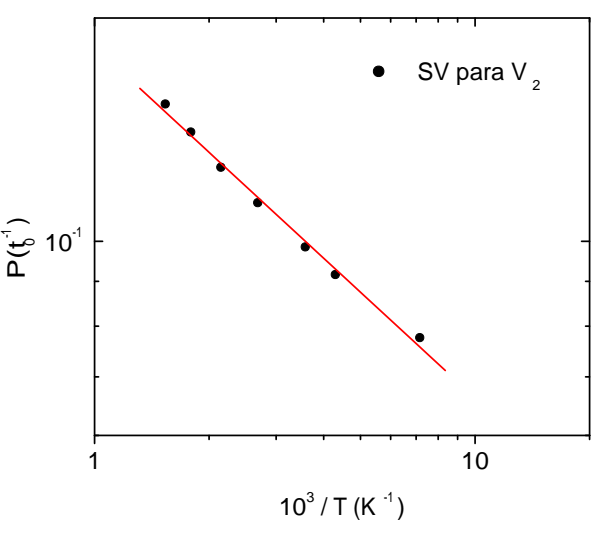

(a)

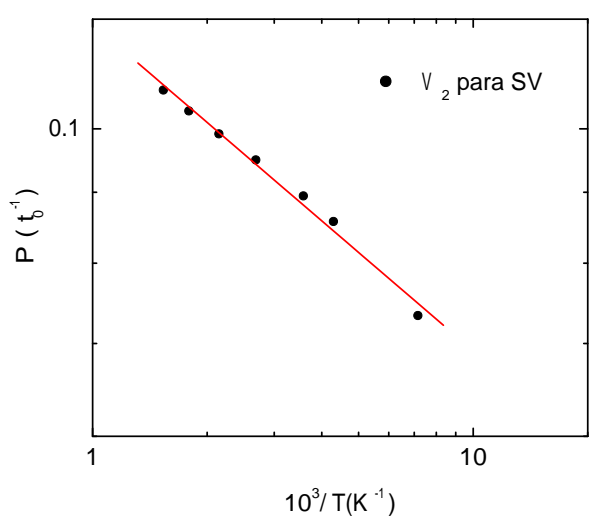

(b)

Figura 21. Os gráficos mostram que uma regressão linear, baseada na equação 4.7 descreve bem as transições entre as topologias $S V$ e $V_{2}$ para a vacância. Os pontos em preto são os dados obtidos por DM.

\subsubsection{Abordagem baseada na teoria de Gilder e Lazarus}

Apesar de a abordagem anterior apresentar bons resultados com relação ao ajuste das curvas aos dados, ela é pouco informativa pois não temos como discutir fisicamente o parâmetro $\alpha$. Vamos agora interpretar os dados segundo uma teoria proposta por H. M. Gilder e D. Lazarus (1975), a qual é calcada em argumentos termodinâmicos e que possibilita uma interpretação física direta dos parâmetros extraídos das curvas ajustadas aos dados obtidos por DM.

Tal como no caso anterior, a teoria é baseada na possibilidade de um único defeito difundir com entalpia de migração (e/ou formação) e entropia de migração (e/ou formação) dependentes da temperatura. Na sequência descreveremos os passos básicos para obtenção da equação que usaremos para analisar nossos dados.

De acordo com a teoria proposta, o único requisito termodinâmico é que a dependência da temperatura dos dois parâmetros relevantes estejam relacionados por

$$
\left(\frac{\partial \Delta h}{\partial T}\right)_{p}=T\left(\frac{\partial \Delta s}{\partial T}\right)_{p}
$$

Como os dois termos definem o calor específico, $\Delta c_{p}$, isso é equivalente a dizer que, para um comportamento não Arrheniano o $\Delta c_{p}$ associado com o movimento e formação 
do defeito deve ser diferente de zero. Gilder e Lazarus (1975) estimaram, em pressão zero e temperatura constante, a mudança no calor específico do cristal perfeito devido à introdução de uma vacância, e encontraram a seguinte expressão:

$$
\Delta c_{p}^{0}=\left(\frac{\partial \Delta h}{\partial T}\right)_{p}=\mu_{v} T,
$$

onde $\mu_{v}=2 \beta_{v} \beta_{0} \Delta V_{0} / K_{0}=2\left(\beta_{v} \Delta V_{0}\right) \gamma_{0} c_{v}^{0} / \Omega_{0}$, sendo $\beta_{v}$ e $\beta_{0}$ os coeficientes de expansão térmica da vacância ativada e do cristal perfeito, respectivamente. $K_{0}$ é compressibilidade isotérmica do cristal perfeito, $\Delta V_{0}$ é o volume de ativação do defeito, $\Omega_{0}$ é o volume atômico da rede e $\gamma_{0}$ é a constante de Grüneisen da rede perfeita.

Com base em uma série de argumentos teóricos e evidências experimentais, consideraram $\mu_{v}$ independente da temperatura e integraram a equação 4.9 para obter

$$
\Delta h(T)=\Delta h\left(T_{0}\right)+\frac{1}{2} \mu_{v}\left(T^{2}-T_{0}^{2}\right)
$$

onde $T_{0}$ é alguma temperatura de referência. Uma vez que a entropia está relacionada à entalpia pela equação 4.8, a equação 4.10 leva ao seguinte resultado para a entropia

$$
\Delta s(T)=\Delta s\left(T_{0}\right)+\mu_{v}\left(T-T_{0}\right) .
$$

Agora, reescrevendo a equação 4.5 para um único defeito com entalpia de ativação e entropia de ativação dependentes da temperatura,

$$
D(T)=D_{0}(T) \exp \left(-\Delta h(T) / k_{b} T\right)
$$

onde

$$
D_{0}(T)=g f p_{0} a^{2} \exp \left(\Delta s(T) / k_{b}\right) .
$$

Substituindo a equação 4.10 e 4.11 em 4.12 obtemos

$$
T \ln (D(T))=-\left(q_{0} / k_{b}\right)+\ln \left(d_{0}\right) T+\frac{1}{2}\left(\mu_{v} / k_{b}\right) T^{2},
$$


onde

$$
q_{0}=\Delta h\left(T_{0}\right)-\frac{1}{2} \mu_{v} T_{0}^{2}
$$

e

$$
\ln d_{0}=\ln \left(g f p_{0} a^{2}\right)+\Delta s\left(T_{0}\right) / k_{b}-\left(\mu_{v} / k_{b}\right) T_{0} .
$$

Portanto, o termo pré-exponencial $D_{0}(T)$ é dado por

$$
\ln D_{0}(T)=\ln d_{0}+\left(\mu_{v} / k_{b}\right) T
$$

e a entalpia de ativação, $\Delta h(T)$, por

$$
\Delta h(T)=q_{0}+\frac{1}{2} \mu_{v} T^{2}
$$

O termo $\frac{1}{2}\left(\mu_{v} / k_{b}\right) T$ é responsável pela curvatura no gráfico de $\ln D(T)$ contra $1 / T$. O grau de curvatura obviamente depende do valor de $\frac{1}{2} \mu_{v} T^{2}$ com relação à entalpia de referência $q_{0}$.

Como já discutido anteriormente, a difusão é obtida a partir do produto de três quantidades: concentração de defeitos, freqüência de pulos e do termo $g f a^{2}$. Deste modo, podemos extrair, em analogia com a equação 4.2, uma expressão para a freqüência de pulos que esteja de acordo com a equação 4.14. Na prática isto envolve apenas trocar $D(T)$ por $P(T)$, excluir os termos que não estão envolvidos com esta quantidade, como por exemplo $g f a^{2}$, e interpretar a entalpia e entropia de ativação como entalpia e entropia de migração.

Na sequência aplicaremos esta teoria aos dados sobre a migração do defeito que obtivemos por DM, isto é, extrairemos $q_{0}, \ln d_{0}$ e $\mu_{v}$ dos ajustes da equação 4.14 (adaptada, tal como discutido no parágrafo anterior) aos dados sobre a freqüência de pulos do defeito obtidos por DM.

As figura 22 e 23 mostram que a equação 4.14 descreve bem o comportamento para todas as transições topológicas cujos gráficos apresentam curvatura. A curva em vermelho foi obtida usando uma regressão polinomial de grau 2 baseado na equação 4.14, sendo as 


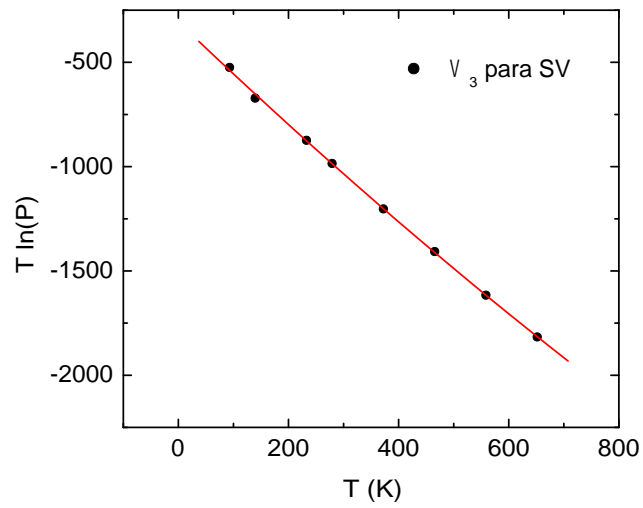

(a)

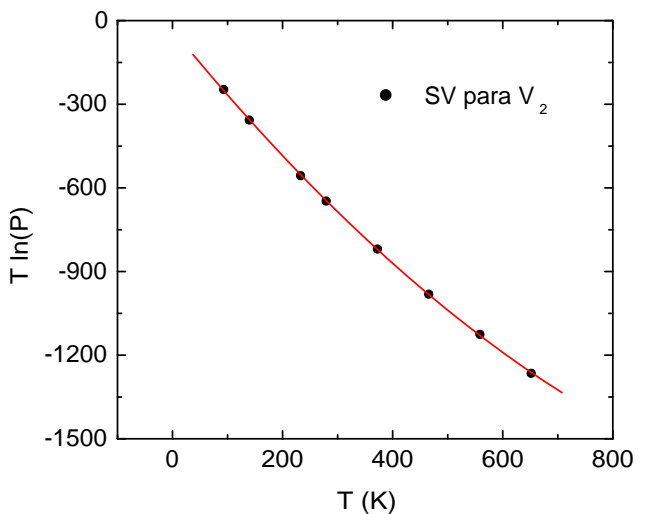

(c)

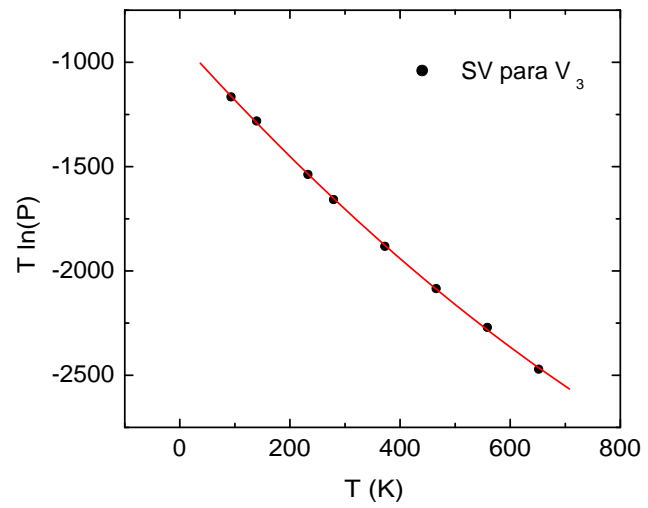

(b)

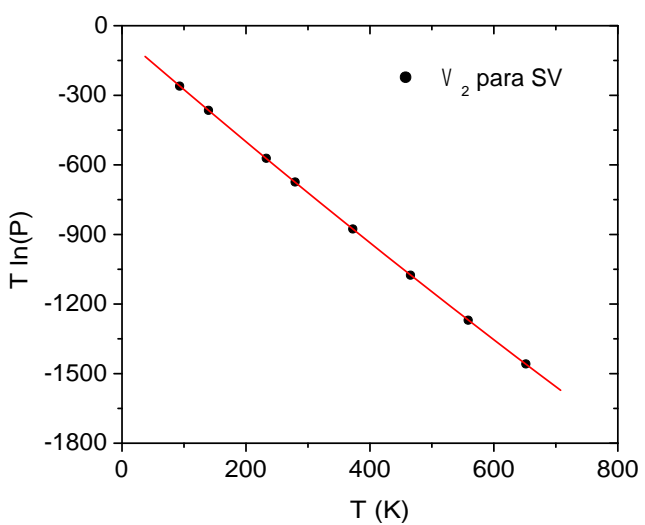

(d)

Figura 22. Os gráficos mostram que uma regressão polinomial de grau 2, baseada na equação 4.14 (em vermelho), descreve muito bem as transições entre várias topologias para a vacância. Os pontos em preto são os dados obtidos por DM.

freqüências de pulo calculadas por DM, tal como descrito anteriormente. A tabela 6 sumariza os parâmetros extraídos do ajuste das curvas aos gráficos das figuras 22 e 23 .

Tabela 6- Parâmetros obtidos do ajuste da equação 4.14 ao dados sobre a freqüência de troca de topologias (freqüência de pulos) de uma vacância no cristal coloidal 2D.

\begin{tabular}{c|ccc}
\hline \hline & $q_{0}(\mathrm{~K})$ & $\ln d_{0}$ & $\mu_{v}(\mathrm{~K})^{-1}$ \\
\hline$S V \rightarrow V_{2}$ & $32 \pm 5$ & $-2.43 \pm 0.03$ & $0.00166 \pm 0.00004$ \\
$V_{2} \rightarrow S V$ & $47 \pm 1$ & $-2.31 \pm 0.01$ & $0.00044 \pm 0.00002$ \\
$S V \rightarrow V_{3}$ & $896 \pm 12$ & $-2.94 \pm 0.07$ & $0.0016 \pm 0.0002$ \\
$V_{3} \rightarrow S V$ & $306 \pm 16$ & $-2.5 \pm 0.1$ & $0.0006 \pm 0.0002$ \\
$V_{2 a} \rightarrow V_{2 b}$ & $492 \pm 17$ & $-4.3 \pm 0.1$ & $0.001 \pm 0.0002$ \\
$V_{2 b} \rightarrow V_{2 a}$ & $459 \pm 14$ & $-4.47 \pm 0.09$ & $0.0024 \pm 0.0002$ \\
$V_{2} \rightarrow P a r$ & $535 \pm 24$ & $-4.9 \pm 0.1$ & $0.0038 \pm 0.0004$ \\
$V_{3} \rightarrow V_{4}$ & $1661 \pm 114$ & $-3.8 \pm 0.6$ & $0.0007 \pm 0.0006$ \\
\hline \hline
\end{tabular}




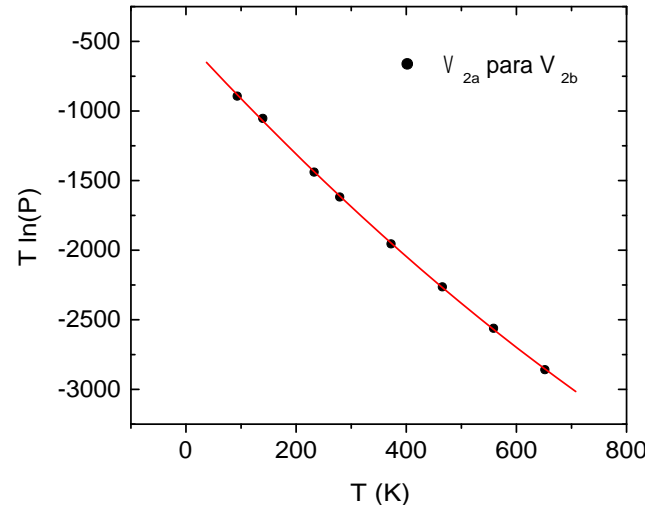

(a)

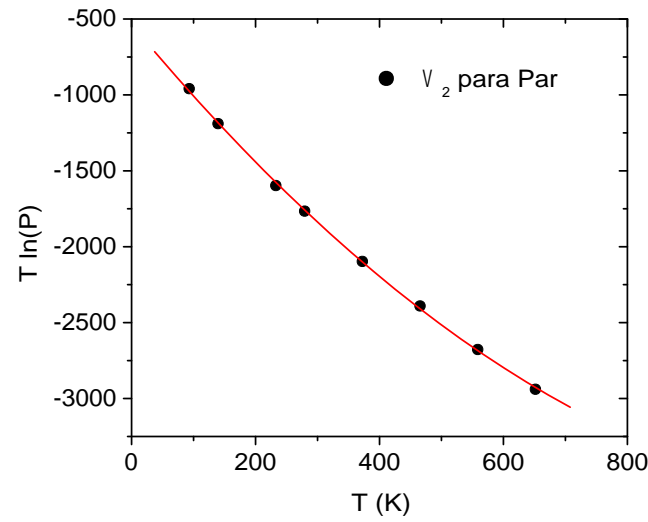

(c)

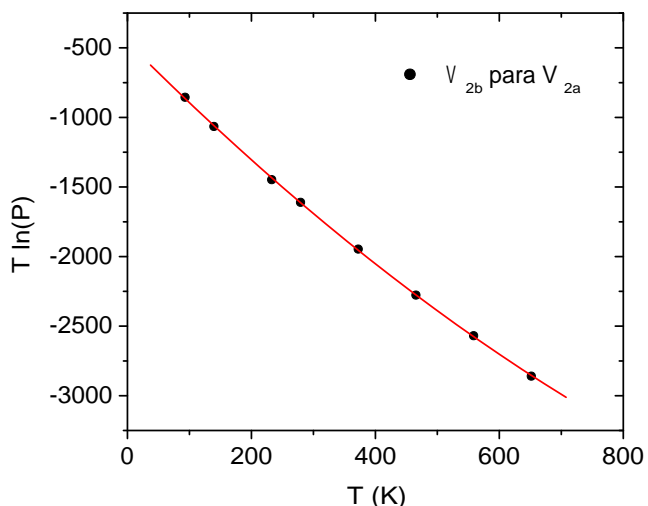

(b)

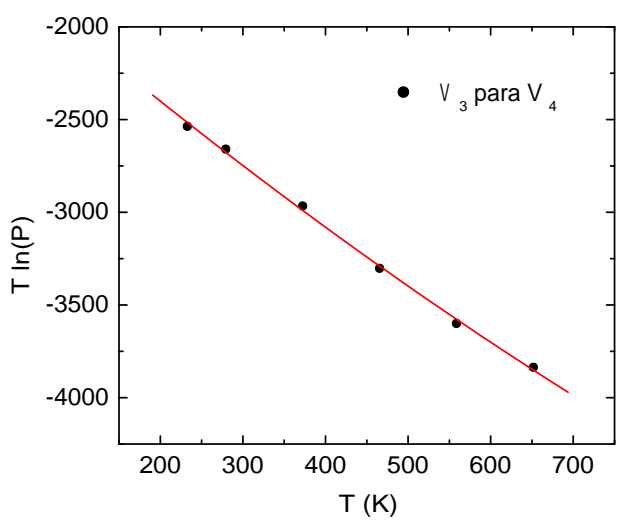

(d)

Figura 23. Os gráficos mostram que uma regressão polinomial de grau 2, baseada na equação 4.14 (em vermelho), descreve muito bem as transições entre várias topologias para a vacância. Os pontos em preto são os dados obtidos por DM.

Observe que a entalpia "característica" de migração, $q_{0}$, está qualitativamente em acordo com os valores calculados para a entalpia de migração obtidos com a abordagem fenomenológica (compare com os dados da tabela 5). Novamente as transições $S V \rightarrow V 2$ e $V 2 \rightarrow S V$ apresentam uma entalpia "característica" muito baixa, o que nos leva a crer que, de fato, entre essas topologias não existe barreira, pois a energia necessária para a troca está abaixo da temperatura média relevante para nosso sistema. Porém, como observado no gráfico da figura 19, uma diferença clara entre essas transições é que $S V \rightarrow V 2$ apresenta uma curvatura muito maior do que a transição contrária. Isto fica evidenciado numericamente na tabela 6 , onde o valor de $\mu_{v}$ da transição $S V \rightarrow V 2$ é quase quatro vezes maior do que o valor de $\mu_{v}$ da transição contrária. A figura 24 mostra como a entalpia de 
migração varia com a temperatura. Todas as transições apresentam aumento da entalpia com a temperatura, o que, em princípio, deveria sugerir uma diminuição na freqüência de troca de topologias; porém a freqüência está aumentando. Isto acontece porque existe uma competição envolvendo a entalpia e a entropia, de modo que o aumento da entropia com a temperatura é que promove este fato.

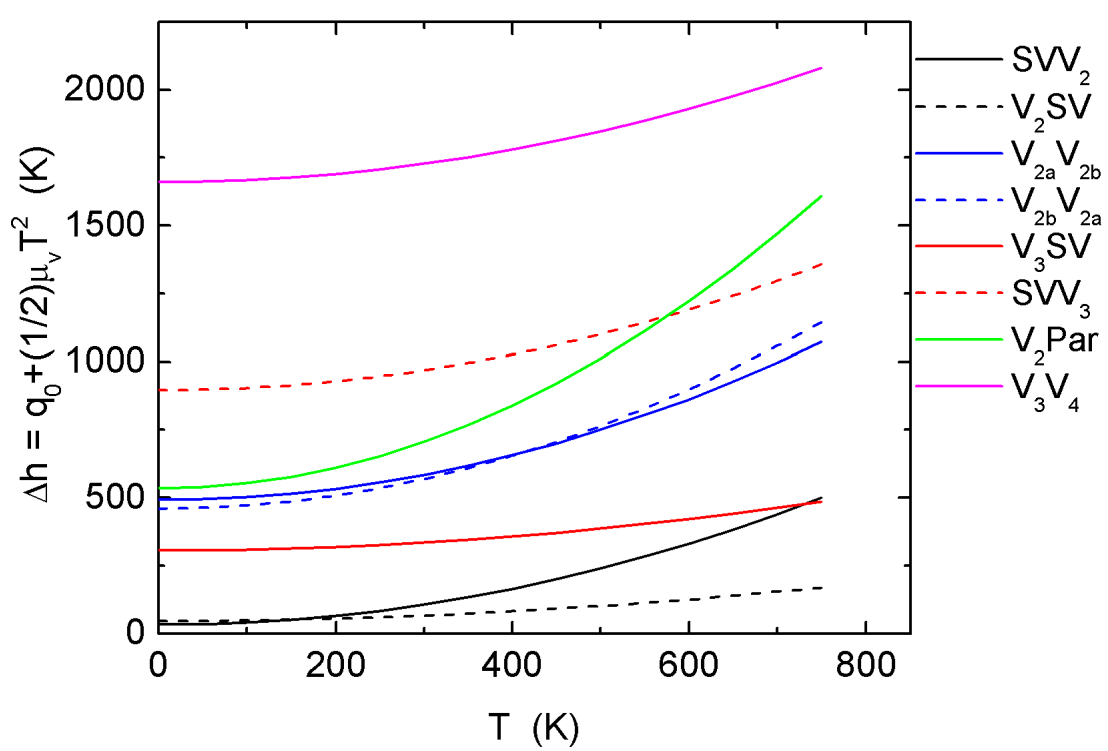

Figura 24. Variação da entalpia de migração com a temperatura para várias trocas topológicas.

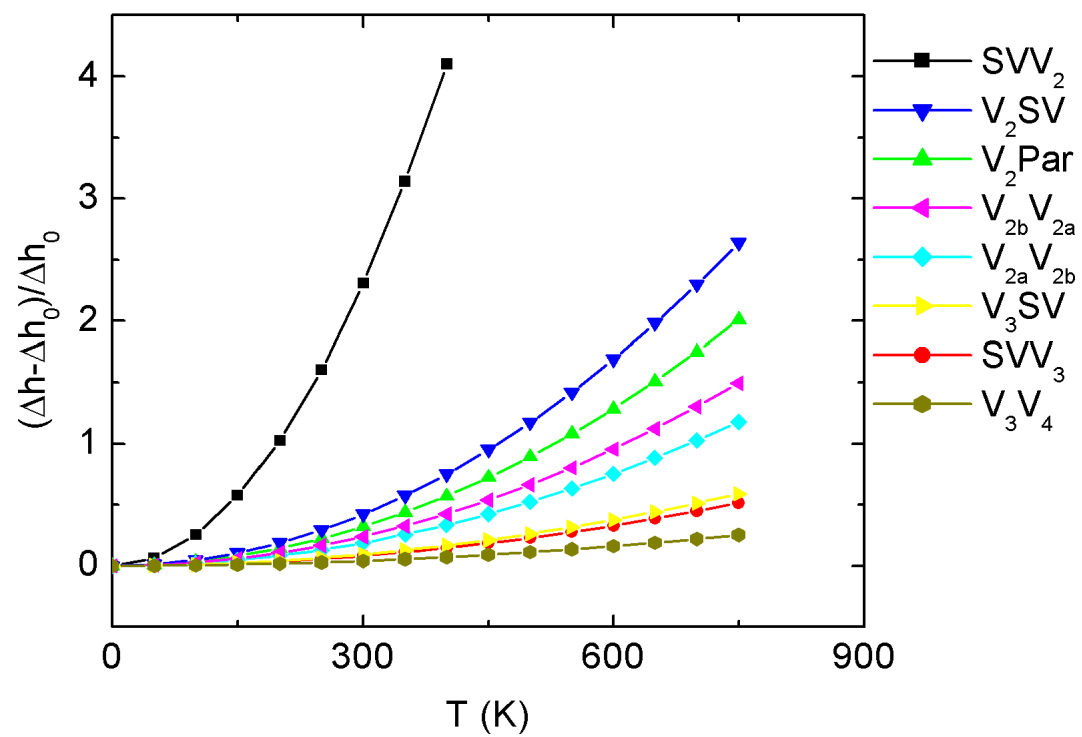

Figura 25. O gráfico mostra o quanto a entalpia, $h(T)$, desvia da entalpia característica, $h\left(T_{0}\right)$, com o aumento da temperatura. 
Nas duas abordagens que empregamos para estimar a entalpia de migração utilizamos uma correção sobre a relação de Arrhenius convencional. Além disso, mostramos evidências de que as transições $V_{2} \rightarrow S V$ e $S V \rightarrow V_{2}$ não se adéquam a essas teorias, pois apresentam entalpias de migração muito baixas, e a obtenção da relação de Arrhenius incorpora uma aproximação que prevê altas barreiras de energia entre configurações vizinhas. O gráfico da figura 25 mostra como a entalpia de migração das várias topologias desviam da entalpia característica à medida que a temperatura aumenta. Observe que as transições mais regulares (comportamento próximo a uma relação de Arrhenius) desviam pouco da entalpia característica. Deste modo, este gráfico oferece um critério para avaliar quando a relação de Arrhenius deve ser obedecida, quando uma correção é suficiente e quando o comportamento é outro, ou seja, a transição segue um comportamento não exponencial. As transições $S V \rightarrow V_{2}$ e $V_{2} \rightarrow S V$ apresentam os maiores desvios e o resultado é a mudança de comportamento $\left(\propto T^{\alpha}\right)$. Para as outras transições apenas uma correção, em maior ou menor intensidade, parece ser suficiente.

\subsubsection{Atração entre deslocações}

Discutiremos agora um caso particular, que envolve as transições $V_{2} \leftrightarrows P a r$. Acabamos de mostrar que há uma barreira de energia na transição $V_{2} \rightarrow$ Par, a qual é caracterizada por uma entalpia de migração $h_{m}$. Para esta transição o aumento da temperatura promove uma agitação maior das partículas que, conseqüentemente, executam um maior número de "pulos", vencendo as barreiras de energia. Por outro lado, a figura 26 mostra que o aumento da temperatura diminui a probabilidade da transição contrária, $\operatorname{Par} \rightarrow V_{2}$, indicando que não há barreira de energia envolvida nesta transição. Neste caso, o potencial "embutido", devido a organização das partículas, favorece a atração entre o par de deslocações. A temperatura, neste caso, desempenha o papel contrário, e tende a sustentar o par de deslocações separados. Quanto maior a temperatura, mais distantes e por mais tempo o par tende a ficar separado. Resumindo, as deslocações se atraem e o estado fundamental é o par ligado de deslocações que juntos formam a topologia $V_{2}$. A atração entre deslocações em cristais coloidais 2D não é uma observação nova, tendo já 
sido apontada em outros estudos (PERTSINIDIS; LING, 2001b; EISENMANN et al., 2005). $\mathrm{Na}$ sequência detalharemos um pouco mais o que foi dito e calcularemos a energia de interação média entre o par de deslocações.

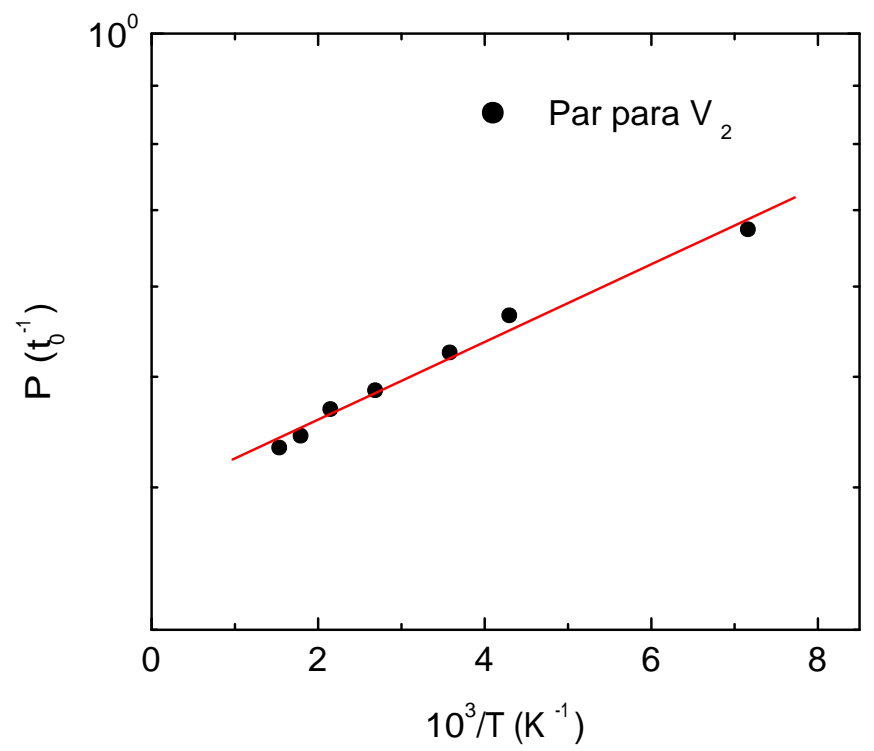

Figura 26. O gráfico mostra o ajuste de uma reta aos dados sobre a freqüência transição da topologia Par para a topologia $V_{2}$.

Uma deslocação isolada numa rede hexagonal 2D é um núcleo com um par de partículas, uma com vizinhança cinco e a outra com vizinhança sete. A linha extra de partículas, a qual define a deslocação, termina na partícula com vizinhança cinco. O vetor de Burger da deslocação, $\vec{b}$, conecta a partícula com $n v=5$ à partícula vizinha mais próxima no sentido anti-horário, depois da partícula com $n v=7$. A figura 27 ilustra um par isolado de deslocações numa rede hexagonal, juntamente com seus vetores de Burger.

Cada configuração topológica do defeito pontual pode ser pensada como um conjunto de deslocações (NELSON, 1987) cujos vetores de Burger têm soma total igual a zero, isto é, $\sum \vec{b}=0$. A maior parte do tempo a vacância apresenta-se como pares ou triplas de deslocações ligadas, tal como ilustrado na figura 9. Porém, observa-se que, estando à vacância em uma topologia $V_{2}$ (um par ligado de deslocações, veja figura $9(\mathrm{a})$ ), ocasionalmente pode ocorrer a dissociação e posterior recombinação das deslocações. A separação entre as deslocações durante a dissociação não passa de alguns parâmetros de rede e está 


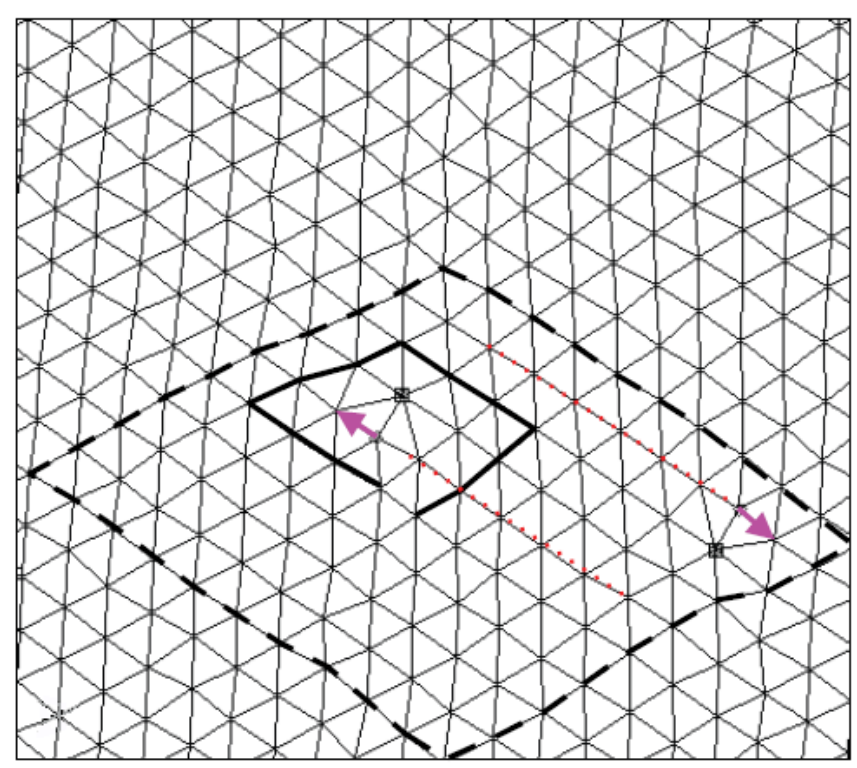

Figura 27. Pares isolados de deslocações numa rede hexagonal 2D, juntamente com seus vetores de Burger. Figura extraída da referência (PERTSINIDIS; LING, 2005).

relacionada à temperatura do sistema. Para o intervalo de temperatura que consideramos a separação média fica em torno de dois parâmetros de rede.

Focando no caso onde o defeito aparece como um par de deslocações separadas, e supondo uma interação $V(\vec{r})$ entre elas, espera-se uma estatística de Boltzmann para a probabilidade de observar as duas deslocações separadas por certa distância $\vec{r}$, isto é, $P_{\text {des }}(\vec{r}) \propto \exp \left(-V(\vec{r}) / k_{b} T\right)$ (PERTSINIDIS; LING, 2001b). Por outro lado, o gráfico 26 mostra as medidas que obtivemos para a freqüência com que um par isolado de deslocações combina-se em um par ligado (topologia $V_{2}$ ) em função da temperatura. Isto é equivalente a medir, para uma dada temperatura, o tempo médio que as deslocações são forçadas a ficar separadas, independente da distância. Deste modo, podemos obter uma aproximação para a energia de atração entre o par de deslocações, ajustando uma reta ao gráfico de $\ln (P(T))$ contra $1 / T$. Isto é análogo o que fizemos para o cálculo das barreiras de energia, porém a interpretação é diferente. No caso dá barreira, o potencial "embutido"impede o "pulo" do defeito e a temperatura favorece. Já para o par de deslocações o potencial "embutido" favorece a aproximação e a temperatura tende a sustentar o par separado. No gráfico 26 mostramos em vermelho o ajuste da reta aos dados, de onde extraímos energia de interação média $V=-78 \pm 4 \mathrm{~K}$. 


\subsubsection{Probabilidade das diferentes configurações topológicas da vacância}

Para entender a dinâmica de uma vacância no cristal coloidal 2D, calculamos a probabilidade de encontrar o defeito em uma dada configuração topológica. O gráfico 28 mostra esta probabilidade, $P_{d}$, em função da temperatura. Para temperaturas baixas o defeito se apresenta praticamente como uma topologia $V_{2}$ ou $S V$, o que lhe confere um caráter de movimento praticamente unidimensional. À medida que a temperatura aumenta, o aparecimento da topologia $V_{3}$ começa a se intensificar. Em altas temperaturas o aparecimento da topologia $I_{4}$ também deixa de ser desprezível. Como estas duas topologias possuem a capacidade de reorientar a posição o defeito, quanto mais alta for à temperatura mais isotrópico tende a ser o movimento da vacância.

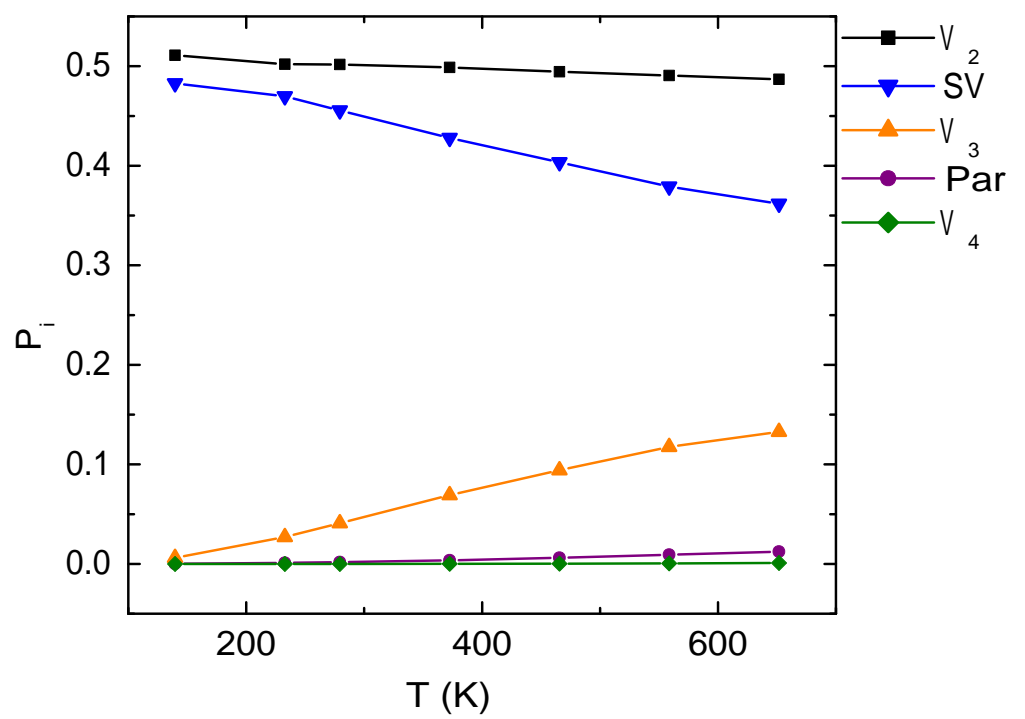

Figura 28. O gráfico mostra a probabilidade de encontrar o defeito em uma dada topologia em função da temperatura.

Defeitos pontuais são termodinamicamente estáveis porque eles aumentam a entropia do cristal, de modo que há uma concentração de defeitos que minimiza a energia livre de Gibbs. De acordo com o primeiro capítulo desta tese, a concentração de vacâncias no equilíbrio, $c_{v}$, é 


$$
c_{v}=\exp \left(-G_{f} / k_{b} T\right)=\exp \left(s_{f} / k_{b}\right) \exp \left(-h_{f} / k_{b} T\right)=A \exp \left(-h_{f} / k_{b} T\right)
$$

onde $G_{f}$ denota a energia livre de Gibbs de formação da vacância, $H_{f}$ e $S_{f}$ são, respectivamente, a entalpia e a entropia de formação da vacância, $k_{b}$ é a constante de Boltzmann e $T$ é a temperatura do sistema.

Por outro lado, estando em equilíbrio termodinâmico, a vacância adota diferentes configurações topológicas, as quais possuem energias de formação distintas. Supondo que cada vacância possa adotar $i$ diferentes topologias, podemos escrever a concentração de vacâncias como:

$$
c_{v}=\sum_{i} c_{i}
$$

onde $c_{i}$ é a concentração da $i$-ésima topologia. Em analogia com a equação (4.19),

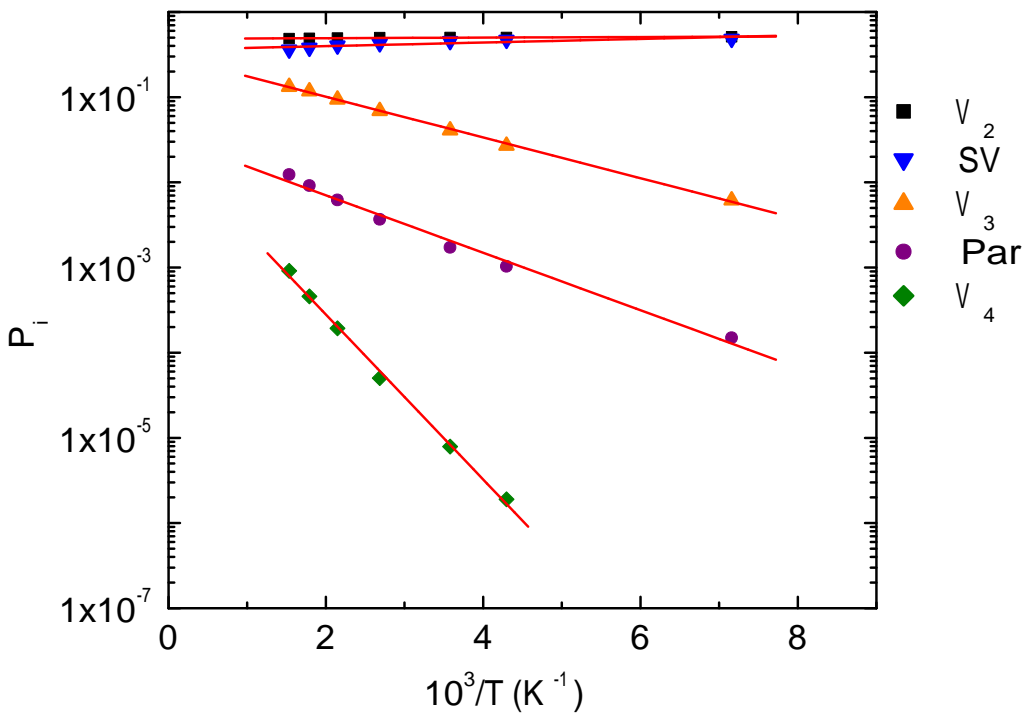

Figura 29. Ajuste de retas aos dados da figura 28.

podemos escrever a concentração da topologia $i$ no equilíbrio como

$$
c_{i}=\exp \left(-G_{i} / k_{b} T\right)=\exp \left(s_{i} / k_{b}\right) \exp \left(-h_{i} / k_{b} T\right)
$$

onde $G_{i}$ denota sua energia livre de Gibbs de formação, $h_{i}$ denota sua entalpia de formação e $s_{i}$ sua entropia. Agora, a probabilidade, $P_{i}$, de encontrar uma vacância na topologia $i$ é 
igual à razão entre a concentração desta topologia pela concentração total de vacâncias, isto é, $P_{i}=c_{i} / c_{v}$. Portanto, podemos escrever esta probabilidade como

$$
P_{i}=\exp \left[-\left(G_{i}-G_{f}\right) / k_{b} T\right]=\exp \left(-\Delta G_{i} / k_{b} T\right)=\exp \left(\Delta s_{i} / k_{b}\right) \exp \left(-\Delta h_{i} / k_{b} T\right)
$$

onde $\Delta h_{i}$ e $\Delta s_{i}$ são respectivamente a entalpia e entropia de formação relativas das diferentes configurações topológicas.

A figura 29 mostra o ajuste de retas aos gráficos de $\ln \left(P_{i}\right)$ contra $1 / T$. Para cada topologia, o coeficiente angular da reta é a entalpia relativa de formação e o coeficiente linear é entropia relativa de formação. A tabela 7 resume os resultados que obtivemos. Valores mais próximos de zero, como no caso das topologias $V_{2}$ e $S V$, indicam uma contribuição maior para o valor de referência.

Tabela 7- Entalpia e entropia, relativas, de formação das principais configurações topológicas de uma vacância.

\begin{tabular}{c|cc}
\hline \hline & $\Delta s_{i}$ & $\Delta h_{i}(K)$ \\
\hline$V_{2}$ & $-0.723 \pm 0.005$ & $-8 \pm 1$ \\
$S V$ & $-1.02 \pm 0.05$ & $-49 \pm 12$ \\
$V_{3}$ & $-1.19 \pm 0.03$ & $550 \pm 8$ \\
$P a r$ & $-3.4 \pm 0.1$ & $777 \pm 35$ \\
$V_{4}$ & $-3.72 \pm 0.16$ & $2230 \pm 57$ \\
\hline \hline
\end{tabular}

\subsection{Considerações Finais}

Apresentamos os cálculos sobre o transporte de vacâncias em um cristal coloidal 2D. Analisamos nossos dados sobre a mobilidade do defeito segundo duas teorias, e concluímos que os resultados obtidos com elas estão qualitativamente de acordo. Mostramos que a vacância difunde seguindo basicamente dois padrões. Em um deles a mobilidade segue uma relação exponencial, mas não estritamente uma relação de Arrhenius, pois o defeito envolve várias partículas e em sua região os efeitos não-harmônicos podem ser fortes, induzindo uma possível dependência da energia de ativação com a temperatura. O segundo padrão de mobilidade parece se adequar melhor a uma relação de potência da temperatura, sendo a razão microscópica uma barreira de energia muito baixa entre as diferentes 
configurações topológicas. Observamos que o defeito vacância pode eventualmente se apresentar como um par isolado de deslocações. Neste caso, mostramos que as deslocações se atraem e estimamos a intensidade desta atração. Finalmente, calculamos a probabilidade de encontrar a vacância em uma de suas configurações topológicas, e estimamos as entalpias e entropias relativas de formação de cada topologia.

Com relação ao interstício, os cálculos estão sendo concluídos e esperamos realizar o mesmo estudo com este defeito. Porém, o interstício despende em torno de $80 \%$ do tempo na topologia $I_{3}$ e isso complica a obtenção das probabilidades de transições, pois os outros estados topológicos são pouco acessados pelo defeito. 


\section{Capítulo 5}

\section{Conclusões finais e trabalhos futuros}

Este trabalho foi dedicado ao estudo de defeitos pontuais em cristais coloidais 2D usando dinâmica molecular. Esta técnica de simulação é apropriada para esse tipo de sistema pois, devido ao tamanho das partículas envolvidas, efeitos quânticos em geral podem ser descartados. Além disso, com DM é possível estudar a dinâmica do sistema, já que as trajetórias das partículas ficam disponíveis durante toda a simulação, o que não se consegue com outras técnicas de simulação clássica, como Monte Carlo. Apresentamos resultados inéditos e fundamentais para a compreensão da estrutura e dinâmica destes defeitos no cristal coloidal 2D, incluindo a energia de formação do defeitos, a interação entre eles e os processos envolvidos no transporte de vacância, inclusive a contribuição de cada topologia. Mostramos que o interstício possui energia de formação menor do que a vacância, sendo portanto mais provável de ser gerado. Os valores obtidos estão de acordo com os resultados experimentais publicados. Por exemplo, uma estimativa experimental da energia de formação de uma vacância em um cristal coloidal 2D (PERTSINIDIS; LING, $2005)$, apontou um valor em torno de $346 k_{b} T(\mathrm{~T}=298 \mathrm{~K})$; valor consistente com nossos cálculos. Porém, como essas energias são altíssimas, a geração desses defeitos termicamente em temperatura ambiente é praticamente impossível. Apesar disso, mostramos que próximo ao ponto de fusão esses defeitos podem ser gerados termicamente e desempenhar um papel importante no mecanismo de fusão do cristal. Os defeitos se atraem em distâncias curtas com uma magnitude maior do que a energia térmica média próximo à 
fusão. Isso significa que os defeitos tendem a se juntar em pares, e como os interstícios têm energia de formação menor, o estado fundamental próximo da fusão deve ser povoado principalmente por pares de interstícios.

Com relação à dinâmica das vacâncias, mostramos que a troca de topologia caracteriza o "pulo" deste defeito. Além disso, mostramos que o centro da vacância desloca-se, em média, meio parâmetro de rede em cada pulo. Estimamos a energia de ativação envolvida na migração da vacância, tomando como base as freqüências de trocas de topologias. Até onde sabemos, é a primeira vez que estas freqüências são empregadas no cálculo destas energias. Extraímos quantitativamente os valores para a entalpia e entropia de migração, com base em duas teorias diferentes. Concluímos que a difusão da vacância não segue estritamente uma relação de Arrhenius, mas um misto de dois comportamentos distintos, a saber: uma relação de Arrhenius corrigida e uma relação de potência da temperatura. Observamos que a topologia $V_{2}$ pode eventualmente se dissociar em um par isolado de deslocações. Neste caso, mostramos que as deslocações se atraem e estimamos a intensidade desta atração. Finalmente, calculamos a probabilidade de encontrar a vacância em uma de suas configurações topológicas. Os números obtidos serviram para três propósitos específicos: (1) inferir que a topologia $V_{2}$ é mais estável que $S V$; (2) Avaliar o padrão de movimento da vacância em baixas e altas temperaturas e (3) estimar as entalpias e entropias relativas de formação de cada topologia.

Seria importante futuramente verificar até que ponto os resultados desse modelo experimental se aplicam aos sistemas reais. Para a energia de formação, as resultados devem se aplicar a qualquer sistema hexagonal 2D com interação entre as partículas dada por um potencial de Coulomb blindado, contanto que o valor da blindagem esteja próximo do valor assumido em nosso sistema. Da mesma forma, acreditamos que nossos resultados para a dinâmica do defeito são aplicáveis para qualquer sistema 2D com estrutura de rede hexagonal, onde o potencial de interação entre partículas seja relativamente "suave" (soft). Os plasmas de poeira (Dusty plasmas) parecem ser um candidato, pois a interação entre as partículas é dada por um potencial de Coulomb blindado. Potenciais com alcance muito curto, provavelmente reproduziriam comportamentos significativamente diferentes. 


\section{Referências}

ALEXANDER, S. et al. Charge renormalization, osmotic pressure, and bulk modulus of colloidal crystals: Theory. The Journal of Chemical Physics, AIP, v. 80, n. 11, p. 5776-5781, 1984.

ALlEN, M. P.; TILDESLEY, D. J. Computer simulation of liquids. New York: Clarendon Press, 1987. ISBN 0-19-855375-7.

ALlnATT, A. R.; LIDIARD, A. B. Atomic Transport in Solids. Cambridge: Cambridge University Press, 1993.

ARORA, A. K. A new set-up for measuring angle-resolved polarised light scattering. Journal of Physics E: Scientific Instruments, v. 17, n. 12, p. 1119-1121, 1984.

ASHKIN, A. et al. Observation of a single-beam gradient force optical trap for dielectric particles. Optics Letters, v. 11, n. 5, p. 288-290, 1986.

BELLONI, L. Electrostatic interactions in colloidal solutions: Comparison between primitive and one-component models. The Journal of Chemical Physics, AIP, v. 85, n. 1, p. 519-526, 1986.

BERENDSEN, H. J. C. et al. Molecular dynamics with coupling to an external bath. The Journal of Chemical Physics, AIP, v. 81, n. 8, p. 3684-3690, 1984.

BROWN, J. C. et al. Light scattering study of dynamic and time-averaged correlations in dispersions of charged particles. Journal of Physics A Mathematical General, v. 8, n. 5, p. 664-682, may 1975.

CÂNDIDO, L.; PHILLIPS, P.; CEPERLEY, D. M. Single and paired point defects in a 2d wigner crystal. Physical Review Letters, American Physical Society, v. 86, n. 3, p. 492-495, Jan 2001.

COCKAYNE, E.; ELSER, V. Energetics of point defects in the two-dimensional wigner crystal. Physical Review B, American Physical Society, v. 43, n. 1, p. 623-629, Jan 1991.

DE FONTAINE, D.; BUCK, O. A monte carlo simulation of the omega phase transformation. Philosophical Magazine, Taylor \& Francis, v. 27, n. 4, p. 967-983, 1973.

DE GENNES, P. G. Soft matter. Review of Modern Physics, American Physical Society, v. 64, n. 3, p. 645-648, Jul 1992.

DE LEEUW, S. W.; PERRAM, J. W.; SMITH, E. R. Simulation of electrostatic systems in periodic boundary conditions. i. lattice sums and dielectric constants. Proceedings of the Royal Society of London Series A, v. 373, n. 1752, p. 27-56, Oct 1980. 
EISENMANN, C. et al. Pair interaction of dislocations in two-dimensional crystals. Physical Review Letters, APS, v. 95, n. 18, p. 185502, 2005.

EVANS, D. J. Computer "experiment" for nonlinear thermodynamics of couette flow. The Journal of Chemical Physics, v. 78, n. 6, p. 3297, Mar 1983.

FEDERER, J. I.; LUNDY, T. S. Diffusion of zr95 and nb95 in b.c.c. (body-centeredcubic) zirconium. Transactions of the American Institute of Mining, Metallurgical and Petroleum Engineers, v. 227, n. 3, p. 592, 1963.

FISHER, D. S.; HALPERIN, B. I.; MORF, R. Defects in the two-dimensional electron solid and implications for melting. Physical Review B, American Physical Society, v. 20, n. 11, p. 4692-4712, Dec 1979.

FRENKEL, D.; SMIT, B. Understanding Molecular Simulations. [S.l.]: Academic Press, 2002.

GAST, A. P.; RUSSEL, W. B. Simple ordering in complex fluids. Physics Today, v. 51, n. 12 , p. 24-30, 1998.

GILDER, H. M.; LAZARUS, D. Role of vacancy anharmonicity on non-arrhenius diffusional behavior. Physical Review B, American Physical Society, v. 11, n. 12, p. 4916-4926, Jun 1975.

GRAY, C. G.; GUBBINS, K. E. Theory of molecular fluids. 1. Fundamentals. Oxford: Clarendon Press, 1984.

GROSBERG, A. Y.; NGUYEN, T. T.; SHKLOVSKII, B. I. Colloquium: The physics of charge inversion in chemical and biological systems. Reviews of Modern Physics, v. 74, n. 2, p. 329-345, 2002.

HACHISU, S.; KOBAYASHI, S.; KOSE, A. Phase separation in monodisperse latexes. Journal of Colloid and Interface Science, v. 42, n. 2, p. 342, 1973.

HAMAKER, H. C. The london-van der waals attraction between spherical particles. Physica, v. 4, p. 1058-1072, 1937.

HEYES, D. M. Electrostatic potentials and fields in infinite point charge lattices. The Journal of Chemical Physics, AIP, v. 74, n. 3, p. 1924-1929, 1981.

HILTNER, P. A.; KRIEGER, I. M. Diffraction of light by ordered suspensions. Journal of Physical Chemistry, v. 73, n. 7, p. 2386-2389, 1969.

HOLLAND, B. T. et al. Synthesis of highly ordered, three-dimensional, macroporous structures of amorphous or crystalline inorganic oxides, phosphates, and hybrid composites. Chemistry of Materials, v. 11, n. 3, p. 795-805, 1999.

IMHOF, A.; PINE, D. J. Ordered macroporous materials by emulsion templating. Nature (London), v. 389, n. 6654, p. 948-951, 1997.

IMHOF, A.; PINE, D. J. Uniform macroporous ceramics and plastics by emulsion templating. Advanced Materials, v. 10, n. 9, p. 697-700, 1998.

ISRAELACHVILI, J. N. Intermolecular and Surface Forces. London: Academic, 1992. 
JAIN, S.; NELSON, D. R. Statistical mechanics of vacancy and interstitial strings in hexagonal columnar crystals. Physical Review E, American Physical Society, v. 61, n. 2, p. 1599-1615, Feb 2000.

JONSSON, B. Ordering and fase transitions in charged colloids. Cap. 11. New York: VCH, 1996.

KHAIRALLAH, S. A.; CEPERLEY, D. M. Superfluidity of dense ${ }^{4}$ He in vycor. Physical Review Letters, APS, v. 95, n. 18, p. 185301, 2005.

KIDSON, G. V. On the anomalous self-diffusion in body-centered cubic zirconium. Canadian Journal of Physics, v. 41, n. 10, p. 1563, 1963.

KIM, E.; CHAN, M. H. W. Probable observation of a supersolid helium phase. Nature (London), v. 427, n. 6971, p. 225-227, 2004.

KOSTERLITZ, J. M.; THOULESS, D. J. Ordering, metastability and phase transitions in two-dimensional systems. Journal of Physics C: Solid State Physics, v. 6, n. 7, p. 1181-1203, 1973.

LIBÁL, A.; REICHHARDT, C.; REICHHARDT, C. J. O. Point-defect dynamics in two-dimensional colloidal crystals. Physical Review E (Statistical, Nonlinear, and Soft Matter Physics), APS, v. 75, n. 1, p. 011403, 2007.

MAITLAND, G. C.; RIGBY, M.; WAKEHAM, W. A. Intermolecular forces: their origin and determination. Oxford: Clarendon Press, 1981.

MCQUARRIE, D. A. Statistical Mechanics. New York: Harper and Row, 1976.

MUNDY, J. N. Effect of pressure on the isotope effect in sodium self-diffusion. Physical Review B, American Physical Society, v. 3, n. 8, p. 2431-2445, Apr 1971.

MUNDY, J. N.; MILLER, T. E.; PORTE, R. J. Self-diffusion in potassium. Physical Review B, American Physical Society, v. 3, n. 8, p. 2445-2447, Apr 1971.

MURDOCK, J. F.; LUNDY, T. S.; STANSBURY, E. E. Diffusion of ti44 and v48 in titanium. Acta Metallurgica, v. 12, n. 9, p. 1033-1039, 1964.

MURRAY, C. A. Bond-orientational Order in Condesed Matter Systems. New York: Springer-Verlag, 1992.

MURRAY, C. A.; SPRENGER, W. O.; WENK, R. A. Comparison of melting in three and two dimensions: Microscopy of colloidal spheres. Physical Review B, American Physical Society, v. 42, n. 1, p. 688-703, Jul 1990.

NELSON, D. R. Phase Transitions and Critical Phenomena. London: Academic, 1987.

PATEY, G. N. The interaction of two spherical colloidal particles in electrolyte solution. an application of the hypernetted-chain approximation. The Journal of Chemical Physics, AIP, v. 72, n. 10, p. 5763-5771, 1980.

PEETERS, F. M.; WU, X. Wigner crystal of a screened-coulomb-interaction colloidal system in two dimensions. Physical Review A, American Physical Society, v. 35, n. 7, p. 3109-3114, Apr 1987. 
PERRAM, J.; PETERSEN, H. Algorithms for computing the dynamical trajectories of flexible bodies. Molecular Physics, v. 65, n. 4, p. 861-874, Nov 1988.

PERTSINIDIS, A.; LING, X. S. Diffusion of point defects in two-dimensional colloidal crystals. Nature (London), v. 413, n. 6852, p. 147-150, 2001.

PERTSINIDIS, A.; LING, X. S. Equilibrium configurations and energetics of point defects in two-dimensional colloidal crystals. Physical Review Letters, American Physical Society, v. 87, n. 9, p. 098303, Aug 2001.

PERTSINIDIS, A.; LING, X. S. Video microscopy and micromechanics studies of oneand two-dimensional colloidal crystals. New Journal of Physics, v. 7, n. 33, p. 33, 2005.

PISMEN, L. M.; RUBINSTEIN, B. Y. Motion of interacting point defects in nematics. Physical Review Letters, American Physical Society, v. 69, n. 1, p. 96-99, Jul 1992.

PUSEY, P. N. The study of brownian motion by intensity fluctuation spectroscopy. Philosophical Transactions of the Royal Society of London. Series A, Mathematical and Physical Sciences, v. 293, n. 1402, p. 429-43, Dec 1979.

PUSEY, P. N.; VAN MEGEN, W. Observation of a glass transition in suspensions of spherical colloidal particles. Physical Review Letters, American Physical Society, v. 59, n. 18, p. 2083-2086, Nov 1987.

RAPAPORT, D. C. The art of molecular dynamics simulation. New York: Cambridge University Press, 1995.

ROBBINS, M. O.; KREMER, K.; GREST, G. S. Phase diagram and dynamics of yukawa systems. The Journal of Chemical Physics, AIP, v. 88, n. 5, p. 3286-3312, 1988.

ROTHMAN, S. J.; PETERSON, N. L.; ROBINSON, J. T. Isotope effect for self-diffusion in single crystals of silver. Physica Status Solidi, v. 39, n. 2, p. 635-645, 1970.

SANCHEZ, J. M.; DE FONTAINE, D. Model for anomalous self-diffusion in group-ivb transition metals. Physical Review Letters, American Physical Society, v. 35, n. 4, p. 227-230, Jul 1975.

SHIMOJO, F. et al. A scalable molecular-dynamics algorithm suite for materials simulations: design-space diagram on 1024 cray t3e processors. Future Generation Computer Systems, v. 17, n. 3, p. 279-291, 2000.

SOGAMI, I. Effective potential between charged spherical particles in dilute suspension. Physics Letters A, v. 96, n. 4, p. 199-203, Jun 1983.

SOGAMI, I.; ISE, N. On the electrostatic interaction in macroionic solutions. The Journal of Chemical Physics, AIP, v. 81, n. 12, p. 6320-6332, 1984.

STONE, A. J. The Theory of Intermolecular Forces. [S.1.]: Oxford university press, 1997.

STOYAN, D.; KENDALL, W. S.; MECKE, J. Stochastic Geometry and Its Aplications. [S.l.]: Wiley, 1995.

VAN BLAADEREN, A.; WILTZIUS, P. Real-Space Structure of Colloidal Hard-Sphere Glasses. Science, v. 270, n. 5239, p. 1177-1179, 1995. 
VAROTSOS, A.; ALEXOPOULOS, K. D. thermodynamics of Point Defecs and their Relation with Bulk Properties. Amsterdam: North-Rolland, 1986.

VERLET, L. Computer "experiments" on classical fluids. i. thermodynamical properties of lennard-jones molecules. Physical Review, American Physical Society, v. 159, n. 1, p. 98, Jul 1967.

WILLIAMS, R.; CRANDALL, R. S. The structure of crystallized suspensions of polystyrene spheres. Physics Letters A, v. 48, n. 3, p. 225-226, 1974.

YETHIRAJ, A.; VAN BLAADEREN, A. A colloidal model system with an interaction tunable from hard sphere to soft and dipolar. Nature (London), v. 421, n. 6922, p. 513-517, 2003.

ZHOU, D.; EDWARDS, C. M.; SULLIVAN, N. S. Quantum diffusion of vacancies and impurities in solid hydrogen. Physical Review Letters, American Physical Society, v. 62, n. 13, p. 1528-1531, Mar 1989. 